Florida International University

FIU Digital Commons

FIU Electronic Theses and Dissertations

University Graduate School

$11-7-2014$

\title{
Development of Presumptive and Confirmatory Analytical Methods for the Simultaneous Detection of Multiple Improvised Explosives
}

Kelley L. Peters

Florida International University, kpete008@fiu.edu

DOI: $10.25148 /$ etd.FI14110757

Follow this and additional works at: https://digitalcommons.fiu.edu/etd

Part of the Analytical Chemistry Commons, and the Other Chemistry Commons

\section{Recommended Citation}

Peters, Kelley L., "Development of Presumptive and Confirmatory Analytical Methods for the Simultaneous Detection of Multiple Improvised Explosives" (2014). FIU Electronic Theses and Dissertations. 1659.

https://digitalcommons.fiu.edu/etd/1659 


\section{FLORIDA INTERNATIONAL UNIVERSITY}

Miami, Florida

\section{DEVELOPMENT OF PRESUMPTIVE AND CONFIRMATORY ANALYTICAL \\ METHODS FOR THE SIMULTANEOUS DETECTION OF MULTIPLE \\ IMPROVISED EXPLOSIVES}

A dissertation submitted in partial fulfillment of

the requirements for the degree of

DOCTOR OF PHILOSOPHY

in

CHEMISTRY

by

Kelley L. Peters 
To: Interim Dean Michael Heithaus

College of Arts and Sciences

This dissertation, written by Kelley L. Peters, and entitled Development of Presumptive and Confirmatory Analytical Methods for the Simultaneous Detection of Multiple Improvised Explosives, having been approved in respect to style and intellectual content, is referred to you for judgment.

We have read this dissertation and recommend that it be approved.

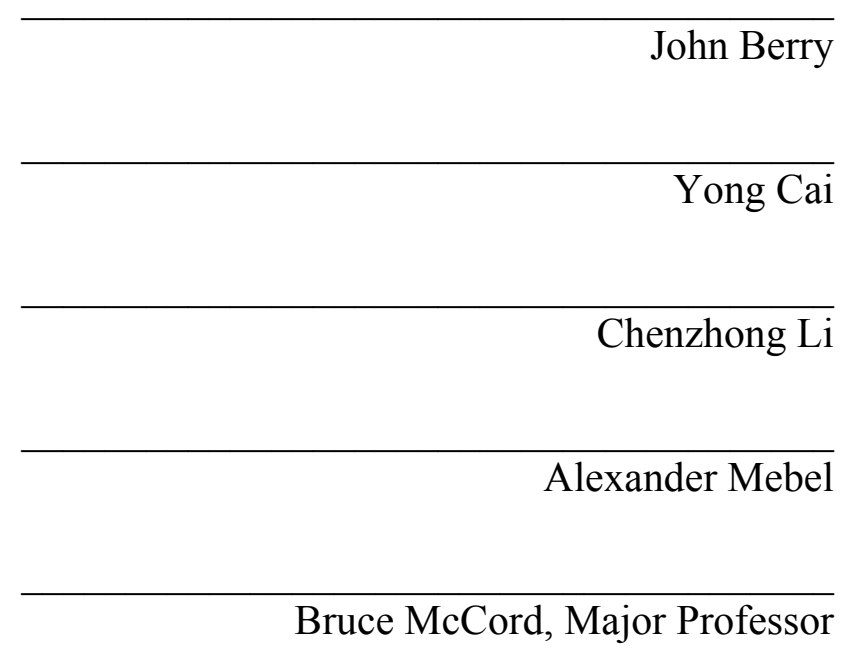

Date of Defense: November 7, 2014

The dissertation of Kelley L. Peters is approved.

Interim Dean Michael Heithaus College of Arts and Sciences

Dean Lakshmi N. Reddi University Graduate School

Florida International University, 2014 
(C) Copyright 2014 by Kelley L. Peters

All rights reserved. 


\section{DEDICATION}

I dedicate this dissertation to my parents. Without their understanding, unconditional support, guidance, and all those trips to China I never would have been able to complete this process. 


\section{ACKNOWLEDGMENTS}

I would like to thank the members of my dissertation committee for their support and assistance. Dr. Bruce McCord has provided me with opportunities to conduct research in the explosive field, providing a great deal of support and assistance along the way. He has also trusted me to deal with instrumental issues and supported me in attending a variety of conferences, both nationally and abroad. Thank you to Dr. John Berry, Dr. Yong Cai, Dr. Chenzhong Li, and Dr. Alexander Mebel for their support and insight throughout this process.

Research focusing on the development of microfluidic paper-based analytical devices ( $\mu$ PADs) for the on-site detection of explosives was funded by the National Institute of Justice (NIJ2012-DN-BX-K048). Kyle Zeribe and Micale Kaufman were imperative in completing this work and a special thanks is given for their tremendous assistance in completing the development of these devices.

I would also like to thank Dr. Alex Landera for his assistance with the complexation modeling utilizing 18-crown-6 ethers and the inorganic explosive ions and the Miami Police Department Bomb Squad for their assistance in completing the postblast work.

Lastly, I would also like to thank all of my wonderful friends and family who have been there to support me throughout my life. I would like to give special thanks to Dr. McCord's chemistry lab members for all of their help and support along the way. 


\title{
ABSTRACT OF THE DISSERTATION \\ DEVELOPMENT OF PRESUMPTIVE AND CONFIRMATORY ANALYTICAL METHODS FOR THE SIMULTANEOUS DETECTION OF MULTIPLE IMPROVISED EXPLOSIVES
}

\author{
by \\ Kelley L. Peters \\ Florida International University, 2014 \\ Miami, Florida \\ Professor Bruce McCord, Major Professor
}

In recent years, there has been a dramatic increase in the use of improvised explosive devices (IEDs) due to ease of synthesis and improved controls placed on commercial/military explosives. Commonly used materials for IED preparations include fertilizers and industrial chemicals containing oxidizers such as $\mathrm{ClO}_{3}{ }^{-}, \mathrm{ClO}_{4}{ }^{-}$, and $\mathrm{NO}_{3}{ }^{-}$, as well as other less stable compounds, such as peroxides. Due to these materials having a wide range of volatility, polarity, and composition, detection can be challenging, increasing the amount of time before any analytical information on the identity of the explosive can be determined. Therefore, this research project developed two analytical methods to aid in the rapid detection of multiple explosive compounds.

The use of microfluidic paper-based analytical devices ( $\mu$ PADs) allows for the development of inexpensive paper devices utilizing colorimetric reactions, which can perform five or more simultaneous analyses in approximately five minutes. Two devices were developed: one for the detection of inorganic explosives including $\mathrm{ClO}_{3}{ }^{-}, \mathrm{ClO}_{4}{ }^{-}$, $\mathrm{NH}_{4}{ }^{+}, \mathrm{NO}_{3}{ }^{-}$, and $\mathrm{NO}_{2}{ }^{-}$, and the second device detects high/organic explosives including 
RDX, TNT, urea nitrate, and peroxides. Limits of detection ranged from $0.4 \mu \mathrm{g}-20 \mu \mathrm{g}$ of explosive residue with an analysis time of less than five minutes.

Development of a confirmatory method utilizing infusion electrochemical detection-electrospray ionization-time-of-flight mass spectrometry (EC-ESI-TOF MS) and 18-crown-6 ethers to produce guest/host complexes with inorganic ions has also been completed. Utilizing this method the inorganic ions present in many IEDs can be successfully detected as ion pairs, while still allowing for the detection of other high explosives ${ }^{1}$. Placing an electrochemical detector before the mass spectrometer permits the detection of hydrogen peroxide, an analyte normally difficult to detect through mass spectrometry. Limits of detection ranged from $0.06 \mathrm{ppm}-2 \mathrm{ppm}$ with an analysis time of less than two minutes.

The development of these presumptive and confirmatory analytical methods permits the detection of a wide range of components present in IEDs. These methods decrease the amount of time required to relay information on the type of explosives present by simplifying the analysis process in the field and in a laboratory. 


\section{TABLE OF CONTENTS}

CHAPTER

PAGE

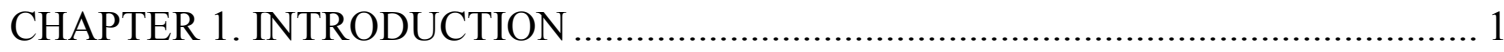

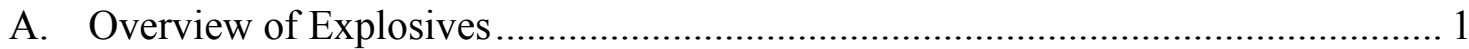

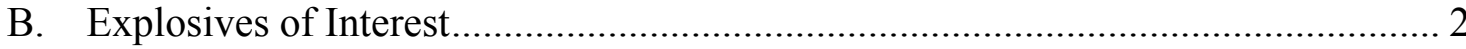

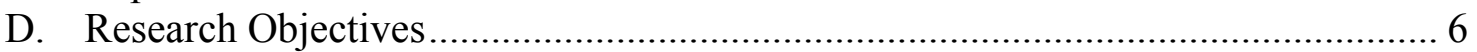

CHAPTER 2. PRESUMPTIVE ON-SITE DETECTION OF EXPLOSIVES.................... 8

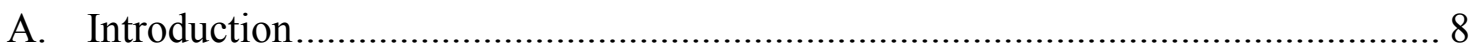

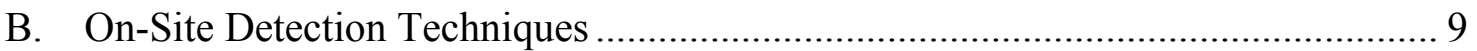

C. Microfluidic Paper-Based Analytical Devices ( $\mu$ PADs) ....................................... 11

CHAPTER 3. CONFIRMATORY DETECTION OF EXPLOSIVES............................. 20

A. Laboratory Detection Techniques.................................................................. 20

B. Infusion Electrochemical Detection Electrospray Ionization Time-of-Flight

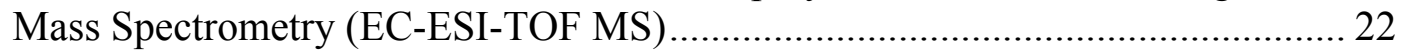

CHAPTER 4. EXPERIMENTAL PROCEDURES.................................................... 30

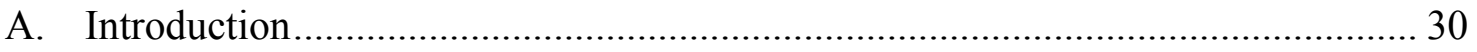

B. Development of Microfluidic Paper-Based Analytical Devices ( $\mu$ PADs) For On-

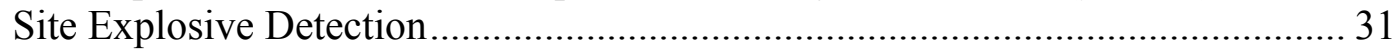

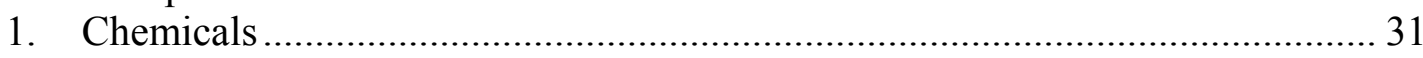

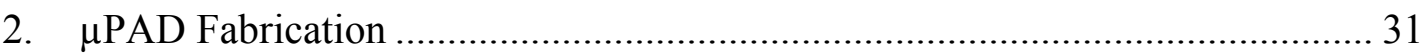

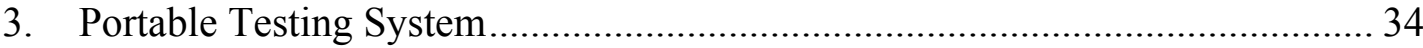

C. Validation of $\mu$ PADs for Explosive Detection ....................................................... 34

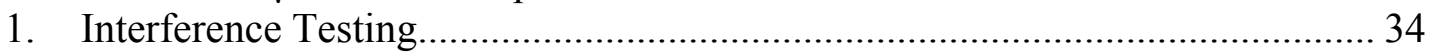

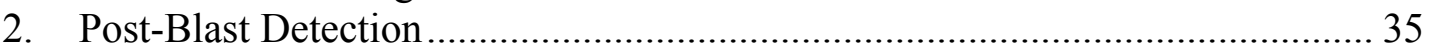

3. On-Site Post-Blast Detection ......................................................................... 35

D. Infusion Electrochemical Detection Mass Spectrometry (EC-ESI-TOF MS) for

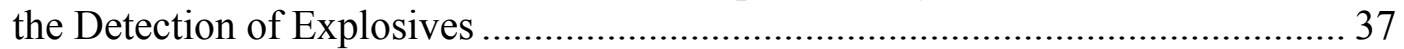

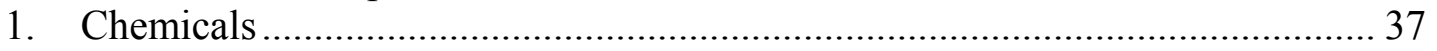

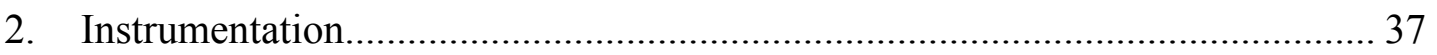

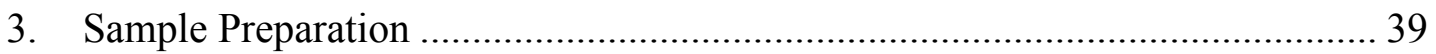

E. Validation of Infusion Electrochemical Detection Mass Spectrometry (EC-ESI-

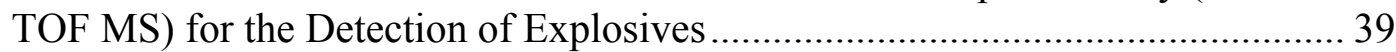

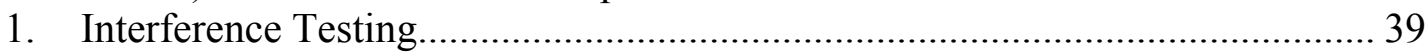

2. Collection of Post-Blast Samples ...................................................................... 39

3. Extraction/Analysis of Post-Blast Samples .......................................................... 40

\section{CHAPTER 5. DEVELOPMENT OF $\mu$ PADs FOR RAPID, ON-SITE EXPLOSIVES}

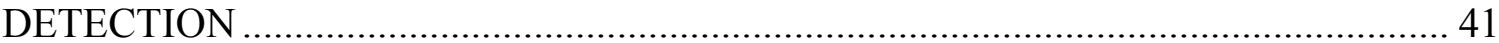

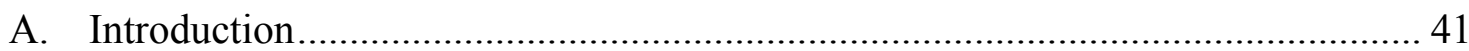

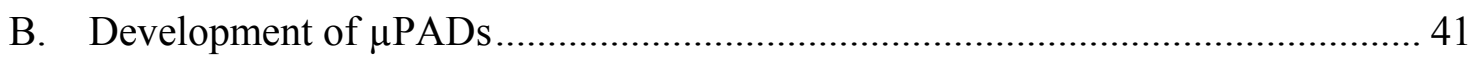

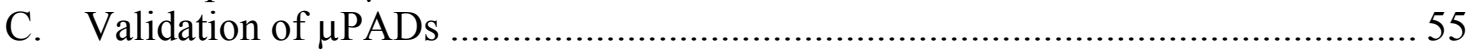




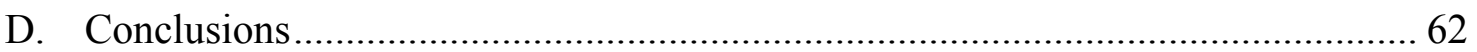

CHAPTER 6. CONFIRMATORY DETECTION UTILIZING INFUSION EC-ESI-

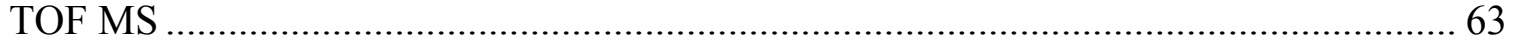

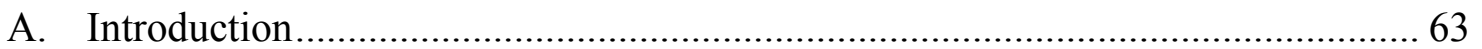

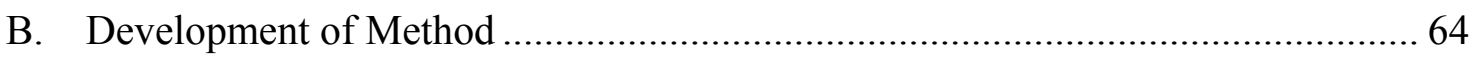

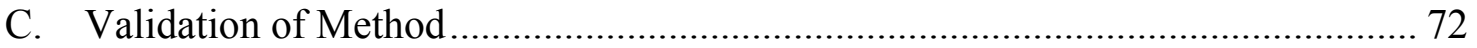

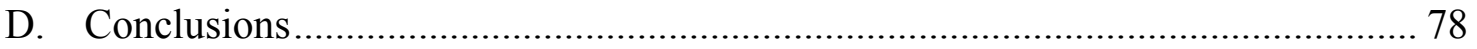

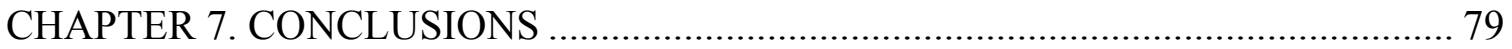




\section{LIST OF TABLES}

TABLE

PAGE

2.1. Advantages and Disadvantages of Different Fabricating Methods for the Development of $\mu$ PADs.

2.2. Advantages and Disadvantages of Techniques Used for Analyte Detection on $\mu \mathrm{PADs}$.

3.1. Comparison of Different Ionization Sources Commonly Used in Mass

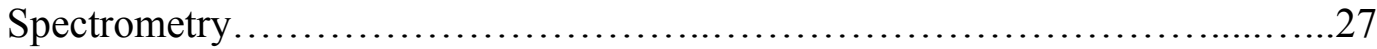

3.2. Advantages and Disadvantages of Mass Analyzers for a Mass Spectrometer....29

5.1. Colorimetric tests and reagents used for the detection of inorganic explosive compounds..........................................................44

5.2 Colorimetric tests and reagents used for the detection of high/organic explosive compounds.................................................50

5.3 Limits of detection determined for each individual colorimetric test using single lane $\mu$ PADs..................................................56

5.4. Real sample analysis with the inorganic explosives $\mu$ PAD $\ldots \ldots \ldots \ldots \ldots \ldots \ldots . .59$

6.1. Compounds of interest and their corresponding $\mathrm{m} / \mathrm{z}$ when complexes

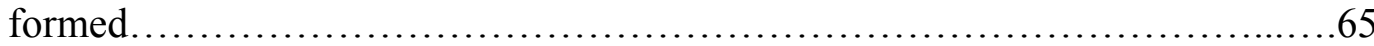

6.2. Ion radii of cations determining selectivity of the 18 -crown-6 ether..............72

6.3. Figures of Merit for the explosive compounds detected using EC-ESI TOF......73

6.4. Mass accuracies determined for the ions formed during analysis with time-of-

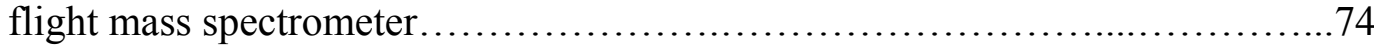

6.5. Mass error for the results obtained for post-blast analysis utilizing the infusion EC-ESI-TOF MS method. 


\section{LIST OF FIGURES}

FIGURE

PAGE

1.1. Structures of two organic peroxide based explosives: (a) triacetone triperoxide (TATP) and (b) hexamethylenetriperoxide diamine (HMTD)

1.2 Explosives detection scheme in forensic analysis

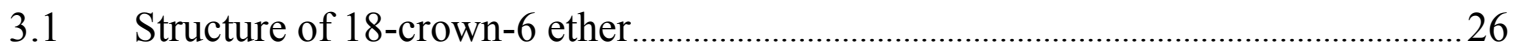

4.1 Design and placement of colorimetric reagents for the $\mu$ PADs ............................... 32

4.2 On-site sampling preformed (a) pre-blast by adding powder samples to a small amount of solvent and (b) post-blast by swiping the tab of the $\mu \mathrm{PAD}$ across a piece of large plastic container

4.3 Detector set-up for the Infusion EC-ESI-TOF MS method utilized for analysis .. 37

4.4 Post-blast sample collection using gauze wetted with $200 \mu \mathrm{L}$ of methanol and swabbed over plastic container remnants generated from the blast.

5.1 The inorganic explosives $\mu \mathrm{PAD}$ device prior to analysis

5.2 Modified Griess reaction used for the detection of nitrate containing compounds such as ammonium nitrate and black powders

5.3 Chemical equation for ammonium test with Nessler's reagent

5.4 Griess test for the detection of nitrite containing compounds......

5.5 Nitrite and nitrate tests run with (a) $1000 \mathrm{ppm}$ potassium nitrite in deionized water.

5.6 Methylene blue compound used for detection of perchlorate 48

5.7 High/organic explosives $\mu \mathrm{PAD}$ prior to analysis

5.8 Reduction to nitrous acid and Griess test for colorimetric detection of RDX/HMX/PETN.

5.9 Janowsky reaction for the detection of TNT, TNB, and tetryl

5.10 Uronium reaction with para-dimethylaminocinnamaldehyde ( $p$-DMAC) 53 
5.11 Urea nitrate test using $p$-DMAC

5.12 Test for hydrogen peroxide $\left(\mathrm{H}_{2} \mathrm{O}_{2}\right)$ using ammonium titanyl oxalate $\left(\left(\mathrm{NH}_{4}\right)_{2} \mathrm{TiO}\left(\mathrm{C}_{2} \mathrm{O}_{4}\right)_{2}\right)$ .55

5.13 Pre- and post-blast results for $\mu$ PADs tested with ANAL 60

5.14 On-site analysis for urea nitrate. 61

6.1 Most stable formation for the potassium chlorate complex with 18-crown-06 ether, $\left[2(18 \mathrm{Cr} 6)+\mathrm{KClO}_{3}+\mathrm{K}\right]^{+}$ 66

6.2 Most stable structure for (a) the ammonium nitrate complex with 18-crown-6 ether $\left(\left[2(18 \mathrm{Cr} 6)+\mathrm{NH}_{4} \mathrm{NO}_{3}+\mathrm{NH}_{4}\right]^{+}\right)$and $(\mathrm{b})$ the ammonium perchlorate complex with 18-crown-6 ether $\left(\left[2(18 \mathrm{Cr} 6)+\mathrm{NH}_{4} \mathrm{ClO}_{4}+\mathrm{NH}_{4}\right]^{+}\right)$

6.3 Most stable structure for (a) 1:1 uronium complex with 18-crown-6 ether $\left(\left[18 \mathrm{Cr} 6+\left(\mathrm{NH}_{2}\right)_{2} \mathrm{COH}\right]^{+}\right)$and (b) the 1:2 uronium complex with 18-crown-6 ether $\left(\left[2(18 \mathrm{Cr} 6)+\left(\mathrm{NH}_{2}\right)_{2} \mathrm{COH}\right]^{+}\right)$.

6.4 Comparison of response generated by the electrochemical detector with varying mobile phases such as methanol (red), $10 \mathrm{mM}$ sodium acetate in water (blue), $10 \mathrm{mM}$ ammonium acetate in water (black), and $10 \mathrm{mM}$ ammonium acetate $\mathrm{pH}$ adjusted with ammonium hydroxide (pink).

6.5 EC-ESI-TOF MS results for a $30 \mathrm{ppm}$ mixture of ammonium nitrate $\left(\left[2(18 \mathrm{Cr} 6)+\mathrm{NH}_{4} \mathrm{NO}_{3}+\mathrm{NH}_{4}\right]^{+}\right)$, urea nitrate $\left(\left[18 \mathrm{Cr} 6+\left(\mathrm{NH}_{2}\right)_{2} \mathrm{COH}\right]^{+}\right.$, $\left[2(18 \mathrm{Cr} 6)+\left(\mathrm{NH}_{2}\right)_{2} \mathrm{COH}\right]^{+}$, potassium chlorate $\left(\left[2(18 \mathrm{Cr} 6)+\mathrm{KClO}_{3}+\mathrm{K}\right]^{+}\right)$, ammonium perchlorate $\left(\left[2(18 \mathrm{Cr} 6)+\mathrm{NH}_{4} \mathrm{ClO}_{4}+\mathrm{NH}_{4}\right]^{+}\right), \mathrm{HMTD}\left([\mathrm{HMTD}+\mathrm{H}]^{+}\right)$, and hydrogen peroxide $\left(\mathrm{H}_{2} \mathrm{O}_{2}\right)$ in $1 \mathrm{mM}$ 18-crown-6 ether in methanol.

6.6 Common interference compounds that could be present on people's hands .76 


\section{LIST OF ABRREVIATIONS AND ACRONYMS}

18Cr6: 18-Crown-6 Ether

AN: Ammonium Nitrate

ANAL: Ammonium Nitrate and Aluminum

ANFO: Ammonium Nitrate and Fuel Oil

C4: Composition-4

CE: Capillary Electrophoresis

CI: Chemical Ionization

CPE: Carbon Paste Electrode

DC: Direct Current

DESI: Desorption Electrospray Ionization

DMSO: Dimethyl Sulfoxide

DNA: Deoxyribonucleic Acid

EC-ESI-TOF MS: Electrochemical Detection-Electrospray Ionization-Time-of-Flight Mass Spectrometry

EI: Electron Ionization

ESI: Electrospray Ionization

FAB: Fast Atom Bombardment

FTIR: Fourier Transform Infrared Spectroscopy

GC/ECD/TEA: Gas Chromatography/Electron Capture Detection/Thermal Energy Analyzer

GC-MS: Gas Chromatography-Mass Spectrometry

HMTD: Hexamethylene Triperoxide Diamine

HMX: Cyclotetramethylene Tetranitramene 
HPLC: High Performance Liquid Chromatography

HPLC-EC: High Performance Liquid Chromatography-Electrochemical Detection

HPLC-UV: High Performance Liquid Chromatography-Ultraviolet Detection

IC: Ion Chromatography

IC-CD: Ion Chromatography-Conductivity Detection

IC-IPD: Ion Chromatography-Ion Photometric Detection

ICR: Ion Cyclotron Resonance

IEDs: Improvised Explosive Devices

IMS: Ion Mobility Spectrometry

IR: Infrared Spectroscopy

LC-MS: Liquid Chromatography-Mass Spectrometry

LED: Light Emitting Diode

MALDI: Matrix-Assisted Laser Desorption Ionization

MW: Molecular Weight

MS-MS: Tandem Mass Spectrometry

NG: Nitroglycerin

p-DMAC: para-dimethylaminocinnamaldehyde

PDMS: Polydimethylsiloxane

PETN: Pentaerythritol Tetranitrate

PTFE: Polytetrafluoroethylene

PVC: Polyvinyl Chloride

RDX: Cyclotrimethylenetrinitramene

SEM/EDS: Scanning Electron Microscope/Energy Dispersive Spectroscopy 
S/N: Signal-to-Noise Ratio

SPME: Solid-Phase Microextraction

TATP: Triacetone Triperoxide

TNB: Trinitrobenzene

TNT: 2,4,6-Trinitrotoluene

TOF: Time-of-Flight

UHPLC-MS: Ultra High Performance Liquid Chromatography-Mass Spectrometry

UN: Urea Nitrate

$\mu$ PADs: Microfluidic Paper-Based Analytical Devices

US EPA: United States Environmental Protection Agency

UV: Ultraviolet

XRD: X-Ray Diffraction 


\section{CHAPTER 1. INTRODUCTION}

\section{A. Overview of Explosives}

An explosive is a material capable of such rapid decomposition that tremendous energy is released instantaneously generating an explosion by its own energy. It consists of a mixture of a fuel and an oxidizer, strongly electron deficient compounds that provide a source of oxygen to produce rapid combustion-like reactions when fuels are added ${ }^{2}$. These components can be present as heterogeneous mixtures, such as ammonium nitrate and fuel oil (ANFO), or may exist in the same molecule, such as trinitrotoluene (TNT) ${ }^{3-5}$. Explosives commonly require some stimulus (e.g., heat, shock, friction, etc.) to generate the explosion, but the stimulus does not contribute to the energy of the explosion.

In general, explosives can be classified into three groups: low explosives, high explosives, and blasting agents. Low explosives are combustible materials which have a subsonic reaction rate (less than $3000 \mathrm{~m} / \mathrm{s}$ ). Some examples are black powder and smokeless powder. When black powder burns, a chemical reaction takes place generating hot gases and inorganic residues. If this reaction is confined, the pressure rises and heat moves quickly through the powder causing extremely rapid combustion known as deflagration. This pressure builds until it overcomes the containment device, fracturing it at the weakest point, and generating an explosion. Therefore, low explosives are commonly contained in a sealed casing to generate an explosion ${ }^{3}$.

High explosives react at a rate faster than the speed of sound (greater than $3000 \mathrm{~m} / \mathrm{s}$ ). This process is known as detonation and an explosion is not dependent on confinement. High explosives can be further divided into two classes: primary and secondary explosives. Primary explosives are highly sensitive to friction, shock, and heat, such as 
mercury fulminate, lead azide, and triacetone triperoxide (TATP). Secondary explosives require a larger energy input for detonation, typically supplied by a suitable primary explosive, due to their increased stability. Secondary explosive materials do not explode readily by heat or shock, and are generally more powerful than low explosives. Some examples are TNT, nitroglycerin (NG), and cyclotrimethylenetrinitramene (RDX) ${ }^{3}$.

A third class of explosives is referred to as blasting agents, which are less sensitive fuel and oxidizer mixtures that can be prepared from fertilizers. This type of explosive will fail to detonate when tested with a number 8 detonator $(0.4 \mathrm{~g}$ pentaerythritol tetranitrate (PETN)). Instead, they require a booster to detonate, where the size of the booster depends on the blasting agents formulation, ranging up to 1 pound or more of high explosives ${ }^{6}$. This class of explosives consists of ammonium nitrate (AN) and urea nitrate (UN).

\section{B. Explosives of Interest}

Explosives detection is performed for two general classes of explosives: improvised/homemade explosives and commercial/military explosives. Improvised explosives can be further divided into three categories: low explosives containing inorganic salts, fertilizer based explosives, and peroxides. Low explosives containing inorganic salts consist of formulations including oxidizers such as chlorate, perchlorate, or nitrate mixed with a fuel source (e.g., sugar, sulfur, etc.). Black powder is a common example of a low explosive consisting of potassium nitrate, charcoal, and sulfur.

Potassium nitrate and perchlorate are also common in the pyrotechnic industry and when mixed with metal fuels such as aluminum or magnesium are known as flash powders. Potassium chlorate can be mixed with appropriate metal fuels (Ba, $\mathrm{Sr}, \mathrm{Cu}$, etc.) and 
nitrate salts to create colored flames and fireworks ${ }^{7}$. However, due to potassium chlorate's relatively low melting point and sensitivity, it is being replaced with the more stable compound potassium perchlorate ${ }^{5}$. Potassium chlorate flash powders have been used in a number of terrorist incidents, most notably, a bombing outside of a popular tourist venue in $\mathrm{Bali}^{8}$ and at the Boston Marathon ${ }^{9}$.

Fertilizer-based explosives are a second class of improvised explosives consisting of AN and UN. Ammonium nitrate is commonly mixed with a fuel oil, such as diesel or kerosene, to generate a bulk explosive or blasting agent; while urea nitrate can be used in its pure state or mixed with aluminum powder ${ }^{3}$. Ammonium nitrate and $\mathrm{UN}$ are easily obtained from fertilizers, which until recently have not been strictly controlled ${ }^{1}$. Agricultural fertilizer containing UN was used in the first World Trade Center attack in 1993 in New York City, $\mathrm{NY}^{10}$ and AN was used in a truck-bomb explosion outside the Alfred P. Murrah Federal Building in Oklahoma City, OK on April 19, $1995^{11}$.

A third class of improvised explosive materials consists of explosives based on organic and inorganic peroxides. These explosives have been encountered more frequently over recent years in IEDs due to the fact that they are easily synthesized from readily obtainable products ${ }^{12}$. Highly concentrated hydrogen peroxide $\left(\mathrm{H}_{2} \mathrm{O}_{2}\right)$ can be used as an explosive when it is combined with fuels, such as flour or pepper. Peroxides can also be present as functional groups, R-O-O-R, in organic compounds ${ }^{13}$. Organic peroxides are typically found as cyclic compounds such as TATP and hexamethylene triperoxide diamine (HMTD) (Figure 1.1). 
(a)

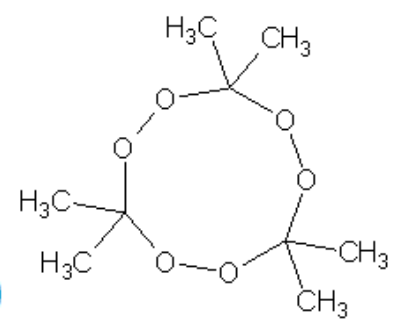

(b)

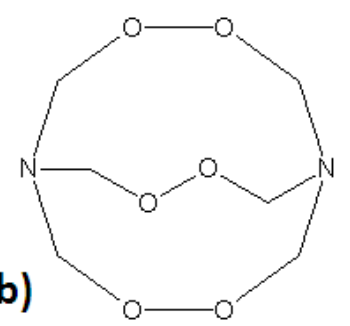

\section{Figure 1.1. Structures of two organic peroxide based explosives: (a) triacetone triperoxide (TATP) and (b) hexamethylenetriperoxide diamine (HMTD).}

Home-made organic peroxide-based explosives were used in the London bombing on July 7, $2005^{14}$ and have also appeared in the Middle East.

Peroxides are dangerous primary explosives, readily initiated by heat, friction, shock, or impact, making them difficult to manufacture safely as a result of their instability ${ }^{13,15-}$ ${ }^{20}$. In addition, TATP and other peroxide explosives can be readily synthesized from easily obtained starting materials and can be difficult to analyze. There are a limited number of methods available for detection due to organic peroxide explosive's poor ability to absorb ultraviolet (UV) light, nonexistent fluorescent characteristics, and lack of a nitro group ${ }^{25-29}$.

In recent years, commercial/military explosives, such as Composition 4 (C4, consisting mainly of RDX, stabilizers, and plasticizers) and Semtex (consisting of PETN, $\mathrm{RDX}$, and plasticizers), have become an increasing concern for use in terrorist activities $^{21}$. These explosive materials can be gleaned and altered from munitions, manufactured, or stolen from military facilities. Therefore, an analytical method for the purpose of explosives detection needs to screen for common improvised explosives along with organic high explosives. 


\section{Explosives Detection}

Explosives detection relies on being able to determine the fuel and oxidizer that are present. There are three classes of fuels: (1) hydrocarbons consisting of gas, diesel,

charcoal, sugar, etc. (2) energetic hydrocarbons such as nitromethane, nitrocellulose, and nitrobenzene and (3) elemental fuels such as aluminum, magnesium, sulfur, etc. ${ }^{2}$.

Historically, most explosive compounds contain organic nitro $\left(\mathrm{NO}_{2}{ }^{-}\right)$groups as oxidizers; so many analytical detection methods have focused on being able to detect the presence of nitrates $\left(\mathrm{NO}_{3}{ }^{-}\right)$, a common inorganic components of explosive mixtures, and nitro groups ${ }^{22-27}$. However, more recently, explosive mixtures have started containing oxidizers such as chlorates $\left(\mathrm{ClO}_{3}{ }^{-}\right)$, perchlorates $\left(\mathrm{ClO}_{4}{ }^{-}\right)$, and peroxides $\left(\mathrm{O}_{2}{ }^{-}\right)$. Less commonly utilized oxidizers include chromates $\left(\mathrm{CrO}_{4}{ }^{2-}\right)$, dichromates $\left(\mathrm{Cr}_{2} \mathrm{O}_{7}{ }^{2-}\right)$, iodates $\left(\mathrm{IO}_{3}^{-}\right)$, and permanganates $\left(\mathrm{MnO}_{4}^{-}\right)^{28}$. With the additional use of these oxidizers, explosives detection has become a more complicated process (Figure 1.2). 


\section{Explosive Residue Detection Flow Chart}

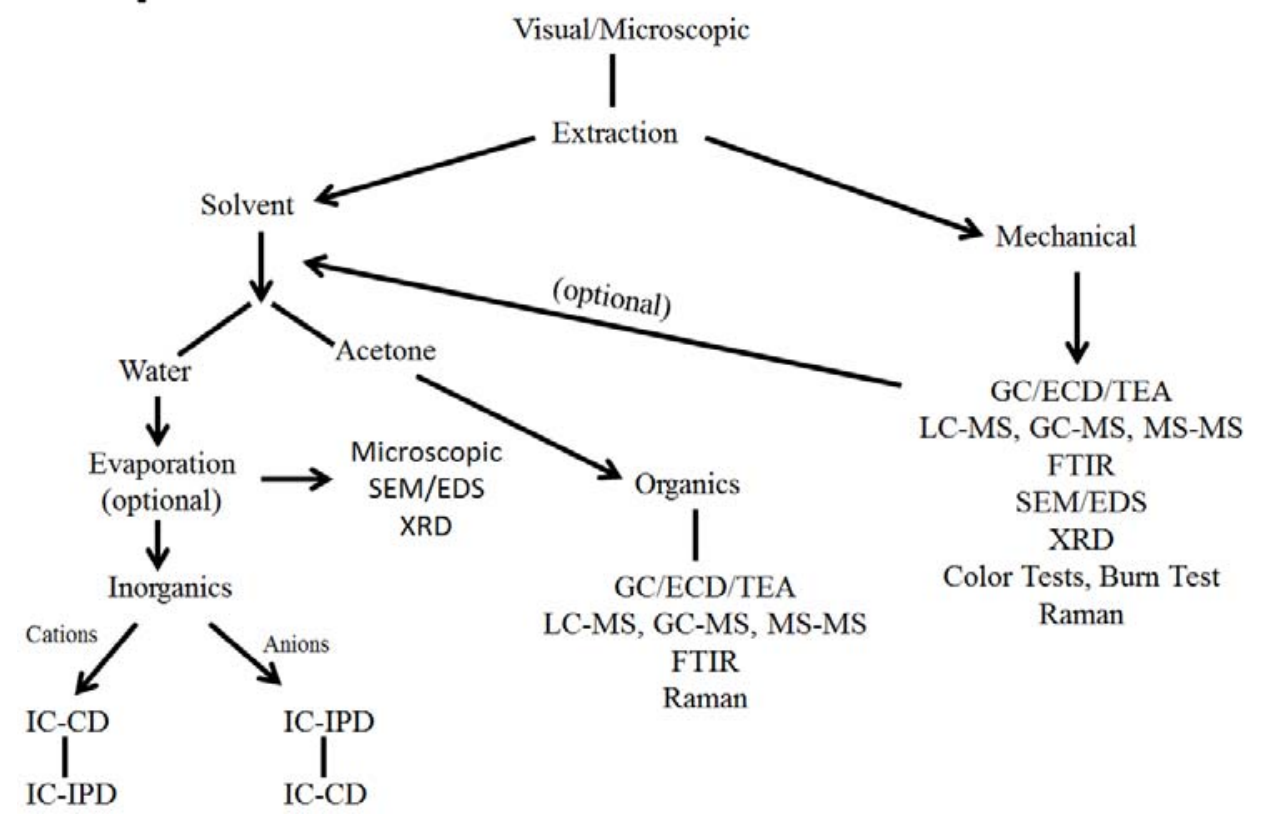

Figure 1.2. Explosives detection scheme in forensic analysis ${ }^{2}$. Gas chromatography/electron capture detector/ thermal energy analyzer (GC/ECD/TEA), liquid chromatography-mass spectrometry (LC-MS), gas chromatography-mass spectrometry (GC-MS), tandem mass spectrometry (MS-

MS), Fourier transform infrared spectroscopy (FTIR), scanning electron microscope/energy dispersive spectrometer (SEM/EDS), x-ray diffraction (XRD), ion chromatography-conductivity detection (IC-CD), ion chromatography-indirect photometric detection (IC-IPD).

The complicated detection scheme necessary for comprehensive explosives analysis ultimately increases analysis time and overall cost of analysis as a result of multiple complicated, expensive pieces of equipment being utilized for the determination of the explosive present.

\section{Research Goals}

To decrease the analysis time and complication of the explosive detection process, two analytical methods, a presumptive and confirmatory method, were developed. The first procedure involved the development of microfluidic paper-based analytical devices 
( $\mu$ PADs) for the on-site detection of multiple explosive compounds. Paper microfluidics allows for the development of simple devices, which can perform five or more simultaneous analyses while costing only pennies. Wax patterns are printed and melted into chromatography paper generating channels, which allow solvent to be directed to specific areas containing colorimetric reagents ${ }^{29}$. To cover the widest possible range of explosive materials, two devices were created: one for the detection of inorganic explosive components such as chlorate $\left(\mathrm{ClO}_{3}{ }^{-}\right)$, nitrate $\left(\mathrm{NO}_{3}{ }^{-}\right)$, ammonium $\left(\mathrm{NH}_{4}{ }^{+}\right)$, nitrite $\left(\mathrm{NO}_{2}{ }^{-}\right)$, and perchlorate $\left(\mathrm{ClO}_{4}{ }^{-}\right)$while the second device detects high/organic explosives such as nitroaromatics (e.g. TNT), nitroamines (e.g. RDX), urea nitrate, and $\mathrm{H}_{2} \mathrm{O}_{2}$.

The second procedure involved the development of a single confirmatory detection technique utilizing non-aqueous infusion and electrochemical detection coupled to electrospray ionization time-of-flight mass spectrometry (EC-ESI-TOF MS). Since inorganic explosives are difficult to detect utilizing mass spectrometry, 18-crown-6 ethers were added to form guest/host complexes with the inorganic ions and increase their molecular weight ${ }^{1}$. Therefore, this method allows ionic compounds to be detected as ion pairs along with other organic explosives, such as HMTD. One analyte, $\mathrm{H}_{2} \mathrm{O}_{2}$, is also low in molecular weight and difficult to detect with a mass spectrometer since it does not complex with 18-crown-6 ether. Therefore, an electrochemical detector is placed prior to the mass spectrometer to aid in the detection of $\mathrm{H}_{2} \mathrm{O}_{2}$. 


\section{CHAPTER 2. PRESUMPTIVE ON-SITE DETECTION OF EXPLOSIVES}

\section{A. Introduction}

In recent years there has been a dramatic increase in the use of IEDs due to improved controls placed on commercial and military explosives. Improvised explosive devices were once limited to war zones, but have become an increasing concern for law enforcement officials who may encounter terrorists manufacturing homemade explosives $^{30}$. In these situations, fast and accurate on-site identification of the explosive material is paramount.

Commonly used materials for improvised explosive preparations include fertilizers and industrial chemicals containing oxidizers such as $\mathrm{ClO}_{3}{ }^{-}, \mathrm{ClO}_{4}{ }^{-}$, and $\mathrm{NO}_{3}{ }^{-}$as well as other less stable compounds, such as peroxides ${ }^{2}$. These materials encompass a wide range of properties, such as volatility, polarity, and composition, which require a variety of different analytical techniques to identify the explosive materials. For example, the combination of gas chromatography-mass spectrometry (GC-MS) and liquid chromatography-mass spectrometry (LC-MS) are often used to identify organic compounds, while ion chromatography (IC) and capillary electrophoresis (CE) are used to determine inorganic ions ${ }^{31,32,23,33}$.

Metals are detected using scanning electron microscopy/energy dispersive spectroscopy (SEM/EDS) or X-ray diffraction (XRD) ${ }^{34,35}$. Each of these techniques requires large, expensive pieces of instrumentation that are not readily portable, so the samples are commonly sent to a laboratory for testing. This cumbersome process increases the amount of time before any analytical information on the identity of the explosive can be provided to on-site personnel. Therefore, a simple, rapid, and 
inexpensive analytical method needs to be developed to detect multiple explosive compounds in the field.

\section{B. On-Site Detection Techniques}

On-site explosive detection techniques need to be user friendly, fast, reliable, selective, and sensitive. Explosives detection canines are the most common on-site explosive detection technique. These trained dogs do not react to a particular scent, but to a combination of scent compounds that are given off by an explosive or narcotic. The disadvantages of this technique are that the dogs cannot state which explosive they are reacting to, have a high cost of maintaining and training, require a skilled handler, cannot work around the clock, and have behavioral and mood variations ${ }^{36}$.

On-site detection can be performed using various analytical instrumentation, such as ion mobility spectrometry (IMS) ${ }^{37}$, Fourier transform infrared spectroscopy, Raman spectroscopy ${ }^{38}$, and spectrometric assays ${ }^{39}$. Methods for standoff or remote detection have also been suggested for RDX and PETN through the use of fluorescence detection resulting in limits of detection at the picogram level for both compounds ${ }^{40}$. These analytical detection devices commonly rely on the detection of volatile components and can be costly and bulky, making them unavailable in many situations. Portable instruments also require a power source such as a battery, which can be drained before the field work is completed ${ }^{41}$.

Colorimetric and immunoassay based tests have also been developed, but the current procedures are not multiplexed and may require multiple tests and reagents for proper use. This extends the time of analysis and increases the amount of sample that is needed if an unknown explosive is present ${ }^{42,43}$. Three classes of commercially available 
colorimetric test kits are currently available. The first type requires the use of multiple liquid reagents for detection ${ }^{44-46}$. An example of this is the ETK Five involving the use of glass ampoules in protective plastic tubes, which are broken in order to apply a few drops of reagent to an absorbent paper. Once the ampoules are broken, the colorimetric reagents are only stable for up to two weeks requiring the frequent replacement of these kits $^{44}$. A second type involves the use of aerosol sprays such as EXPRAY, where chemical reagents are sprayed onto absorbent chemical pads used for swipe sampling. This kit only detects polynitroaromatics, nitrate esters, nitramines, and inorganic nitrate compounds ${ }^{47}$ leaving out a large set of improvised explosives, such as peroxides, chlorates, and perchlorates. The last type of on-site detection kit available involves swipe analysis and a portable colorimetric detector. An example of this is the XCAT, which consists of specially formulated optical inks present on detection cards. These cards are swiped on the sample area and inserted into the XCAT, where software is used to identify the explosive present ${ }^{48}$.

These commercially available kits have major drawbacks such as needing to carry liquid reagents for testing, which can be easily spilled or glass ampoules broken before they are able to be used. They also require multiple liquid reagents which only last a short period of time before another kit needs to be obtained for use. If an unknown explosive sample is being analyzed with certain kits, multiple tests may need to be run requiring multiple samples, which may not be available. They are also fairly expensive and can cost anywhere from a few dollars per test strip to hundreds of dollars for test kits. Most test kits also do not supply a test for perchlorate, which has replaced chlorate in pyrotechniques and can be found in many improvised explosive mixtures. 


\section{Microfluidic Paper-Based Analytical Devices ( $\mu$ PADs)}

Microfluidics involves the application of lithographic and other microfabrication techniques such as embossing to produce devices which can move nanoliter quantities of liquids on small glass or plastic supports. These glass or plastic chips are connected to micro-scale pumps, valves, and elecrophoretic power systems to transport the sample to different locations on the device for extraction, separation, and detection. By miniaturizing the system and exploiting the properties of fluids at the micro level, the sample volume is minimized, the reagent volume is reduced, and the overall separation efficiency of the system is increased ${ }^{49}$. Commercial microfluidic systems are beginning to appear for applications in proteomics and deoxyribonucleic (DNA) separations where small sample volumes are necessary, or where multiplexed analyses are needed and laboratory space is at a premium.

Currently, microfluidic systems utilize narrow channels etched or embossed in glass and plastic devices. Typically, these systems are not reused due to their high susceptibility to clogging from dust or precipitates. The initial prototyping of these devices can be very expensive and the complex systems of valves and fluidic channels can be difficult to engineer.

As a result of these issues, paper has become an increasingly attractive substrate for on-site microfluidic testing since it provides many advantages over traditional microfluidic devices including:

(1) Inexpensive compared to traditional microfluidic devices

(2) Samples can be easily segregated into different regions

(3) Multiple assays can be performed simultaneously making it suitable for 


\section{biological applications}

(4) Movement of liquid occurs due to capillary action and does not require external pumps or other electrical equipment ${ }^{50}$

(5) Combustible and biodegradable makeup allowing for easy eliminations of hazardous waste through incineration ${ }^{51}$

(6) Applicable for trace detection, since it is compatible with small volumes of samples

(7) Circumvents problems associated with bubbles that plague traditional microfluidic systems ${ }^{50}$

(8) Paper surface can be easily manipulated through printing, coating, and impregnation

(9) Easy to fabricate in large quantities in a small amount of time

(10) Can be easily stored and transported

(11) Paper properties can be changed to suit different applications

Microfluidic paper-based analytical devices have primarily found use as healthcare diagnostic devices in developing regions of the world that do not have the infrastructure to support traditional diagnostic equipment ${ }^{52}$. These devices utilize small amounts of antibodies combined with enzymatic or other colorimetric detection systems to detect the presence of disease states, diabetes, or parasitic infections ${ }^{53,54}$. The results are photographed and the image can be quickly transmitted to an expert in a hospital or laboratory setting who can evaluate the results and recommend a course of treatment ${ }^{29}$. Devices have also been created in a similar manner for pharmaceutical testing ${ }^{55}$ and environmental monitoring ${ }^{56}$. 
Paper can be made from many different sources such as wood, cotton, jute, flax, hemp, bamboo, ramie, sisal, bagasse, grass, and straw. Wood is used in $90 \%$ of the raw material for the paper industry, since processing of non-wood plants is more expensive. The main issue with this type of paper is the high concentration of lignin in the wood, which causes the paper to discolor, affecting the reading of colorimetric tests. Therefore, for paper microfluidic purposes, paper made from $100 \%$ cotton is used. Cotton based papers are commonly used for filter paper and chromatography paper, which are manufactured using high-quality cotton linters with a minimum $\alpha$-cellulose content of $98 \%{ }^{51}$. There is no single type of paper that possesses the desired characteristics for all paper microfluidics applications, but the most frequently used paper is Whatman no. 1 chromatography paper. This is a result of the paper's smooth surface, low cost, uniformity on both sides, hydrophilic character, medium flow rate, and $0.18 \mathrm{~mm}$ thickness, which meets the standard for commercially available printers ${ }^{57-59}$. Microfluidic paper-based analytical devices permit the development of inexpensive analytical devices through the fabrication of hydrophobic patterns on chromatography paper ${ }^{29}$. There are many different ways of fabricating $\mu$ PADs such as photolithography, plotting, inkjet etching, plasma treatment, wax printing, ink jet printing, flexography printing, screen printing, cutting, and laser treatment ${ }^{60}$ (Table 2.1). 
Table 2.1. Advantages and Disadvantages of Different Fabricating Methods for the Development of $\mu$ PADs ${ }^{51,57,60}$.

\begin{tabular}{|c|c|c|}
\hline $\begin{array}{l}\text { Fabrication } \\
\text { Techniques }\end{array}$ & Advantages & Disadvantages \\
\hline Photolithography & $\begin{array}{l}\text { - Can be adapted to use low-cost } \\
\text { instruments such as a hot plate } \\
\text { or sunlight } \\
\text { - Can pattern a wide variety of } \\
\text { papers } \\
\text { - High resolution of microfluidic } \\
\text { channels }\end{array}$ & $\begin{array}{ll}\text { - } & \text { Requires multistep } \\
\text { process and extensive } \\
\text { equipment } \\
\text { - } \text { Contamination with } \\
\text { photoresist } \\
\text { - } \text { Barriers are susceptible to } \\
\text { damage when bent or } \\
\text { folded } \\
\text { - } \text { Can clog paper pores }\end{array}$ \\
\hline Plotting & $\begin{array}{l}\text { - Low cost of } \\
\text { polydimethylsiloxane (PDMS) } \\
\text { patterning agent } \\
\text { - } \quad \text { Less demanding viscosity } \\
\text { ranges than in printing } \\
\text { - } \text { Can work with any surface } \\
\text { - } \\
\text { Flexible devices }\end{array}$ & $\begin{array}{l}\text { Inconsistent control over } \\
\text { hydrophobic barrier } \\
\text { formation } \\
\text { - } \\
\text { Requires customized } \\
\text { plotter (hard to obtain) } \\
\text { - } \begin{array}{l}\text { Deteriorated barrier } \\
\text { definition }\end{array} \\
\text { - Cannot be used for high } \\
\text { throughput production }\end{array}$ \\
\hline Ink Jet Etching & $\begin{array}{l}\text { Requires a single printing } \\
\text { apparatus to create channels by } \\
\text { etching and to print } \\
\text { bio/chemical sensing reagents }\end{array}$ & $\begin{array}{l}\text { - Printing apparatus must be } \\
\text { customized } \\
\text { - Not suitable for mass } \\
\text { fabrication }\end{array}$ \\
\hline $\begin{array}{c}\text { Plasma } \\
\text { Treatment }^{61}\end{array}$ & $\begin{array}{l}\text { - Low cost due to use of cheap } \\
\text { patterning agent } \\
\text { - Useful for labs with a plasma } \\
\text { cleaner wishing to make many } \\
\text { replicates of a few simple } \\
\text { patterns }\end{array}$ & $\begin{array}{l}\text { - Requires different metal } \\
\text { masks for different } \\
\text { microfluidic patterns } \\
\text { - Cannot produce arrays of } \\
\text { free-standing hydrophobic } \\
\text { patterns }\end{array}$ \\
\hline Wax Printing & $\begin{array}{l}\text { Produce massive amount of } \\
\text { devices with simple and fast } \\
\text { fabrication process } \\
\text { - Bio-degradability of barriers } \\
\text { - Computer designed patterns }\end{array}$ & $\begin{array}{l}\text { Expensive wax printers } \\
\text { - } \quad \text { Requires extra heating } \\
\text { step after wax deposition } \\
\text { - Designs of patterns must } \\
\text { account for spreading of } \\
\text { the wax in paper }\end{array}$ \\
\hline
\end{tabular}




\begin{tabular}{|c|c|c|}
\hline Ink Jet Printing & $\begin{array}{l}\text { - Applicable with modified office } \\
\text { printers of extremely low cost } \\
\text { and high availability } \\
\text { - Computer designed patterns } \\
\text { - Produce massive amount of } \\
\text { devices with simple and fast } \\
\text { fabrication process }\end{array}$ & $\begin{array}{l}\text { - } \\
\text { - } \text { Rezzle clogging } \\
\text { step after deposition } \\
\text { - Designs for } \\
\text { microfabrication are } \\
\text { costly }\end{array}$ \\
\hline $\begin{array}{c}\text { Flexography } \\
\text { Printing }\end{array}$ & $\begin{array}{l}\text { - Low ink usage } \\
\text { - Avoids heat treatment of } \\
\text { printed patterns } \\
\text { - Compatible with large scale } \\
\text { production }\end{array}$ & $\begin{array}{l}\text { Requires sequentially } \\
\text { printing layers of } \\
\text { polystyrene solution to } \\
\text { create waterproof barriers } \\
\text { - } \\
\text { Requires different printing } \\
\text { plates } \\
\text { - Print quality relies on the } \\
\text { smoothness of paper } \\
\text { surface } \\
\text { - Limited compatibility of } \\
\text { solvents so requires } \\
\text { frequent cleaning to avoid } \\
\text { contamination }\end{array}$ \\
\hline Screen Printing & 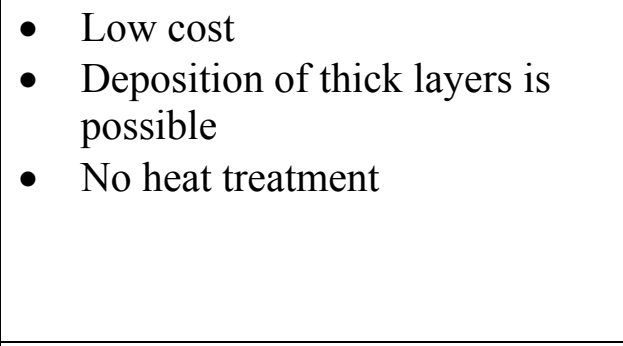 & $\begin{array}{l}\text { - Inconsistent deposition of } \\
\text { ink deposited through the } \\
\text { screen results in low } \\
\text { resolution } \\
\text { - Different printing screens } \\
\text { needed for creating } \\
\text { different patterns }\end{array}$ \\
\hline Cutting $^{54}$ & $\begin{array}{l}\text { - No contamination from } \\
\text { chemicals } \\
\text { - Fabrication of 3D structures } \\
\text { from paper and tape }\end{array}$ & $\begin{array}{l}\text { - Manual method results in } \\
\text { low resolution } \\
\text { - Devices must be enclosed } \\
\text { in tape } \\
\text { - Cannot produce arrays of } \\
\text { free-standing hydrophobic } \\
\text { patterns }\end{array}$ \\
\hline Laser Treatment & - High resolution & $\begin{array}{l}\text { - } \\
\text { Requires specialized laser } \\
\text { - } \quad \text { Chaipment } \\
\text { lateral flow of liquids } \\
\text { - } \\
\text { Requires extra coating for } \\
\text { fluid flow }\end{array}$ \\
\hline
\end{tabular}


One of the most effective ways to produce $\mu$ PADs is wax printing due to the ease of application and minimal instrumentation required (commercially available printer and laminator). This printing method allows for a low-cost production of the devices, as low as $\$ 0.001$ or less for devices made from inexpensive papers, approximately $\$ 0.60$ for an 8.5 in $\mathrm{x} 11$ in sheet of $\mu$ PADs on Whatman no. 1 chromatography paper ${ }^{63}$. The wax channels are used to compartmentalize chemical reactions and direct liquid samples toward individual sections of paper containing test reagents ${ }^{63}$. In this method, wax ink is printed onto chromatography paper using a computer design and then the paper is run through a laminator to allow the wax to melt and diffuse into the paper forming hydrophobic barriers. When the wax is melted, it spreads vertically and horizontally into the paper. This vertical spreading creates a hydrophobic barrier across the thickness of the paper, while the lateral spreading decreases the resolution of the printed pattern resulting in patterns that are wider than those originally printed ${ }^{63-65}$. The entire printing process is completed within a few minutes and is capable of producing tens to hundreds of copies of the device ${ }^{51}$. The reproducibility of this printing technique is controlled by the width of the wax line and the heating temperature, so if these remain the same for each device they can easily be reproducible ${ }^{59}$.

Detection is most commonly performed using colorimetric schemes, however, electrochemical, chemiluminescence, and fluorescence techniques can also be used (Table 2.2). 
Table 2.2. Advantages and Disadvantages of Techniques Used for Analyte Detection on $\mu$ PADs.

\begin{tabular}{|c|c|c|}
\hline $\begin{array}{l}\text { Detection } \\
\text { Techniques }\end{array}$ & Advantages & Disadvantages \\
\hline $\begin{array}{l}\text { Colorimetric } \\
\text { Sensing }\end{array}$ & $\begin{array}{ll}\text { - } & \text { Simple } \\
\text { - } & \text { Most adopted }\end{array}$ & $\begin{array}{l}\text { - Judgment of final color } \\
\text { can be challenging } \\
\text { - Influenced by } \\
\text { background noise of } \\
\text { paper or sample }\end{array}$ \\
\hline $\begin{array}{l}\text { Electrochemical } \\
\text { Sensing }\end{array}$ & $\begin{array}{l}\text { - Fast sensor responses } \\
\text { - Higher sensitivity (nM } \\
\text { range) } \\
\text { - Independent of } \\
\text { ambient light } \\
\text { - Less prone to } \\
\text { interference from the } \\
\text { color/deterioration of } \\
\text { the paper }\end{array}$ & $\begin{array}{l}\text { Requires reading } \\
\text { equipment increasing } \\
\text { complexity and cost per } \\
\text { test }\end{array}$ \\
\hline Chemiluminescence $^{70}$ & $\begin{array}{l}\text { Based on the emission } \\
\text { of light by a chemical } \\
\text { reaction } \\
\text { - Increased specificity } \\
\text { and sensitivity }\end{array}$ & $\begin{array}{l}\text { Requires darkness or } \\
\text { reading equipment } \\
\text { making interpretation of } \\
\text { results more } \\
\text { complicated }\end{array}$ \\
\hline Fluorescence $^{71}$ & $\begin{array}{l}\text { - Increased specificity } \\
\text { and sensitivity }\end{array}$ & $\begin{array}{l}\text { - Scattering of light on } \\
\text { the cellulose fibers } \\
\text { - Influence of index } \\
\text { refraction between } \\
\text { cellulose and air } \\
\text { - High cost }\end{array}$ \\
\hline
\end{tabular}

Colorimetric detection is a well-established, fundamental technique that has been the most adopted sensing mechanism for paper microfluidics ${ }^{51}$. Using physical and chemical properties of the chosen analyte, reagents and analytes interact to produce a visible color change when the analyte of interest is present. Color spot tests may be presumptive or specific, and are used in the detection many different types of analytes. 
They respond to intact compounds ${ }^{72}$, ions/functional groups ${ }^{73}$, metals ${ }^{74}$, or biomarkers ${ }^{75}$ and can be based in classical wet chemistry methods ${ }^{76}$, nanoparticle aggregation ${ }^{77}$, or antibody/aptamer detection ${ }^{75,78}$. By using multiple indicators for the same compound, the user's ability to discriminate between different shades and intensities of color indicating concentration is increased and data can be accurately interpreted ${ }^{64}$. For ions and small molecules, multiple indicators for the same compound may also help avoid a false positive result, since the interferences for tests using different reagents or mechanisms for the same analyte are unlikely to be the same for both. Changing the chemistry would permit detection of the same compound but differing responses. Therefore as a result of their applicability to paper, versatility, and ease of analysis, colorimetric spot tests will be used for detection on $\mu$ PADs.

Colorimetric detection can be performed using visual detection along with scanners, digital cameras, camera phones, and spectrophotometers. Detection using the human eye can be subjective and influenced by lighting and conditions of dry and wet paper, so color charts are commonly included with the devices. When using instrumental techniques, differences in illumination may cause variations in color intensity and hue which can be solved by background correction, subtraction of the background color, or comparison with a calibration curve of standards of known color and intensity. An office scanner can also be utilized to provide high resolution and focus of the digitalized image. These scanners can be portable, easy to use, and are widely used all over the world. Digital cameras with automatic white balance can also be used. After the image is photographed, it is typically analyzed using computer programs such as Adobe Illustrator, Adobe Photoshop, or Image J. Using this software, the total value or 
individual channels of the color space can be utilized for quantification purposes. This response is given as the average of the pixel intensity in the detection zone after subtraction from the average intensity for the control (white) region. Software for cell phone cameras is also being developed ${ }^{51}$ to allow for quantification in the field. Once captured, images can also be easily sent to a specialist for further analysis using email or text messaging. Lastly, spectrophotomers have been utilized, mostly as a way to optimize the fabrication process in the laboratory due to their large size ${ }^{51,57}$.

Researchers have been developing new on-site colorimetric tests. Ercag et al. has developed a sensing method for nitroaromatic and nitramine based explosives. Explosives such as TNT, PETN, and RDX, were pre-adsorbed on a poly vinyl chloride surface and sprayed with different reagents for each group of explosives generating different colors ${ }^{79}$. Explosives detection has also been developed utilizing $\mu$ PADs. Taudte et al. utilized a $\mu \mathrm{PAD}$ with circular patterns that required the explosive sample to be placed in the small circular area containing pyrene. Under UV light the $\mu \mathrm{PAD}$ fluoresced, but when an explosive sample was present the fluorescence was quenched ${ }^{71}$. Pesenti et al. published a method to detect three types of trinitroaromatic explosives on $\mu$ PADs with $6 \mathrm{~mm}$ circular patterns. Potassium hydroxide was used to detect trinitroaromatics through a colorimetric reaction with limits of detection determined to be $7.5 \mathrm{ng}$ for trinitrobenzene (TNB), $12.5 \mathrm{ng}$ for TNT, and $15.0 \mathrm{ng}$ for tetryl ${ }^{68}$. Salles et al. developed a $\mu \mathrm{PAD}$ for the detection of organic peroxides and nitrobenzenes. The analysis time was 15 minutes with a limit of detection at $0.2 \mu \mathrm{g}$ of explosives. This method required the use of a smart phone, custom-made software, and a closed chamber in order to differentiate the color profiles ${ }^{80}$. All of these procedures focused on detecting 
a small subset of explosives utilizing spectroscopic detection but failed to present a method for the detection of improvised explosives, particularly those developed from fertilizers and pyrotechnic materials.

\section{CHAPTER 3. CONFIRMATORY DETECTION OF EXPLOSIVES}

\section{A. Laboratory Detection Techniques}

In previous studies, explosives have been detected via a variety of analytical methods. Bulk detection of explosive compounds is commonly done through Raman and Infrared (IR) spectroscopy.

Trace detection is done through analytical techniques such as GC-MS, LC-MS, IC, and CE. Inorganic compounds, such as AN, are typically detected by $\mathrm{IC}^{23,24}$ or $\mathrm{CE}^{25,26,33,81-84}$ while organic explosives, such as TNT, are commonly analyzed by GC$\mathrm{MS}^{31}$ or LC-MS ${ }^{13,32,85}$. However, there are few analytical methods developed which are capable of rapidly detecting inorganic and organic explosives simultaneously, particularly at trace levels. Examples of these selected methods include FTIR, Raman, and specific types of mixed mode ion chromatography.

Inorganic nitrate, chlorate, and perchlorate salts are ionic species; therefore many methods have been developed utilizing ion chromatography with conductivity detection, which measures the electrical conductance between two electrodes and allows for detection of ionic species. Ion chromatography has also been utilized, but perchlorate is strongly retained by anion-exchange stationary-phase materials and requires special eluents for detection. Ion-pairing and ion-exclusion reagents can be used to adjust the retention of late-eluting peaks ${ }^{24}$; however, the best procedure for inorganic explosives 
screening is gradient ion chromatography ${ }^{86}$. Capillary electrophoresis can also be used to separate ionic species, typically using indirect UV detection ${ }^{25,84}$ or contactless conductivity detection. Ion chromatography-mass spectrometry instruments have recently been developed and proven useful in explosive analysis. For example, an anionexchange HPLC column coupled to a mass spectrometer and negative electrospray ionization has been used to successfully detect chlorate, chlorite, perchlorate, and nitrate ions $^{87}$.

Portable techniques utilizing microfluidic systems have also been developed to quickly detect ions ${ }^{25,33,83,88}$. These systems use indirect fluorescence detection with laser or light emitting diode (LED) excitation. An approach known as dual opposite injection permits the simultaneous measurements of both cations and anions by CE or microfluidic capillary electrophoresis ${ }^{81,83}$. Methods have also been developed to detect ions from home-made explosive residue samples, emulsion explosive residues, and firework perchlorate-based explosives ${ }^{22-24,89}$.

Peroxide-based explosives can be difficult to analyze due to problems with thermal stability and the lack of a UV chromophor ${ }^{90}$. While low injector temperature can be used for analysis of peroxide-based explosives to avoid the problems of decomposition in gas chromatographic injectors, liquid based methods have been developed to detect TATP or HMTD through determination of $\mathrm{H}_{2} \mathrm{O}_{2}$, a precursor and degradation product. Most of these procedures have utilized either UV irradiation or a short-burst laser treatment to degrade peroxide-based explosives post-column, but prior to being introduced to the detector. Infrared and Raman spectroscopy have been utilized to screen for peroxide based explosives $^{85,90-92}$. Multiple mass spectrometry methods have also been developed 
including headspace GC-MS and solid phase microextraction (SPME) GC-MS ${ }^{93}$ along with ESI-MS ${ }^{94}$, desorption electrospray ionization (DESI)-MS ${ }^{95}$, and LC-MS ${ }^{12,31,87,96,97}$. Electrochemical methods have been unable to detect TATP, although they successfully detected its precursor and degradation product $\mathrm{H}_{2} \mathrm{O}_{2}{ }^{82,98-101}$. There have been no methods reported using a form of electrochemical detection for the direct detection of HMTD and TATP along with $\mathrm{H}_{2} \mathrm{O}_{2}$. Nanotube array sensors have also been developed to detect organic peroxide explosives ${ }^{102}$.

No methods have been reported for a comprehensive analysis of improvised explosives including inorganic salts and peroxide based explosives. While there have been analyses completed utilizing ultra-high performance liquid chromatography-mass spectrometry (UHPLC-MS) for the detection of high explosives and organic peroxides ${ }^{32}$, these methods are not capable of detecting inorganic explosives and $\mathrm{H}_{2} \mathrm{O}_{2}$. The current standard for the analysis of explosive compounds is US EPA method 8330, which utilizes HPLC-UV to detect nitroaromatic and nitroamine compounds, ${ }^{32,103,104}$ but this method does not include a procedure for the detection of peroxide explosives and inorganic oxidizers. Therefore, a method capable of detecting a wide variety of both organic and inorganic materials needs to be developed to rapidly screen unknown debris from a postblast scene.

\section{B. Infusion Electrochemical Detection Electrospray Ionization Time-of-Flight Mass Spectrometry (EC-ESI-TOF MS)}

A method utilizing non-aqueous infusion electrochemical detection electrospray ionization time-of-flight mass spectrometry has the potential to detect multiple explosive compounds using one analytical method. For the detection of $\mathrm{H}_{2} \mathrm{O}_{2}$, a procedure was 
previously established by Tarvin et al. utilizing high performance liquid chromatography with electrochemical detection (HPLC-EC). The optimized mobile phase was determined to be $150 \mathrm{mM}$ aqueous sodium acetate at a $\mathrm{pH}$ of 10.5 . The electrochemical detector consisted of a $3 \mathrm{~mm}$ gold working electrode, a palladium-hydrogen reference electrode, and a palladium auxiliary electrode with an applied potential of $+400 \mathrm{mV}$. The detection limit was determined to be $0.6 \mu \mathrm{M}$ for hydrogen peroxide ${ }^{99}$.

To detect inorganic explosive components such as AN and UN, a mass spectrometry method was previously developed. Ammonium and nitrate ions are common endogenous ions in the environment and the detection of these compounds separately does not necessarily mean that an explosive is present. To improve the reliability of the detection, ionic compounds should be detected as ion pairs. This can be accomplished through the use of a non-aqueous mobile phase, ensuring that the ions do not dissociate, and 18crown-6-ethers to form an ion pair complex capable of being detected using a mass spectrometer ${ }^{1}$. These crown ethers do not interact with organic explosives allowing for both inorganic and organic explosives to be detected using one analytical method. de Perre et al. previously developed a procedure utilizing 18-crown-6 ether complexation and mass spectrometry for $\mathrm{UN}$ and $\mathrm{AN}$ detection. A non-aqueous solvent (methanol) was utilized since the presence of water reduced specificity for the uronium ion by allowing protonation of urea. Detection limits were determined to be $0.16 \mathrm{ppm}$ for $\mathrm{AN}$ and 0.25 ppm for $\mathrm{UN}^{1}$. It was also noted that inorganic ions such as chlorate and perchlorate could be detected as well as organic explosives via direct detection or through the formation of adduct ions. 
These two previously developed methods will be combined and the parameters optimized to create one analytical method for the simultaneous identification of improvised explosives. An electrochemical detector will be placed in front of the mass spectrometer to aid in detection of $\mathrm{H}_{2} \mathrm{O}_{2}$, while the mass spectrometer will detect inorganic complexation and organic ions.

\section{8-Crown-6 Ethers}

Crown ethers are cyclic organic compounds that can contain oxygen, nitrogen, sulfur, or other heteroatoms. The heteroatoms alternate with carbon bridges to form these cyclic compounds, such as 18 -crown-6 ether ${ }^{105}$ (Figure 3.1).

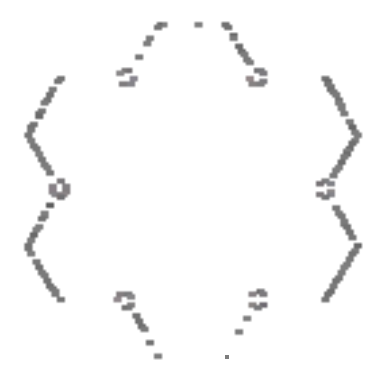

\section{Figure 3.1. Structure of 18 -crown-6 ether}

Crown ethers were discovered by Charles Pedersen, who received a Nobel Prize for his work in 1987. They have a macrocycle ring (generally larger than 12 members) where four or more heteroatoms are separated by a carbon-containing unit of two or more atoms. Oxygen is typically the heteroatom that binds alkali metals, while nitrogen is present for the binding of transition metals. The exterior of the macrocycle ends up being hydrophobic, while the interior is hydrophilic and with the appropriately sized cation, an ion complex can be formed. If the macroring hole and the cation diameter are identical, the cation will be embedded in the ring. If the ring is larger than the cation, the ring can 
pucker to allow the donor-group-to-ion contacts to be the appropriate size and position. When the cation is larger than the ring, the cation can sit on the ring or be held between two rings. These complexes can also be formed using organic cations, such as ammonium $\left(\mathrm{NH}_{4}{ }^{+}\right)$, through the oxygen atoms in the macroring, which can function as hydrogen bond acceptors. Therefore, 18 -crown-6 ethers will form ion complexes with inorganic explosives such as ammonium nitrate and urea nitrate along with ammonium perchlorate and potassium chlorate ${ }^{105}$.

\section{Electrochemical Detector}

Since hydrogen peroxide has a low molecular weight $(\mathrm{MW}=34.01)$ it is difficult to detect utilizing a mass spectrometer, so an electrochemical detector is used. This type of detection involves the use of three electrodes: a working electrode, reference electrode, and auxiliary electrode. During the oxidation process the electrochemical reaction allows for the release of electrons into the working electrode. This flow of electrons is the current, which is detected by the electrochemical detector. Through the use of an amperometric electrode, the current is proportional to the concentration of the analyte. In this method, the working electrode is a carbon paste electrode (CPE), which is highly sensitive and gives the highest signal to noise $(\mathrm{S} / \mathrm{N})$ ratios for all electrodes ${ }^{106}$. To construct the CPE, chemically cleaned graphite particles (10-25 $\mu \mathrm{m}$ diameter) are combined with binder and packed tightly into the cavity of a plastic electrode block and the surface is smoothed to a glossy finish ${ }^{107}$.

Since it is not possible to determine the absolute potential of an electrode, the electrode potential must always be compared to an arbitrary zero point determined through a reference electrode. The most widely available reference electrode is a 
silver/silver chloride electrode. In this electrode the internal electrolyte and external electrolyte are in ionic contact through a small porous ceramic plug sealed into the end of the glass tubing. An auxiliary electrode is also present to specifically collect the current flowing in the circuit and allows the reference electrode to remain at its reference potential ${ }^{107}$.

These three electrodes are encased in a thin-layer cell. The liquid enters the detector cell through a micro-port and then flows over a solid working electrode. The flow continues past the reference and auxiliary electrodes. The working electrode is grounded through the detector electronics and the voltage between the auxiliary and reference electrode is controlled to regulate the potential required for the electrochemical reaction. The body of the cell is formed from two solid blocks, one PTFE block containing the working electrode, while the second is made of stainless steel and forms the auxiliary electrode. Connection of these electrodes to the electronics of the system is through gold pins and electrical connectors ${ }^{107}$.

\section{Ionization Source}

The analyte flow then continues from the electrochemical detector into the ionization source of the mass spectrometer. There are many types of ionization sources for mass spectrometers such as electron ionization, chemical ionization, electrospray ionization, and fast atom bombardment (Table 3.1). 
Table 3.1. Comparison of Different Ionization Sources Commonly Used in Mass Spectrometry.

\begin{tabular}{|c|c|c|c|c|}
\hline $\begin{array}{c}\text { Ionization } \\
\text { Method }\end{array}$ & Typical Analytes & $\begin{array}{c}\text { Sample } \\
\text { Introduction }\end{array}$ & $\begin{array}{l}\text { Typical } \\
\text { Mass } \\
\text { Range } \\
\end{array}$ & Method Highlights \\
\hline $\begin{array}{c}\text { Electron } \\
\text { Ionization (EI) }\end{array}$ & $\begin{array}{l}\text { Relatively small } \\
\text { and volatile }\end{array}$ & $\begin{array}{l}\text { GC or LC } \\
\text { Solid Probe }\end{array}$ & $1-1,000$ & $\begin{array}{ll}\text { - } & \text { Hard method } \\
\text { - } & \text { Used for small } \\
\text { molecules } \\
\text { - } & \text { Versatile } \\
\text { - } & \text { Provides } \\
\text { structural info } \\
\text { - Standardized, } \\
\text { allowing for } \\
\text { libraries }\end{array}$ \\
\hline $\begin{array}{c}\text { Chemical } \\
\text { Ionization }(\mathrm{CI})\end{array}$ & $\begin{array}{l}\text { Relatively small } \\
\text { and volatile }\end{array}$ & $\begin{array}{l}\text { GC or LC } \\
\text { Solid Probe }\end{array}$ & $60-1,200$ & $\begin{array}{l}\text { - Soft method } \\
\text { - Used for small } \\
\text { molecules } \\
\text { - See molecular } \\
\text { ion peak }\end{array}$ \\
\hline $\begin{array}{c}\text { Electrospray } \\
\text { Ionization (ESI) }\end{array}$ & $\begin{array}{l}\text { Peptides, proteins, } \\
\text { non-volatile }\end{array}$ & $\mathrm{LC}$ or $\mathrm{CE}$ & $\begin{array}{c}100- \\
50,000\end{array}$ & $\begin{array}{ll}\text { - } & \text { Soft method } \\
\text { - } & \text { Ions can be } \\
\text { multiply charged } \\
\text { - See molecular } \\
\text { ion peak }\end{array}$ \\
\hline $\begin{array}{l}\text { Fast Atom } \\
\text { Bombardment } \\
\quad(\text { FAB })\end{array}$ & $\begin{array}{l}\text { Carbohydrates, } \\
\text { organometallics, } \\
\text { peptides, non- } \\
\text { volatile }\end{array}$ & $\begin{array}{l}\text { Sample mixed } \\
\text { in viscous } \\
\text { matrix }\end{array}$ & $\begin{array}{c}300- \\
5,000\end{array}$ & $\begin{array}{l}\text { Soft method but } \\
\text { harder than ESI } \\
\text { or MALDI }\end{array}$ \\
\hline $\begin{array}{l}\text { Matrix Assisted } \\
\text { Laser } \\
\text { Desorption } \\
\text { Ionization } \\
\text { (MALDI) }\end{array}$ & $\begin{array}{l}\text { Peptides, proteins, } \\
\text { nucleotides }\end{array}$ & $\begin{array}{l}\text { Sample mixed } \\
\text { in solid matrix }\end{array}$ & $\begin{array}{c}500- \\
100,000\end{array}$ & $\begin{array}{ll}- & \text { Soft method } \\
\text { - } & \text { Very high mass } \\
\text { range } \\
\text { - } \\
\text { Molecule needs } \\
\text { to absorb at the } \\
\text { wavelength of } \\
\text { the laser to } \\
\text { ionize it }\end{array}$ \\
\hline
\end{tabular}


Since ion pair complexes are being detected, a soft ionization technique is used to ensure the ion complexes do not break apart ${ }^{1}$. Therefore, electrospray ionization is used because it allows for a large mass range and is a soft ionization technique. It also allows for interfacing with an autosampler for a LC, which is required for interfacing with an electrochemical detector.

Electrospray ionization is produced by applying a strong electric field under atmospheric pressure to a liquid passing through a capillary tube. This electric field creates a charge accumulation at the end of the capillary, which will break and form highly charged droplets. These droplets pass through a drying gas in order to desolvate the ions and then are directed into the mass analyzer ${ }^{108}$.

Mass Analyzer

The ions expelled from the ionization process are then focused using lenses and accelerated towards a mass analyzer such as a quadrupole, time-of-flight, or orbitrap. 
Table 3.2. Advantages and Disadvantages of Mass Analyzers for a Mass Spectrometer $^{108}$.

\begin{tabular}{|c|c|c|}
\hline Analyzer & Advantages & Disadvantages \\
\hline Quadrupole & $\begin{array}{ll}\text { - } & \text { Unit mass resolution } \\
\text { - } & \text { Fast scan } \\
\text { - } & \text { Low cost }\end{array}$ & - Lower resolution \\
\hline $\begin{array}{c}\text { Sector (magnetic and/or } \\
\text { electrostatic) }\end{array}$ & $\begin{array}{ll}- & \text { High resolution } \\
\text { - } & \text { Exact mass }\end{array}$ & $\begin{array}{l}\text { - Limited resolving } \\
\text { power }\end{array}$ \\
\hline Time-of-Flight (TOF) & $\begin{array}{l}\text { - Theoretically no limitation for } \\
\mathrm{m} / \mathrm{z} \text { maximum } \\
\text { - High throughput } \\
\text { - High resolution }\end{array}$ & $\begin{array}{ll}\text { - } & \text { More expensive } \\
\text { - } & \text { High vacuum }\end{array}$ \\
\hline $\begin{array}{l}\text { Ion Cyclotron Resonance } \\
\text { (ICR) }\end{array}$ & $\begin{array}{l}\text { - } \quad \text { Very high resolution } \\
\text { - } \quad \text { Exact mass } \\
\text { - } \quad \text { Perform ion chemistry } \\
\end{array}$ & $\begin{array}{l}\text { - } \quad \text { Very expensive } \\
\text { - High vacuum }\end{array}$ \\
\hline Orbitrap & $\begin{array}{l}\text { - } \text { High resolution } \\
\text { - } \quad \text { Exact mass }\end{array}$ & $\begin{array}{ll}\text { - } & \text { Slower analysis } \\
& \text { than others } \\
\text { - } & \text { Most expensive } \\
\text { - } & \text { High vacuum }\end{array}$ \\
\hline
\end{tabular}

A reflectron time-of-flight (TOF) mass analyzer was selected due to its large mass range allowing for detection of ion complexes with crown ether. It also allows for exact mass calculations to determine the ion complexes that are being formed.

In a TOF, ions are accelerated toward a flight tube by a difference of potential applied between an electrode and extraction grid. The ions acquire the same kinetic energy, and when leaving the acceleration region enter a field-free region where they are separated according to their velocities. Smaller ions will move faster while larger ions move slower allowing for separation. The separated ions approach a reflectron, acting like an ion mirror, and are sent back through the flight tube before reaching the detector positioned at the other end of the flight tube. The advantage of utilizing a reflectron is the correction of the kinetic energy dispersion of the ions leaving the source with the same $\mathrm{m} / \mathrm{z}$ ratio. Ions with a higher kinetic energy will penetrate the reflectron more 
deeply than ions with lower kinetic energy. This allows the faster ions to spend more time in the reflectron and reach the detector at the same time as slower ions with the same $\mathrm{m} / \mathrm{z}^{109}$.

The mass-to-charge ratios are then determined by measuring the time that ions take to move through the field-free region between the source and the detector, a photomultiplier tube. This is then sent to a computer where a mass spectrum is generated $^{108}$.

\section{CHAPTER 4. EXPERIMENTAL PROCEDURES}

\section{A. Introduction}

The goal of this project was to develop a presumptive and confirmatory method for the detection of multiple explosive compounds, focusing on the wide variety of explosive materials utilized in improvised explosive devices. The presumptive method involved the development of microfluidic paper-based analytical devices ( $\mu \mathrm{PAD}$ ) for the inexpensive, on-site colorimetric detection of explosive compounds. Two devices were developed: one for the detection of inorganic explosives including $\mathrm{ClO}_{3}{ }^{-}, \mathrm{ClO}_{4}^{-}, \mathrm{NH}_{4}{ }^{+}, \mathrm{NO}_{3}^{-}$, and $\mathrm{NO}_{2}{ }^{-}$, and the second device detects high/organic explosives including RDX, TNT, UN, and peroxides.

The confirmatory method involved a procedure that combines amperometric detection for peroxides with electrospray ionization time-of-flight mass spectrometry for inorganic and organic explosives. In the mass spectrometer, inorganic ions were detected using 18-crown-6 ether to capture ions and ion pairs. When switched to negative ion mode, military grade explosives, such as TNT and RDX, can also be detected. These 
procedures provide detection of the widest possible variety of explosives, precursors, and reaction products.

\section{B. Development of Microfluidic Paper-Based Analytical Devices ( $\mu$ PADs) For On- Site Explosive Detection}

\section{Chemicals}

All reagents and chemicals were analytical grade. Explosive standards such as TNT, RDX, and urea nitrate were obtained as dilute solutions in acetonitrile from law enforcement sources. Potassium chlorate, ammonium nitrate, potassium nitrite, and potassium perchlorate were all purchased from Sigma-Aldrich. 30\% aqueous hydrogen peroxide solution was purchased from Fisher Scientific.

The handling of explosives can be hazardous and should be performed with appropriate laboratory safeguards. All materials were stored as dilute solutions in sealed plastic vials in an explosion proof freezer. All experiments involving explosives were conducted with appropriate protection including face shield, gloves, and lab coat. Laboratory fume hoods were used when appropriate.

\section{2. $\mu$ PAD Fabrication}

The $\mu$ PADs were designed using Microsoft paint and printed using blue ink on Whatman no. 1 chromatography paper with a wax-based printer (Xerox ColorQube 8750). The paper was then placed into an aluminum foil carrier and run through a laminator at $160^{\circ} \mathrm{C}$, speed 1 . This melting process was repeated and the $\mu$ PADs were cut

to appropriate size for use. Two microliters of each colorimetric reagent were spotted onto the $\mu$ PADs and allowed to dry for approximately 1 minute. 
This process was used for all colorimetric reagents on both the single lane $\mu$ PADs and five lane $\mu$ PADs (Figure 4.1).

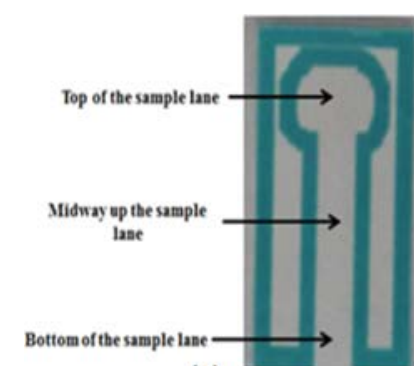

(a)

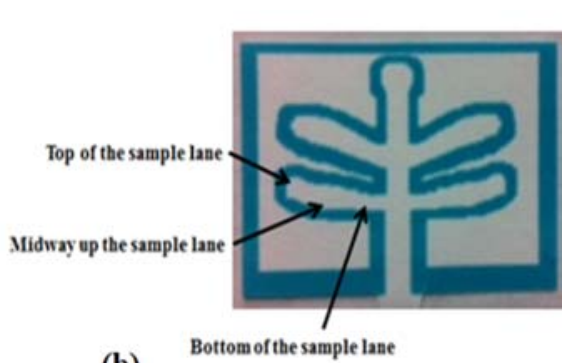

(b)

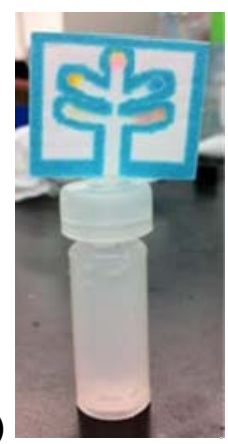

Figure 4.1. Design and placement of colorimetric reagents for the $\mu$ PADs. (a) Single lane $\mu$ PADs $(2.6 \mathrm{~cm} \times 1.7 \mathrm{~cm}$, lane size: $2.3 \mathrm{~cm}$ x $0.4 \mathrm{~cm}$, bulb size: $0.6 \mathrm{~cm}$ x $0.9 \mathrm{~cm})$ used for optimization of colorimetric tests and (b) five lane $\mu$ PADs $(4.1 \mathrm{~cm} x$ $4.9 \mathrm{~cm}$, lane size: $1.5 \mathrm{~cm} \times 0.3 \mathrm{~cm}$ ) for multiple explosive analysis. (c) Testing set up for single lane and five lane $\mu$ PADs.

After all of the colorimetric reagents were added to their respective lanes on each devices, the $\mu$ PADs were laminated using $3 \mathrm{~mm}$ lamination sheets at $110^{\circ} \mathrm{C}$, speed 4 . Certain reagents, notably Nessler's reagent, are heat sensitive and care must be taken to avoid heating the region around this reagent during the lamination step. Inorganic Explosives $\mu P A D$

The five lane inorganic explosives detection $\mu \mathrm{PAD}$ included a test for chlorate, nitrate, ammonium, nitrite, and perchlorate in each of their individual lanes. To detect chlorate, an aniline sulfate reagent was spotted at the midpoint of the sample lane and $50 \% \mathrm{H}_{2} \mathrm{SO}_{4}$ was spotted at the top of the sample lane. For the nitrate test, 3 steps were involved: (1) a solid reducing mixture consisting of $0.08 \mathrm{~g}$ sulfanilic acid, $1.87 \mathrm{~g}$ sodium acetate, and $0.37 \mathrm{~g}$ zinc powder was made into a slurry using a saturated trehalose 
solution in ethanol and pressed into the bottom of the sample lane using a small metal spatula; (2) $20 \% \mathrm{H}_{2} \mathrm{SO}_{4}$ was spotted midway up the lane; (3) 2.5\% 1-napthol in ethanol was spotted at the top of the sample lane. To detect ammonium, Nessler's reagent was spotted at the top of the sample lane. For the nitrite test, the Griess test was prepared by spotting $0.5 \%$ aqueous sulfanilic acid midway up the sample lane and $0.1 \%$ aqueous 1 napthylamine at the top of the sample lane. To detect perchlorate, $0.05 \%$ aqueous methylene blue solution was spotted at the top of the sample lane. This $\mu$ PAD was run using deionized water as the solvent.

\section{High/Organic Explosives $\mu P A D$}

The five lane high/organic explosives $\mu \mathrm{PAD}$ includes tests for RDX/HMX/PETN, TNT/TNB/Tetryl, urea nitrate, nitrate, and hydrogen peroxide. For the detection of RDX/HMX/PETN, three steps were utilized: (1) A solid reducing mixture of zinc powder was made into a paste using $50 \%$ acetic acid and pressed into the bottom of the sample lane using a small metal spatula; (2) midway up the sample lane $0.1 \%$ sulfanilic acid in water was spotted; (3) $0.05 \%$ 1-napthylamine in water was spotted at the top of the sample lane. To detect TNT/TNB/Tetryl, 1.5 M potassium hydroxide was spotted at the top of the sample lane. For the urea nitrate test, $0.023 \mathrm{M}$ paradimethylaminocinnamaldehyde in ethanol was spotted at the top of the sample lane. To test for hydrogen peroxide, $1 \mathrm{M}$ aqueous ammonium titanyl oxalate was spotted at the top of the sample lane. This $\mu \mathrm{PAD}$ utilized $50 \%$ acetone $/ 50 \%$ water as the solvent. 


\section{Portable Testing System}

A portable testing system was developed for use with the microfluidic devices. The kit included plastic $1 \mathrm{~mL}$ vials or reduced volume $250 \mu \mathrm{L}$ vials with a slit cut in the lid, allowing the insertion of the $\mu \mathrm{PAD}$ device into the solvent (Figure $4.1 \mathrm{c}$ ). Plastic pipettes and two solvents (water and 50\% acetone $/ 50 \%$ water) were also included. To perform the analysis, a small amount of powder is placed into the solvent and allowed to dissolve. The $\mu \mathrm{PAD}$ is then inserted through the slit in the lid and the lid is placed on the vial. The bottom tip of the paper device in the solvent allows capillary action to carry the solvent and the analytes up the $\mu \mathrm{PAD}$ into the lanes containing the colorimetric test reagents. This entire process, including run time, takes approximately 5 minutes to complete.

\section{Validation of $\mu$ PADs for Explosive Detection}

\section{Interference Testing}

Gold Bond blue powder, Gold Bond yellow powder, Gold Bond white powder, Publix baking powder, Publix baking soda, salt, iodized salt, Publix powdered whip topping, Publix laundry detergent (powder form), Publix flour, Crystal Light Pink Lemonade mix, and Crystal Light Iced Tea mix were purchased from supermarkets in Miami, FL, United States. Codeine, ephedrine, methamphetamine, and cocaine were obtained in powder form from the International Forensic Research Institute at Florida International University. One thousand ppm samples were prepared for each interferant in the appropriate solvent depending on which $\mu \mathrm{PAD}$ was being tested to determine if any of these commonly encountered white household powders produced interferences when present. 


\section{Post-Blast Detection}

The Hodgdon Pyrodex and Triple Seven black powder substitutes were both obtained from Hodgdon Powder Company, Inc. GOEX black powder was obtained from GOEX and Red Dot smokeless powder was obtained from Alliant Powder. American Pioneer Powder FFG and Jim Shockey's Gold were obtained from American Pioneer Powder, Inc. The Lemon Drop firework was obtained from a retail store.

To perform post-blast analysis for these samples, a small amount of each powder was placed onto a watch glass and burned with a match. This step was performed in a fume hood and with a face shield to ensure safety. The resulting burned powder was collected using a metal spatula and deposited into a small vial containing the respective solvent.

\section{On-Site Post-Blast Detection}

With the assistance of the Miami Police Department bomb squad, on-site and post-blast analysis was conducted using the $\mu$ PADs. Small polyvinyl chloride (PVC) pipes filled with the respective explosive material and capped with two PVC end caps were used for each shot. These pipe bombs were then placed into a large plastic container for containment and sampling purposes and detonated using a blasting cap. Eight different pipe bombs were constructed and contained different explosive mixtures including ammonium nitrate and aluminum (ANAL), Vaseline and potassium chlorate, triacetone triperoxide, Helix (nitromethane and aluminum), gel dynamite, detasheet, urea nitrate boosted with sheet, and Composition-4. 


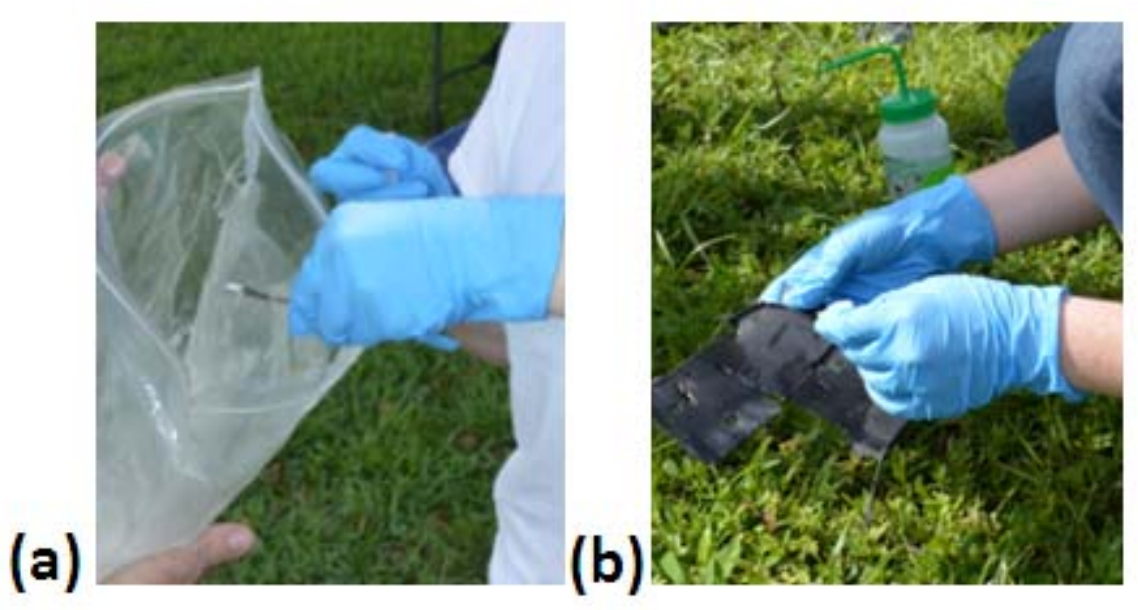

Figure 4.2. On-site sampling preformed (a) pre-blast by adding powder samples to a small amount of solvent and (b) post-blast by swiping the tab of the $\mu$ PAD across a piece of large plastic container.

Sampling was performed both pre- and post-blast. Pre-blast testing consisted of collecting a small amount of the explosive material or mixture before detonation (Figure 4.2a). This material was placed into a small plastic vial containing the $\mu$ PAD's respective solvent and allowed to develop for approximately five minutes. Results were then photographed and documented. After the blast was completed, a piece of the large plastic container was collected and the bottom tab of each respective $\mu \mathrm{PAD}$ was swiped over the plastic to collect any post-blast residue present. These tabs were laminated on the back, but not the front allowing for swipe samples to be collected (Figure 4.2b). These $\mu$ PADs were then placed in their respective solvents and allowed to develop for approximately five minutes. Results were photographed and documented. 


\section{Infusion Electrochemical Detection Mass Spectrometry (EC-ESI-TOF MS) for the Detection of Explosives}

\section{Chemicals}

All reagents and chemicals were analytical grade. Explosive samples such as TNT, RDX, and urea nitrate were prepared as dilute solutions in acetonitrile from law enforcement sources. Potassium chlorate, ammonium nitrate, and ammonium perchlorate were all purchased from Sigma-Aldrich. Thirty percent aqueous hydrogen peroxide solution and 18-crown-6 ether was purchased from Fisher Scientific.

The handling of explosives can be hazardous and should be performed with appropriate laboratory safeguards. All materials were stored as dilute solutions in sealed plastic vials in an explosion-proof freezer. All experiments with explosives were conducted with appropriate protection including face shield, gloves, and lab coat. Laboratory fume hoods were used when appropriate.

\section{Instrumentation}

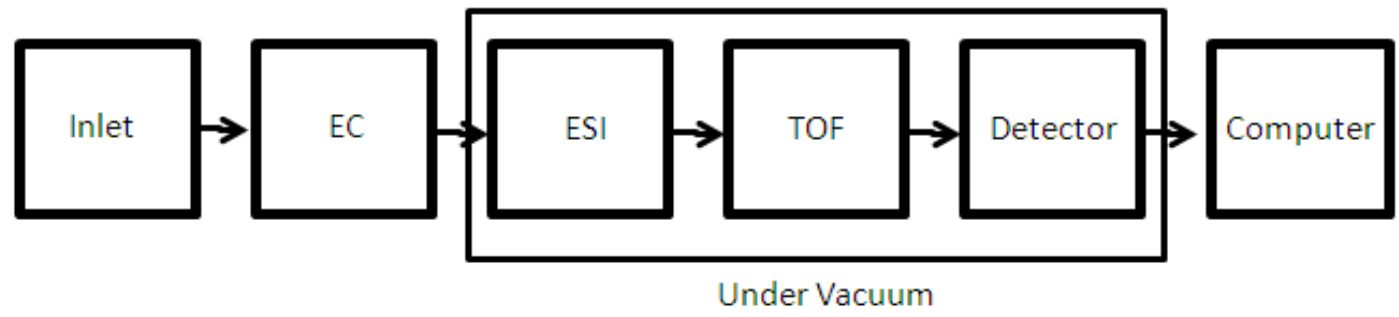

Figure 4.3. Detector set-up for the Infusion EC-ESI-TOF MS method utilized for analysis.

To detect multiple explosive compounds in one analytical method, a detector scheme was developed consisting of infusion into an electrochemical detector followed by analysis with a mass spectrometer (Figure 4.3). This detection system first starts with an 
inlet system such as a direct probe, chromatography, or capillary electrophoresis system. In this case, sample introduction was done using an Agilent 1100 (G1313A) liquid chromatograph with an autosampler (G1312A; Agilent). No HPLC column was used for this infusion based procedure, as the goal was to operate in a non-aqueous environment to maintain the composition of ion pairs. The output tubing from the autosampler was connected to an electrochemical detector (Bioanalytical systems connected to CHI (8107) amperometric detector) consisting of a carbon paste working electrode, silver/silver chloride reference electrode, and a steel auxiliary electrode. A $50 \mu \mathrm{m}$ spacer was used in the flow cell. Cyclic voltammetry, performed previously, determined the optimal working potential for the detection of hydrogen peroxide to be $+400 \mathrm{mV}$ in $\mathrm{DC}$ mode ${ }^{99}$.

Following amperometric measurement, the sample is carried into an Agilent G1969A ESI-TOF mass spectrometer (Santa Clara, CA, USA) to perform the analysis of explosives in the presence of complexing agents. Optimization of the fragmentor and skimmer voltages was performed previously ${ }^{1}$, where the best conditions were determined to be positive ion mode, capillary voltage $3000 \mathrm{~V}$, fragmentor voltage $125 \mathrm{~V}$, skimmer voltage $40 \mathrm{~V}$, octapole voltages $300 \mathrm{~V}$, gas temperature $150^{\circ} \mathrm{C}$, drying gas (nitrogen) flow rate $5 \mathrm{~L} / \mathrm{min}$, and nebulizer gas (nitrogen) pressure $10 \mathrm{psig}$. Two reference compounds [purine (m/z 121.0509) and HP0921 standard (m/z 922.0098)] were added to the sheath solution to improve the mass accuracy during the analysis. 
The following complexation ions were used to determine the presence of UN, AN, potassium chlorate $\left(\mathrm{KClO}_{3}\right)$, and ammonium perchlorate $\left(\mathrm{NH}_{4} \mathrm{ClO}_{4}\right)$ : $[18 \mathrm{Cr} 6+$ $\left.\left(\mathrm{NH}_{2}\right)_{2} \mathrm{COH}\right]^{+},\left[2(18 \mathrm{Cr} 6)+\left(\mathrm{NH}_{2}\right)_{2} \mathrm{COH}\right]^{+},\left[2(18 \mathrm{Cr} 6)+\mathrm{NH}_{4} \mathrm{NO}_{3}+\mathrm{NH}_{4}\right]^{+},[2(18 \mathrm{Cr} 6)+$ $\left.\mathrm{KClO}_{3}+\mathrm{K}\right]^{+}$, and $\left[2(18 \mathrm{Cr} 6)+\mathrm{NH}_{4} \mathrm{ClO}_{4}+\mathrm{NH}_{4}\right]^{+}$. HMTD was detected as $[\mathrm{HMTD}+\mathrm{H}]^{+}$, since it did not complex with the 18 -crown- 6 ether.

\section{Sample Preparation}

Samples were prepared by dissolving the respective solid in a $1 \mathrm{mM} 18$-crown-6 solution in methanol. This stock solution was used for all dilutents and made fresh for optimal results.

\section{E. Validation of Infusion Electrochemical Detection Mass Spectrometry (EC-ESI - TOF MS) for the Detection of Explosives}

\section{Interference Testing}

Corn oil, coffee, Gatorade, Pepsi, Windex, bleach, lubricating oil (WD-40), hand sanitizer, Sweets, diesel, and gasoline, were purchased from supermarkets in Miami, FL, United States. One hundred microliters of the respective interferant were used to spike $395 \mu \mathrm{L}$ of the respective $100 \mathrm{ppm}$ solution of explosive in methanol. Five microliters of $100 \mathrm{mM} 18$-crown-6 in methanol was then added to the mixture and the samples were vortexed for 10 seconds to ensure mixing.

\section{Collection of Post-Blast Samples}

With the assistance of the Miami Police Department bomb squad detail, a pipe bomb study was conducted to collect post-blast samples for analysis utilizing the EC-ESI-TOF MS method. Eight different shots were completed consisting of ammonium nitrate and aluminum (ANAL), Vaseline and potassium chlorate, triacetone triperoxide, Helix 
(nitromethane and aluminum), gel dynamite, Detasheet, urea nitrate boosted with Detasheet, and C4.

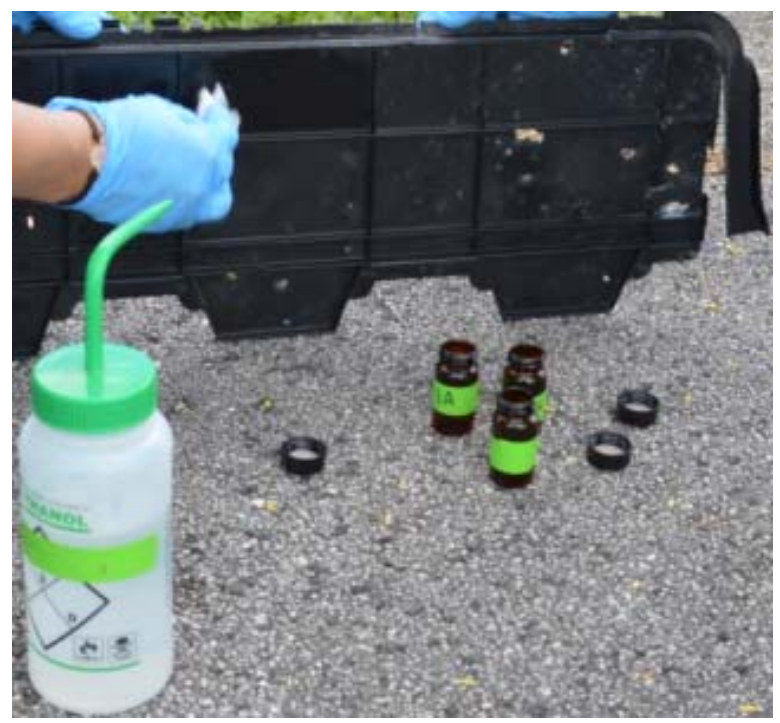

Figure 4.4. Post-blast sample collection using gauze wetted with $200 \mu \mathrm{L}$ of methanol and swabbed over plastic container remnants generated from the blast.

After the blast was completed, a piece of the large plastic container was collected and sampled using a 2x2 inch sterile gauze wetted with $200 \mu \mathrm{L}$ methanol. Two different swabs were collected from two different plastic remnants. These swabs were then placed into separate $20 \mathrm{~mL}$ amber vials and sealed with a screw top lid and parafilm to prevent contamination. Soil samples were also collected from directly under the plastic container blast area. The sample was placed into a $20 \mathrm{~mL}$ amber vial and sealed with a screw top lid and parafilm. Plastic pieces were also collected and sealed with a heat sealer in plastic nylon bags in case additional testing was needed.

\section{Extraction/Analysis of Post-Blast Samples}

The pieces of gauze used to sample the post blast explosives were extracted by 
centrifugation utilizing spin baskets. This involved placing a gauze sample wet with 450 $\mu \mathrm{L}$ methanol (dry swabs $550 \mu \mathrm{L}$ methanol) in a plastic spin basket that was inserted in a $1.5 \mathrm{~mL}$ tube. After centrifugation (Beckman microfuge 12, $3000 \mathrm{~g}, 5 \mathrm{~min}$ ), $495 \mu \mathrm{L}$ of extract was then removed and transferred into $1 \mathrm{~mL}$ glass vials along with $5 \mu \mathrm{L}$ of $1 \mathrm{mM}$ 18-crown-6 ether in methanol. The samples were then injected into the infusion EC-ESITOF MS system run in positive and negative ion mode (for high explosives detection) using the optimized conditions described previously.

\section{CHAPTER 5. DEVELOPMENT OF $\mu$ PADS FOR RAPID, ON-SITE EXPLOSIVES DETECTION}

\section{A. Introduction}

A presumptive method for the on-site detection of multiple explosive compounds was developed utilizing $\mu$ PADs. Two different $\mu$ PADs were created: the first was designed to detect inorganic materials including important oxidizers used in pyrotechnic manufacturing such as nitrates, perchlorates, and chlorates. In addition, this $\mu \mathrm{PAD}$ contained test lanes for ammonium, to detect the common fertilizer based explosive ammonium nitrate, and a lane for nitrite, which is a post blast reaction product that appears following the deflagration of nitrate salts. The second $\mu \mathrm{PAD}$ was designed for the detection of military explosives such as TNT, RDX and PETN. It also contained tests for UN, a common fertilizer based explosive, and peroxide based explosives.

\section{B. Development of $\mu$ PADs}

A tree shaped template consisting of a stem and five branches has been utilized to 
allow for a uniform flow along the branches and for multiple tests to be run simultaneously in a minimal amount of time. ${ }^{59}$ The external size of these devices during developmental stages was $45 \mathrm{~mm}$ x $38 \mathrm{~mm}$ with lane sizes of $13 \mathrm{~mm}$ x $4 \mathrm{~mm}$. This size was later reduced to $24 \mathrm{~mm} \times 17 \mathrm{~mm}$ with lane sizes of $7 \mathrm{~mm} \times 2 \mathrm{~mm}$ to minimize analysis time. Single lane $\mu$ PADs were also designed for the development and testing of individual colorimetric tests.

Printing of the $\mu$ PADs was completed using a wax based printer on Whatman no. 1 chromatography paper. This type of paper is an ideal substrate for fabricating $\mu$ PADs to allow faster transfer of solutions, better analytical performance, and high color intensities for colorimetric tests compared to filter paper and other thicker substrates $^{58}$. To ensure that the wax ink was fully embedded into the paper, the $\mu$ PADs were run twice through the laminator set at $160^{\circ} \mathrm{C}$, speed 1 .

The $\mu$ PADs were originally printed using black ink, but significant bleeding of the ink occurred as a result of the organic solvents that were used. Therefore, a comparison of the effects of the wax ink colors and solvent composition was performed to optimize the devices. Solvents chosen were selected based on their ability to maintain the solubility of the explosive compounds being detected. The optimal wax color chosen was bright blue since none of the subsequent colorimetric tests generated this color and it produced minimal problems with solvent induced bleeding. White ink was not an option since it is not readily available and lighter colors (light blue, light pink, lavender, light grey) did not provide a sufficiently solid barrier to solvent flow.

Deionized water was used as the optimal solvent for all experiments using the 
inorganic explosives $\mu \mathrm{PAD}$, since all of the inorganic explosives are soluble in water. For detection with the high/organic explosives $\mu \mathrm{PAD}$, multiple solvents were tested including acetone, acetonitrile, methanol, ethanol, deionized water, 50\% dimethyl sulfoxide (DMSO) $/ 50 \%$ water, $50 \%$ acetone $/ 50 \%$ water, $75 \%$ acetone $/ 25 \%$ water, $50 \%$ methanol $/ 50 \%$ water, and $75 \%$ methanol $/ 25 \%$ water. When the percentage of organic solvent was above $50 \%$, a noticeable increase in the bleeding of wax ink occurred due to dissolution of the dye, affecting visualization of color changes. The optimal solvent for this $\mu \mathrm{PAD}$ was determined to be $50 \%$ acetone $/ 50 \%$ deionized water to maintain the solubility of all tested compounds and minimize bleeding of the wax ink. The optimized solvent and wax color were used for all further experiments.

The first $\mu \mathrm{PAD}$ was developed for the detection of inorganic explosives such as pyrotechnic mixtures, black powders, and ammonium nitrate (Figure 5.1).
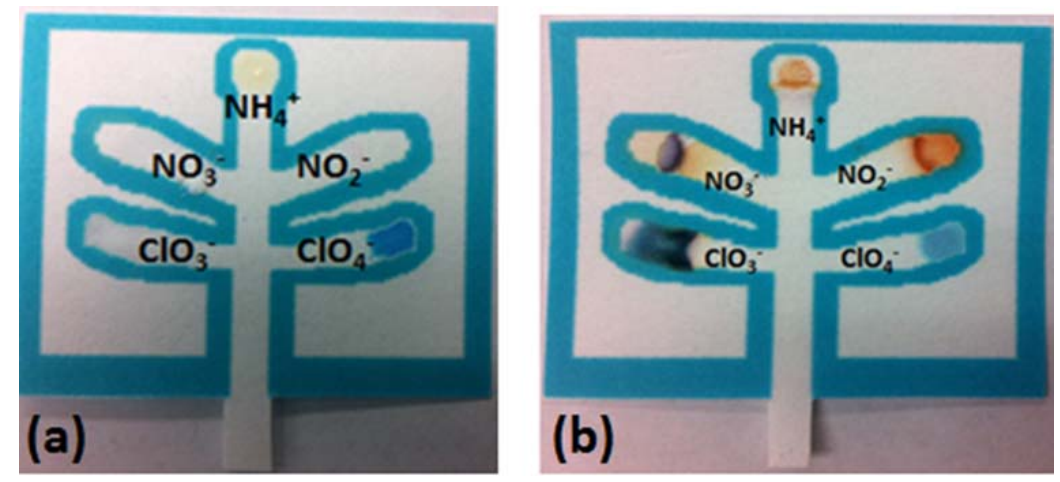

Figure 5.1. (a) The inorganic explosives $\mu \mathrm{PAD}$ device prior to analysis. (b) The same $\mu \mathrm{PAD}$ following analysis of a $1000 \mathrm{ppm}$ mixture of potassium chlorate, ammonium nitrate, potassium nitrite, and potassium perchlorate in deionized water. Color changes started after 5 minutes, with a total run time of approximately 18 minutes.

Table 5.1 lists the relevant tests and reagents for each lane in the inorganic $\mu$ PAD. 
Table 5.1. Colorimetric tests and reagents used for the detection of inorganic explosive compounds. These $\mu$ PADs were prepared using $2 \mu \mathrm{L}$ of each reagent spotted onto the $\mu \mathrm{PAD}$ and allowed to dry (see Experimental Procedures section).

All tests were run using $1000 \mathrm{ppm}$ of the corresponding explosive compound dissolved in deionized water. Deionized water was used as the blank. The reaction time for the single lane $\mu$ PADs is about 5 minutes.

\begin{tabular}{|c|c|c|c|}
\hline $\begin{array}{c}\text { Compound } \\
\text { Targeted }\end{array}$ & Reagents & $\begin{array}{c}\text { Color } \\
\text { Change }\end{array}$ & $\begin{array}{c}\text { Results } \\
\text { Blank / Sample }\end{array}$ \\
\hline $\begin{array}{l}\text { Chlorate }^{110} \\
\left(\mathrm{ClO}_{3}^{-}\right)\end{array}$ & $\begin{array}{l}\text { (1) Aniline sulfate } \\
\text { (2) } 50 \% \text { sulfuric acid }\end{array}$ & $\begin{array}{l}\text { Colorless to } \\
\text { dark green }\end{array}$ & \\
\hline $\begin{array}{l}\text { Nitrate }^{111,112} \\
\quad\left(\mathrm{NO}_{3}^{-}\right)\end{array}$ & $\begin{array}{l}\text { (1) Paste of saturated trehalose } \\
\text { solution with solid reducing } \\
\text { mixture of sulfanilic acid, } \\
\text { sodium acetate, and zinc } \\
\text { powder } \\
\text { (2) } 20 \% \text { sulfuric acid } \\
\text { (3) } 1 \text {-napthol }\end{array}$ & $\begin{array}{l}\text { Colorless to } \\
\text { orange }\end{array}$ & \\
\hline $\begin{array}{l}\text { Ammonium } \\
\left(\mathrm{NH}_{4}{ }^{+}\right)\end{array}$ & Nessler's Reagent & $\begin{array}{l}\text { Pale yellow to } \\
\text { brown }\end{array}$ & \\
\hline $\begin{array}{l}\text { Nitrite }{ }^{110} \\
\left(\mathrm{NO}_{2}^{-}\right)\end{array}$ & $\begin{array}{l}\text { Griess test: (1) sulfanilic acid } \\
\text { (2) 1-napthylamine }\end{array}$ & $\begin{array}{l}\text { Colorless to } \\
\text { orange/brown }\end{array}$ & \\
\hline $\begin{array}{l}\text { Perchlorate } \\
\quad\left(\mathrm{ClO}_{4}^{-}\right)\end{array}$ & $0.05 \%$ methylene blue & Blue to Purple & \\
\hline
\end{tabular}


Initially, the tests performed on these $\mu \mathrm{PADs}$ were chosen based on a literature study of previously developed liquid based colorimetric tests used in qualitative analysis. However, many of these original colorimetric tests required acid concentrations that were high enough to digest paper. Therefore, reagents were modified to permit the development of distinctive color changes without the use of strong acids. For example, the first colorimetric test for chlorate utilized concentrated sulfuric acid and an aniline sulfate solution. To adapt this test for use with a $\mu \mathrm{PAD}$, concentration of the concentrated sulfuric acid $\left(\mathrm{H}_{2} \mathrm{SO}_{4}\right)$ was varied from 0 to $80 \%$ and the colorimetric test was performed in a test tube to determine the minimum acid concentration that could be used, while still being able to detect a color change for chlorate. The optimal level was determined to be approximately $50 \% \mathrm{H}_{2} \mathrm{SO}_{4}$ and then tested on the $\mu \mathrm{PAD}$. Fifty percent concentrated $\mathrm{H}_{2} \mathrm{SO}_{4}$ was spotted onto multiple $\mu$ PADs and allowed to sit in the ambient environment for about 1 month. After 1 month, there was no visible degradation of the $\mu$ PADs and the resulting colorimetric test successfully detected chlorate.

For the detection of nitrate, which is present in black powder as well as fertilizer based explosives (ammonium, potassium, and urea nitrates), a sequential three step test was chosen based on a modified Griess test ${ }^{111,112}$. A solid mixture of sulfanilic acid, sodium acetate, and zinc powder was placed at the bottom of the sample lane. A saturated trehalose solution was then used to make a paste with the solid mixture for two reasons: (1) facilitated an easier application to the paper devices and (2) the trehalose slows down migration of the liquid sample on the $\mu \mathrm{PAD}$ allowing more time for the nitrate to interact with the solid reducing mixture. 
The powdered zinc is present to reduce the nitrate $\left(\mathrm{NO}_{3}{ }^{-}\right)$to nitrite $\left(\mathrm{NO}_{2}{ }^{-}\right)$. The nitrite is converted to nitrous acid using the $20 \% \mathrm{H}_{2} \mathrm{SO}_{4}$, facilitating the formation of a diazonium salt in the presence of sulfanilic acid.
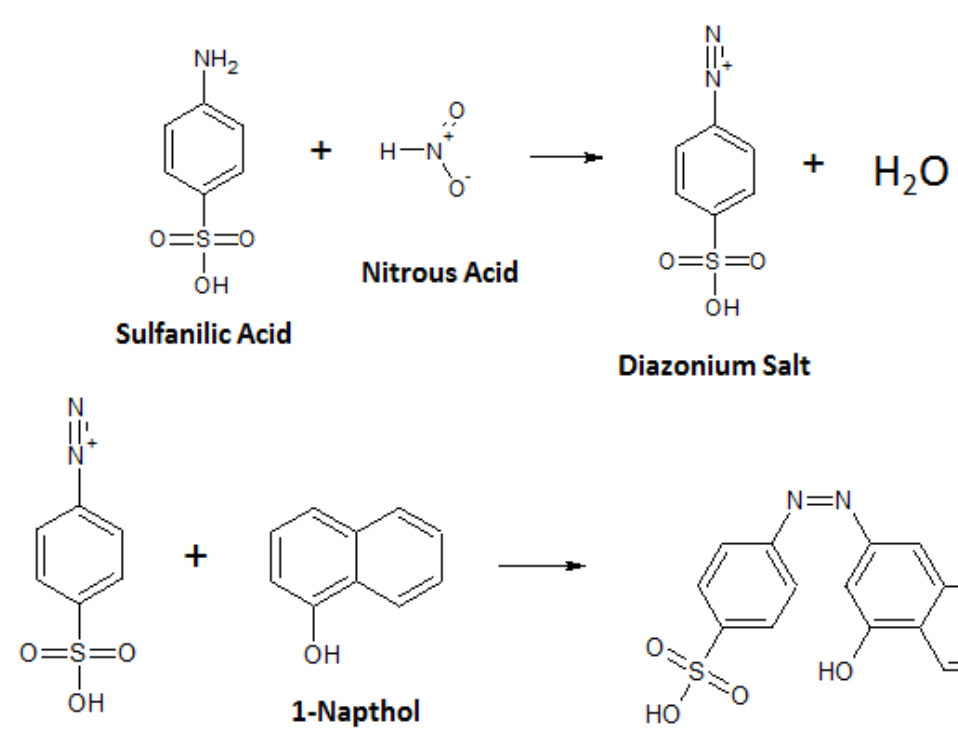

Diazonium Salt

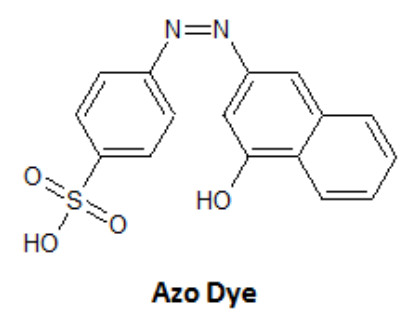

Figure 5.2. Modified Griess reaction used for the detection of nitrate containing compounds such as ammonium nitrate and black powders. This colorimetric test results in a color change from colorless to orange.

The diazonium salt continues to travel up the sample lane to 1-napthol spotted at the end of the sample lane (Figure 5.2). The reaction between the diazonium salt and 1-napthol produces an azo dye, resulting in formation of an orange color ${ }^{114}$.

The ammonium test involves the use of Nessler's reagent, which consists of potassium iodide and mercuric iodide. Potassium hydroxide $(\mathrm{KOH})$ is present to reduce ammonium $\left(\mathrm{NH}_{4}{ }^{+}\right)$to ammonia $\left(\mathrm{NH}_{3}{ }^{+}\right)$. Ammonia then reacts with Nessler's reagent $\left(\mathrm{K}_{2} \mathrm{HgI}_{4}\right)$ to produce a brown color complex $\left(\mathrm{NH}_{2} \mathrm{Hg}_{2} \mathrm{I}_{3}\right)^{115,116}$. 


$$
2 \mathrm{~K}_{2} \mathrm{HgI}_{4}+2 \mathrm{NH}_{3} \rightarrow \mathrm{NH}_{2} \mathrm{Hg}_{2} \mathrm{I}_{3}+\mathrm{NH}_{4} \mathrm{I}+4 \mathrm{KI}
$$

Figure 5.3. Chemical equation for ammonium test with Nessler's reagent. Ammonia is produced from the reduction of ammonium with potassium hydroxide. Reaction results in a color change from pale yellow to brown.

An additional test lane was developed specifically for nitrite and did not include a reducing agent. This procedure utilized the Griess test where nitrite first reacted with sulfanilic acid to form a diazonium salt followed by visualization with 1-napthylamine present at the end of the sample lane (Figure 5.4) ${ }^{111,117}$.
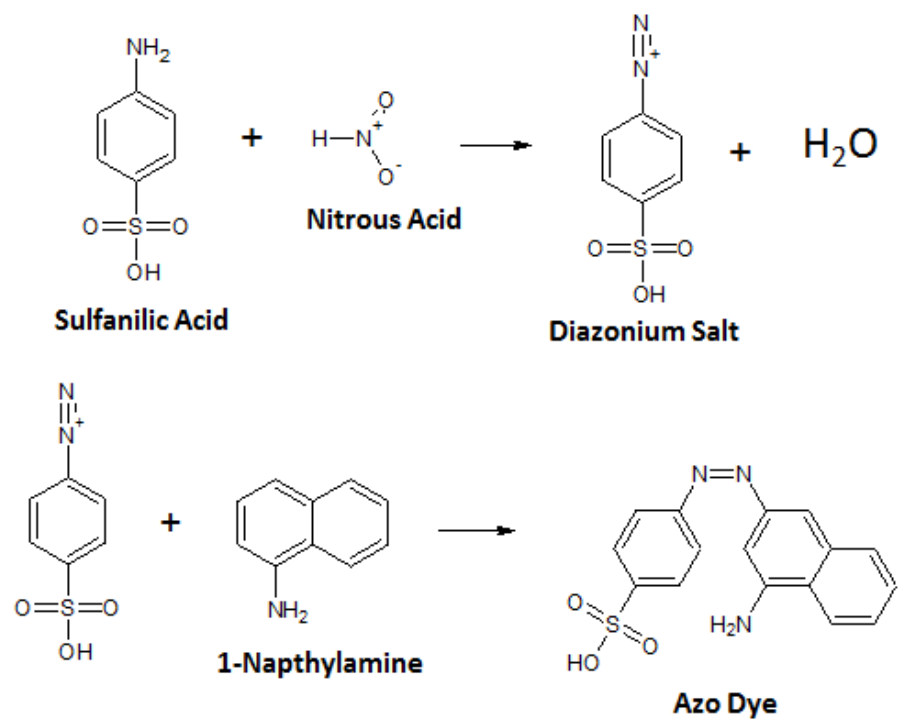

Figure 5.4. Griess test for the detection of nitrite containing compounds. Reaction results in a color change from colorless to orange/brown.

Following the development of these two lanes, a study was performed to determine if nitrate could be differentiated from nitrite utilizing a single $\mu$ PAD. As shown in Figure 5.5, when only nitrite was present, the nitrite channel appeared orange/brown and the nitrate channel was purple, presumably due to reduction of nitrite. When only nitrate was present, the orange color appeared only in the nitrate channel while the nitrite channel was blank. When both salts were present, both channels 
appeared colored, with an orange/brown color visible in the nitrite lane, and purple and orange colors in the nitrate lane. Therefore, the device successfully differentiated nitrate and nitrite based explosive compositions as well as detected the presence of nitrite in post blast samples resulting from the reduction of nitrate.

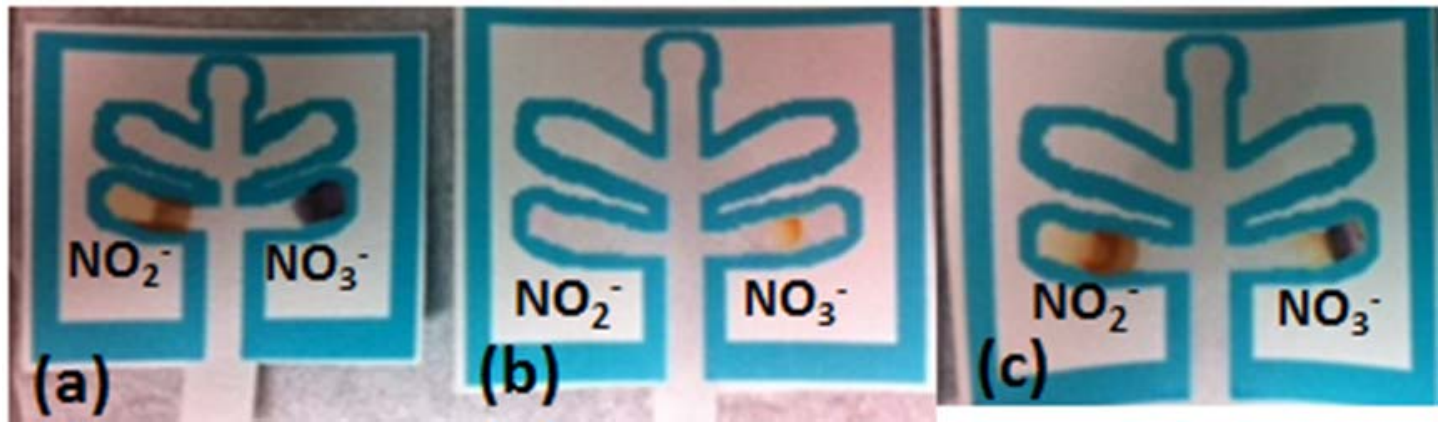

Figure 5.5. Nitrite and nitrate tests run with (a) $1000 \mathrm{ppm}$ potassium nitrite in deionized water. The nitrate spot test generates a dark purple color, while the nitrite spot test produces an orange-brown color. (b) $1000 \mathrm{ppm}$ potassium nitrate in deionized water. The nitrate spot test generates an orange color while the nitrite spot test does not show any color change. (c) $1000 \mathrm{ppm}$ mixture of potassium nitrate and potassium nitrite. The nitrite spot test produces an orange-brown color, while the nitrate spot test shows a dark purple and orange color.

The perchlorate test utilizes a common biological reaction with methylene blue (Figure 5.6).<smiles>CN(C)c1ccc2nc3ccc(=[N+](C)Cl)cc-3sc2c1</smiles>

Figure 5.6. Methylene blue compound used for detection of perchlorate. The reaction results in a blue to purple color change. 
When perchlorate is present, it binds with the methylene blue complex and causes a weighting effect, precipitating out a purple color complex. Therefore, if perchlorate is present a blue to purple color change will occur ${ }^{113,118}$.

The second $\mu \mathrm{PAD}$ was designed for the detection of organic explosives, urea nitrate, and peroxides (Figure 5.7).
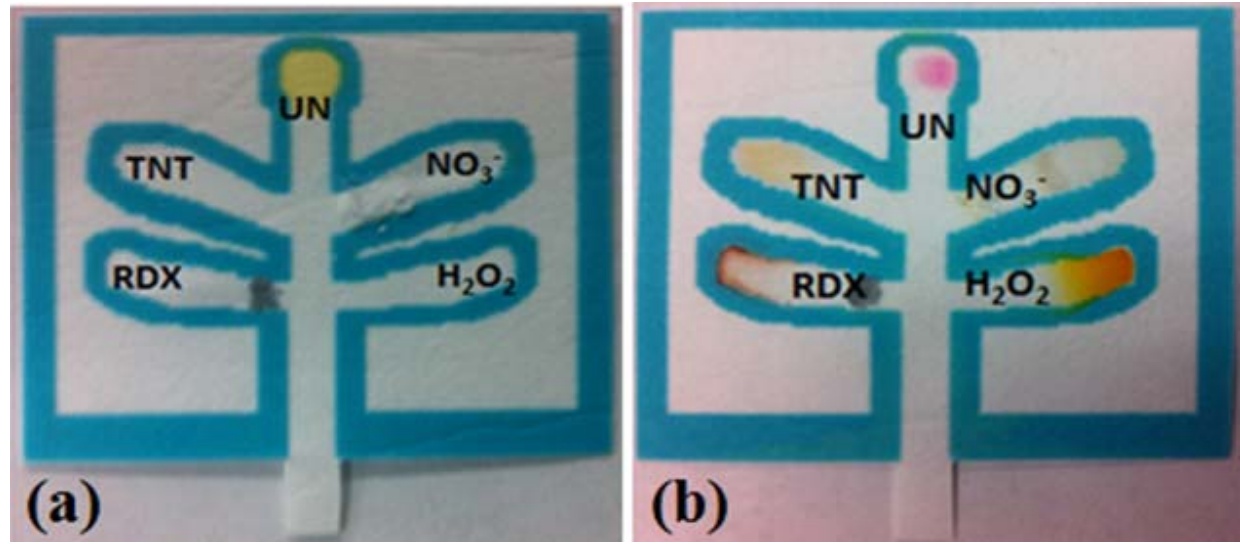

Figure 5.7. (a) High/organic explosives $\mu \mathrm{PAD}$ prior to analysis. (b) The same $\mu \mathrm{PAD}$ following analysis of a $1000 \mathrm{ppm}$ mixture of RDX, TNT, UN, and $\mathrm{H}_{2} \mathrm{O}_{2}$ in $50 \%$ acetone $/ \mathbf{5 0 \%}$ water. Color changes begin to occur after 5 minutes with a total run time of approximately 18 minutes.

The overall composition of the high/organic explosives $\mu \mathrm{PAD}$ is shown in Table 5.2 along with the color changes observed for a positive result. 
Table 5.2. Colorimetric tests and reagents used for the detection of high/organic explosive compounds. These $\mu$ PADs were prepared using $2 \mu \mathrm{L}$ of each reagent spotted onto the $\mu$ PAD and allowed to dry (see Experimental Procedures section).

All tests were run using $1000 \mathrm{ppm}$ of the corresponding explosive compound dissolved in $\mathbf{5 0} \%$ acetone $/ 50 \%$ deionized water and $50 \%$ acetone $/ 50 \%$ deionized water was used as the blank. The reaction time for single lane $\mu$ PADs is about 5 minutes.

\begin{tabular}{|c|c|c|c|}
\hline $\begin{array}{l}\text { Compound } \\
\text { Targeted }\end{array}$ & Reagents & $\begin{array}{l}\text { Color } \\
\text { Change }\end{array}$ & $\begin{array}{c}\text { Results } \\
\text { Blank/Sample }\end{array}$ \\
\hline $\begin{array}{l}\text { RDX, HMX, } \\
\text { PETN }^{119}\end{array}$ & $\begin{array}{c}\text { (1) Zinc powder in } 50 \% \\
\text { acetic acid } \\
\text { (2) Sulfanilic acid } \\
\text { (3) 1-napthylamine }\end{array}$ & $\begin{array}{c}\text { Colorless } \\
\text { to } \\
\text { Red/Pink }\end{array}$ & \\
\hline $\begin{array}{l}\text { Trinitrotoluene } \\
\text { (TNT), } \\
\text { Trinitrobenzene } \\
\text { (TNB), Tetryl }{ }^{110}\end{array}$ & 1.5 M Potassium hydroxide & $\begin{array}{l}\text { Colorless } \\
\text { to Red- } \\
\text { orange }\end{array}$ & \\
\hline $\begin{array}{l}\text { Urea Nitrate }^{73} \\
\text { (UN) }\end{array}$ & $\begin{array}{c}p-D M A C \text { (para- } \\
\text { dimethylaminocinnamaldehyde) }\end{array}$ & $\begin{array}{l}\text { Yellow to } \\
\text { Red }\end{array}$ & \\
\hline $\begin{array}{l}\text { Nitrate }{ }^{111,112} \\
\quad\left(\mathrm{NO}_{3}^{-}\right)\end{array}$ & $\begin{array}{l}\text { (1)Paste of saturated trehalose } \\
\text { solution and solid reducing } \\
\text { mixture of sulfanilic acid, } \\
\text { sodium acetate, and zinc } \\
\text { powder } \\
\text { (2) } 20 \% \text { sulfuric acid } \\
\text { (3) } 1 \text {-napthol }\end{array}$ & $\begin{array}{l}\text { Colorless } \\
\text { to orange }\end{array}$ & \\
\hline $\begin{array}{c}\text { Hydrogen } \\
\text { Peroxide } \\
\left(\mathrm{H}_{2} \mathrm{O}_{2}\right)\end{array}$ & Ammonium titanyl oxalate & $\begin{array}{l}\text { Colorless } \\
\text { to Yellow }\end{array}$ & \\
\hline
\end{tabular}


The test for military explosives RDX, HMX, and PETN involves a Griess test with sulfanilic acid and 1-napthylamine. A zinc paste is generated using acetic acid and placed at the bottom of the sample lane. This zinc and acetic acid paste allows for the generation and acidification of $\mathrm{NO}_{2}^{-}$to nitrous acid (Figure 5.8).
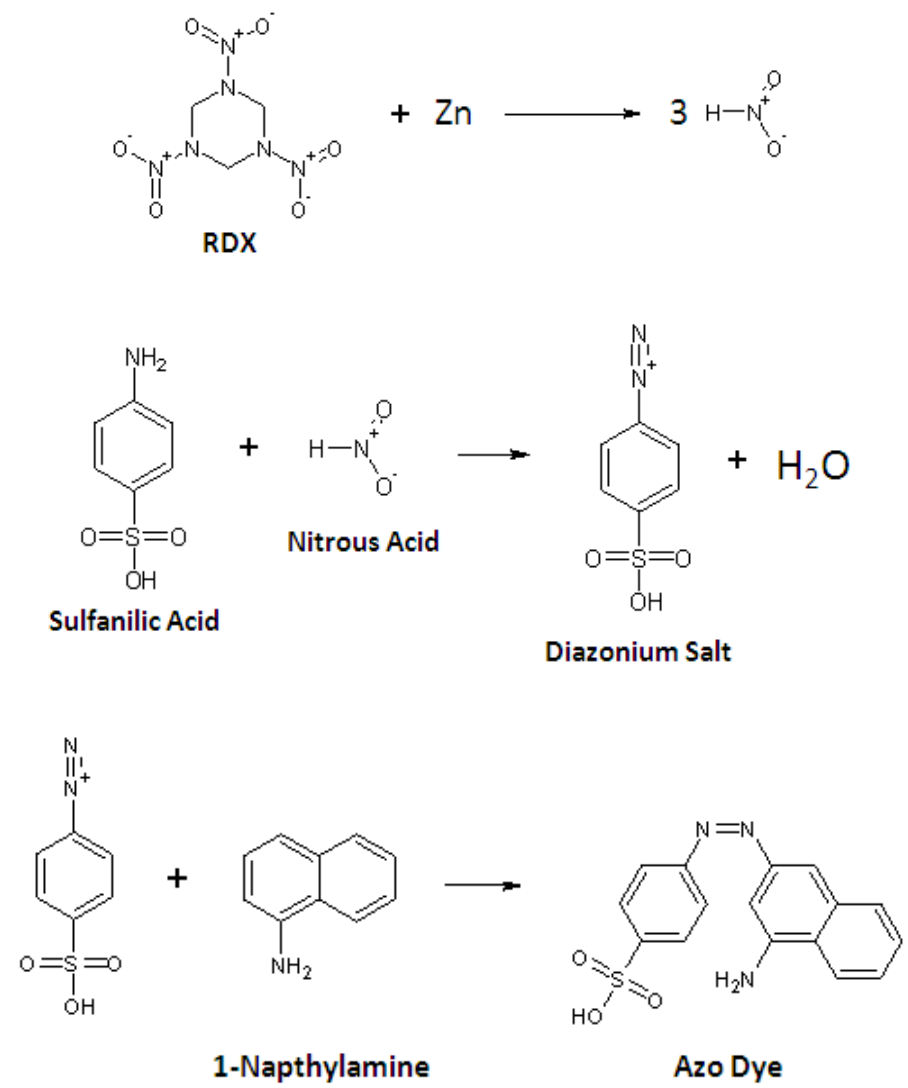

Figure 5.8. Reduction to nitrous acid and Griess test for colorimetric detection of RDX/HMX/PETN. Reaction results in a color change from colorless to pink/red.

Nitrous acid continues up the lane to interact with the sulfanilic acid. A diazonium salt is generated and continues traveling up the lane to the sample loop where it reacts with 1napthylamine. This results in the formation of a water soluble pink/red azo dye ${ }^{119,121}$. 
Since a form of the Griess test is used for the nitrate and nitrite tests, a study was completed to determine if nitrite or nitrate would cause a false positive. It was determined that nitrite and nitrate both produce an orange-brown color change, while RDX, HMX, and PETN will produce a red/pink color change allowing for the compounds to be readily differentiated.

Nitroaromatics, such as TNT, were detected through the use of $1.5 \mathrm{M}$ potassium hydroxide. When polynitroaromatic compounds react with alkaline solutions (such as potassium hydroxide), a Janowsky reaction occurs (Figure 5.9).
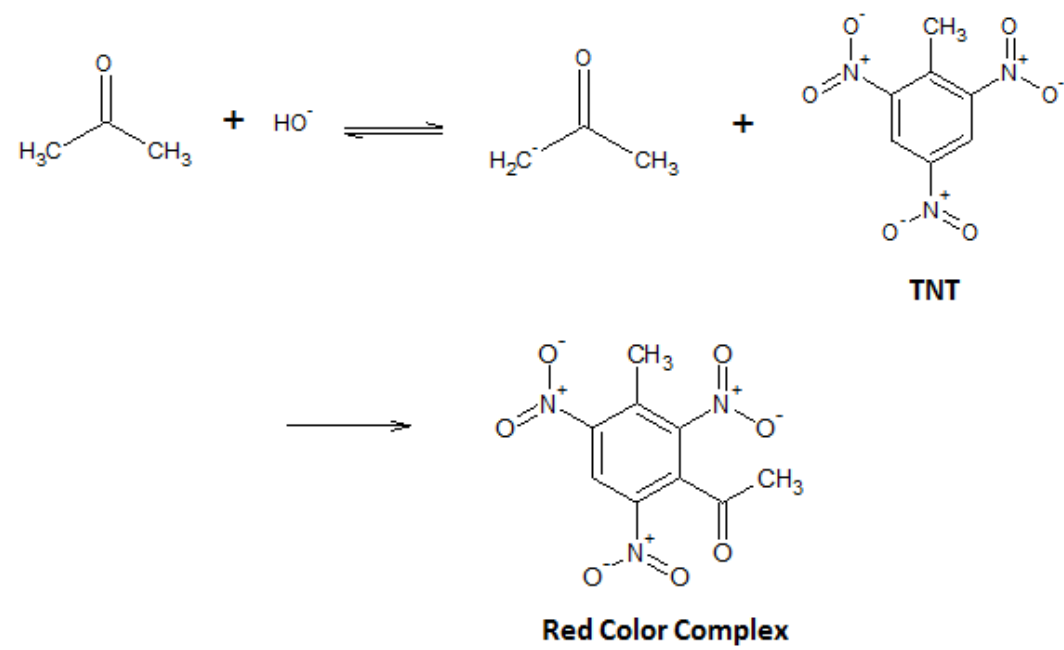

Figure 5.9. Janowsky reaction for the colorimetric detection of TNT, TNB, and tetryl. This reaction results in the formation of a red color for trinitroaromatics and a blue/purple color for dinitroaromatics.

This reaction involves the removal of a hydrogen from the acetone solvent that is present. Then, a nucleophilic aromatic addition occurs and generates a red color for trinitroaromatics while a blue to purple color is generated for dinitroaromatics ${ }^{110,119,122}$. 
The detection of urea nitrate involves detection of the uronium ion, which is only present if urea nitrate is present. As the uronium complex travels to the sample loop, it reacts with para-dimethylaminocinnamaldehyde (p-DMAC) to produce a color change from yellow to red (Figure 5.10) ${ }^{73}$. Uronium must be present to supply the hydrogen necessary to protonate the $\mathrm{p}$-DMAC complex, resulting in the formation of water as a leaving group. This allows for a nucleophilic substitution to occur, where uronium is added to p-DMAC with the loss of water.

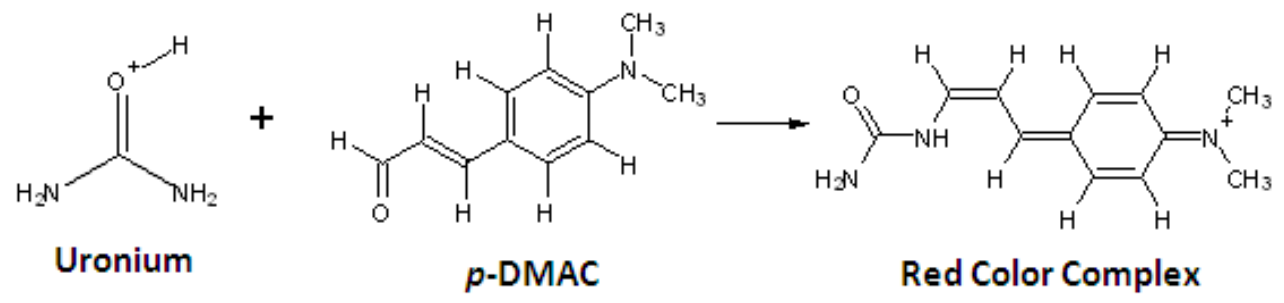

Figure 5.10. Uronium reaction with para-dimethylaminocinnamaldehyde ( $p$ DMAC). This reaction results in a color change from yellow to red when uronium is present.

If only urea, a common component in fertilizer, is present in the sample, no color change will be produced, allowing for this test to be specific for the detection of uronium (Figure 5.11). 

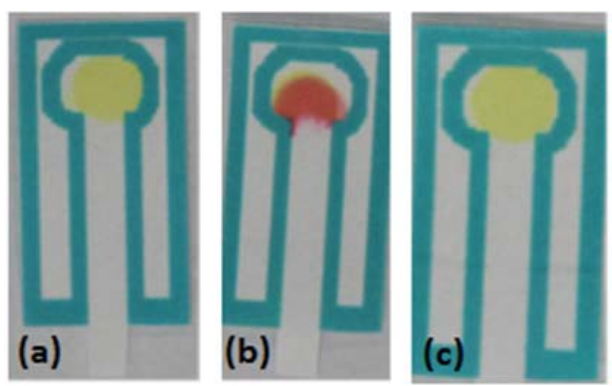

Figure 5.11. Urea nitrate test using $p$-DMAC. (a) Blank run with $\mathbf{5 0 \%}$ acetone $/ 50 \%$ water. (b) $1000 \mathrm{ppm}$ urea nitrate in $50 \%$ acetone $/ 50 \%$ water producing a red color. (c) $1000 \mathrm{ppm}$ urea in $\mathbf{5 0 \%}$ acetone $/ \mathbf{5 0} \%$ deionized water resulting in no color change.

Urea nitrate is strongly acidic ( $\mathrm{pH} \mathrm{1-2)} \mathrm{compared} \mathrm{to} \mathrm{urea,} \mathrm{as} \mathrm{a} \mathrm{result} \mathrm{of} \mathrm{the} \mathrm{nitric} \mathrm{acid}$ moiety in urea nitrate. Therefore, neutral urea will not react with $p$-DMAC while urea nitrate will, by providing the necessary acidity for the colorimetric reaction to occur ${ }^{73}$.

The addition of the aforementioned nitrate test on the five lane $\mu \mathrm{PAD}$ permits the user to distinguish between urea and ammonium nitrate. If the nitrate test is positive but the urea nitrate test is not, ammonium nitrate could be present. However, this test is not specific for ammonium nitrate and will show an orange color in the presence of any nitrate salt, while nitrite salts will appear purple. The nitrate test also permits the detection of nitrocellulose and nitroglycerin containing smokeless powders.

Hydrogen peroxide was detected using ammonium titanyl oxalate and the formation of a yellow color (Figure 5.12) ${ }^{120}$. This test will also produce a weak orange color in the presence of triacetone triperoxide (TATP). 


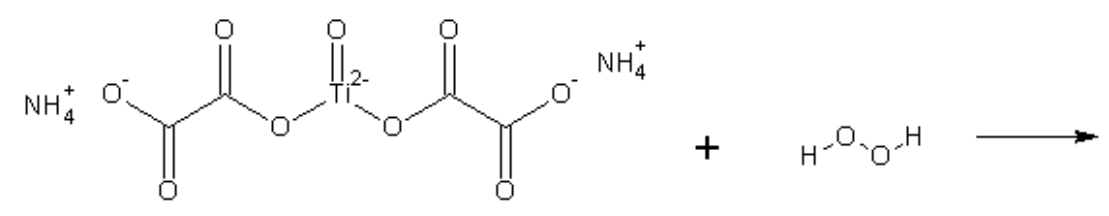

Ammonium Titanyl Oxalate

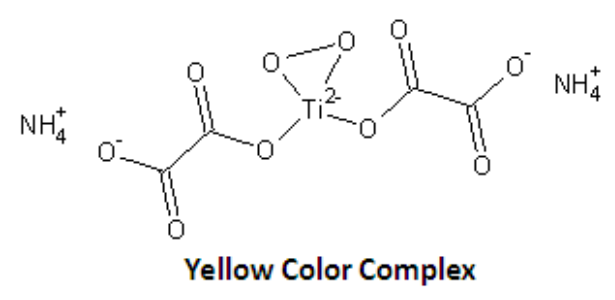

Figure 5.12. Test for hydrogen peroxide $\left(\mathrm{H}_{2} \mathrm{O}_{2}\right)$ using ammonium titanyl oxalate $\left(\left(\mathrm{NH}_{4}\right)_{2} \mathrm{TiO}\left(\mathrm{C}_{2} \mathrm{O}_{4}\right)_{2}\right)$. Reaction results in a colorless to yellow color change.

\section{Validation of $\mu$ PADs}

Sensitivity

Limits of detection were determined for these $\mu$ PADs as the lowest concentration that a color change could still visibly be detected (Table 5.3). Instrumental limits of detection were determined through the use of a Camag Scanner 3 color densitometer plate reader or through a digital photograph and Image $\mathbf{J}$ software. It was then calculated by determining the concentration equal to three times the standard deviation of ten replicates at the lowest visible concentration. 
Table 5.3. Limits of detection determined for each individual colorimetric test using single lane $\mu$ PADs. Visible limits of detection were determined based on the lowest color change that could be detected on the paper based on the human eye. Instrumental LODs were determined using a color scanner. Those marked with an asterisk (*) were determined using Image $\mathbf{J}$ software due to orientation problems with the color scanner. Experiments were run in triplicate with a run time of about 5 minutes for each sample.

\begin{tabular}{|c|c|c|c|c|}
\hline $\begin{array}{c}\text { Compound being } \\
\text { Detected }\end{array}$ & $\begin{array}{c}\text { Visually } \\
\text { Minimum } \\
\text { Detectable } \\
\text { Amount } \\
(\boldsymbol{\mu g})\end{array}$ & $\begin{array}{c}\text { Visible } \\
\text { LOD } \\
\mathbf{( p p m )}\end{array}$ & $\begin{array}{c}\text { Instrumental } \\
\text { Minimum } \\
\text { Detectable } \\
\text { Amount }(\boldsymbol{\mu g})\end{array}$ & $\begin{array}{c}\text { Instrumental LOD } \\
\mathbf{( p p m )}\end{array}$ \\
\hline Chlorate & 2.64 & 100 & 1.40 & 53 \\
\hline Nitrite & 2.64 & 100 & 1.37 & 52 \\
\hline Ammonium* & 7.92 & 300 & 7.13 & 270 \\
\hline Nitrate & 21.12 & 800 & 19.8 & 750 \\
\hline Perchlorate* & 10.56 & 400 & 8.18 & 510 \\
\hline TNT & 1.31 & 50 & 1.31 & 15 \\
\hline Hydrogen Peroxide* & 2.62 & 100 & 0.39 & 280 \\
\hline RDX* & 7.86 & 300 & 7.34 & 350 \\
\hline Urea Nitrate & 10.48 & 400 & 9.17 & \\
\hline
\end{tabular}

Three different procedures were used for the determination of limits of detection for the colorimetric tests. For visual detection, single lane $\mu$ PADs were run for each colorimetric test from $50 \mathrm{ppm}$ to $1000 \mathrm{ppm}$ and the lowest visible color change compared to the blank was determined. Two instrumental procedures were also utilized, the first involved a Camag TLC Scanner 3 and the second a digital camera (Canon Rebel EOS T3i, 18-135 mm lens), followed by processing with Image J software.

For calculations using the Camag Scanner 3 color scanner, measurements were determined by absorbance detection. The intensity of the color that develops in the test zone is a function of the concentration of the analyte. Therefore, the more analyte present, the higher the intensity of the color and the higher the absorbance detected. The 
wavelength used for analysis was determined by scanning a test zone area at $500 \mathrm{~nm}$ wavelength to identify the location of the test zone with highest color intensity. This location was then fixed as wavelengths were scanned from $200 \mathrm{~nm}$ to $700 \mathrm{~nm}$. The wavelength generating the highest absorbance at this location was used for all future measurements for that analyte. The absorbance was then measured for each $\mu \mathrm{PAD}$ and plotted versus concentration.

For calculations using Image J, measurements were based on the number of pixels counted from pictures of the $\mu$ PADs using a specific analyte. $\mu$ PADs were run from 50 ppm to $1000 \mathrm{ppm}$ and one picture was taken of all $\mu$ PADs for each analyte. This picture was then loaded into Image $J$ and a pixel color range was selected for the measurements by determining the range in which the highest concentration generated the most pixels, while the blank generated no pixel count in that specified range. This range was fixed for all measurements for the specified analyte and the pixel count was measured and plotted versus concentration.

\section{Selectivity: Interference Testing}

Common white household powders (see Experimental Procedures) were tested as interferences for all colorimetric tests, since they are similar in appearance to many explosive powders. It was determined that no false positives were produced. These powders were also run with individual explosives and explosive mixtures and did not produce false negatives for any of the colorimetric tests. 
Controlled substances, such as methamphetamine, cocaine, codeine, and ephedrine were also tested as possible interferences for both $\mu$ PADs in the same manner as the household powders. None of these substances produced any false positives or negatives.

\section{Influence of $\mu P A D$ Dimensions on Reaction Time}

The $\mu \mathrm{PAD}$ size and set up was also adjusted to facilitate an inexpensive, portable testing system, and to reduce analysis times. The $\mu \mathrm{PAD}$ size was reduced from $45 \mathrm{~mm} \mathrm{x}$ $38 \mathrm{~mm}$ to $24 \mathrm{~mm} \times 17 \mathrm{~mm}$ for future testing analysis. This reduced the time to obtain results from approximately 18 minutes to less than 5 minutes. The colorimetric changes were still clearly visible and the amount of solvent used was significantly reduced because of the shortened time needed to run the $\mu \mathrm{PAD}$. Therefore, the decrease of size reduced both analysis time and cost.

\section{Stability Testing}

The $\mu$ PADs were initially stored in an ambient environment, but this resulted in slight color changes and deterioration of colorimetric reagents within a week. They were then sealed in nylon bags with a heat sealer and placed in small plastic Ziploc bags. These storage techniques both resulted in slight color changes and deterioration of the colorimetric reagents within one month. The powder pastes were also falling off of the $\mu \mathrm{PADs}$ during the storage time as a result of the drying of the liquids used to create the paste. The next storage technique involved lamination of the $\mu$ PADs at $110^{\circ} \mathrm{C}$, speed 4 using $3 \mathrm{~mm}$ lamination sheets. This allowed for the pastes to be securely attached to the $\mu$ PADs and resulted in a storage time of about three months. The addition of the plastic 
cover also prevented evaporation of the solvents, protected the surface from

contamination, and eliminated dehydration during analysis ${ }^{59}$.

Real Samples

Real samples were tested using fireworks, black powder, black powder substitutes, and smokeless powders. These powders were tested pre-burned and postburned to determine which compounds were present (Table 5.4) and the results were compared to those previously obtained through a variety of analytical techniques ${ }^{86}$.

Table 5.4. Real sample analysis with the inorganic explosives $\mu$ PAD. All tests were performed at $1000 \mathrm{ppm}$ of powder in deionized water.

\begin{tabular}{|c|c|c|c|}
\hline Powder name & $\begin{array}{c}\text { Non-Burned } \\
\text { Powder }\end{array}$ & $\begin{array}{c}\text { Burned } \\
\text { Powder }\end{array}$ & Powder content \\
\hline $\begin{array}{c}\text { Hodgdon Pyrodex (The FFFG } \\
\text { equivalent) }\end{array}$ & $\mathrm{NO}_{3}^{-}, \mathrm{ClO}_{4}^{-}$ & $\mathrm{NO}_{3}^{-}, \mathrm{NO}_{2}^{-}$ & $\mathrm{KNO}_{3}, \mathrm{KClO}_{4}$ \\
\hline $\begin{array}{c}\text { Alliant Powder Red Dot } \\
\text { Smokeless Powder }\end{array}$ & $\mathrm{NO}_{3}^{-}$ & $\mathrm{NO}_{2}^{-}, \mathrm{NO}_{3}^{-}$ & $\begin{array}{c}\text { Nitrocellulose, } \\
\text { nitroglycerin }\end{array}$ \\
\hline $\begin{array}{c}\text { FFFg GOEX Black Rifle } \\
\text { Powder }\end{array}$ & $\mathrm{NO}_{3}^{-}$ & $\mathrm{NO}_{2}^{-}, \mathrm{NO}_{3}^{-}$ & $\mathrm{KNO}_{3}$ \\
\hline $\begin{array}{c}\text { FFG Hodgdon Triple Seven } \\
\text { American Pioneer }\end{array}$ & $\mathrm{NO}_{3}^{-}, \mathrm{ClO}_{4}^{-}$ & $\mathrm{NO}_{2}^{-}, \mathrm{NO}_{3}^{-}$ & $\begin{array}{c}\mathrm{KNO}_{3}, \mathrm{KClO}_{4}, 3- \\
\text { nitrobenzoic acid }\end{array}$ \\
\hline Jim Shockey's Gold FFG & $\mathrm{NO}_{3}^{-}, \mathrm{ClO}_{4}^{-}$ & $\mathrm{NO}_{3}^{-}, \mathrm{ClO}_{4}^{-}, \mathrm{NO}_{3}^{-}$ & $\mathrm{KNO}_{3}, \mathrm{KClO}_{4}$ \\
\hline Lemon Drop Firework & $\mathrm{NO}_{3}^{-}, \mathrm{ClO}_{4}^{-}, \mathrm{NO}_{3}^{-}$ & $\mathrm{KNO}_{3}^{-}, \mathrm{KClO}_{4}$ \\
$\mathrm{NO}_{3}^{-}, \mathrm{NO}_{2}^{-}$ & $\mathrm{KNO}_{3}, \mathrm{KClO}_{4}$ \\
\hline
\end{tabular}

Nitrate was detected in all of the powders, both non-burned and burned. Nitrite was only detected in the burned powders, while perchlorate was detected in the firework powder and all black powder substitutes. The Alliant Powder Red Dot smokeless powder produced a positive result for nitrate, which could be due to nitrocellulose, nitroglycerin, or a combination of the aforementioned two. A pure nitroglycerin or nitrocellulose 
sample at suitable concentrations for detection was not able to be obtained to determine which compound is causing the positive result. All of the results obtained for the $\mu$ PADs correlated with previous analysis done using varying analytical instrumentation ${ }^{86}$.

Pre- and post-blast detection was also performed on-site with the assistance of the Miami Police Departments bomb squad. The first blast consisted of ammonium nitrate and aluminum powder (ANAL). AN was successfully detected in the $\mathrm{NH}_{4}{ }^{+}$lane and the $\mathrm{NO}_{3}{ }^{-}$lanes on the $\mu$ PADs in both a pre-blast and post-blast scenario (Figure 5.13).
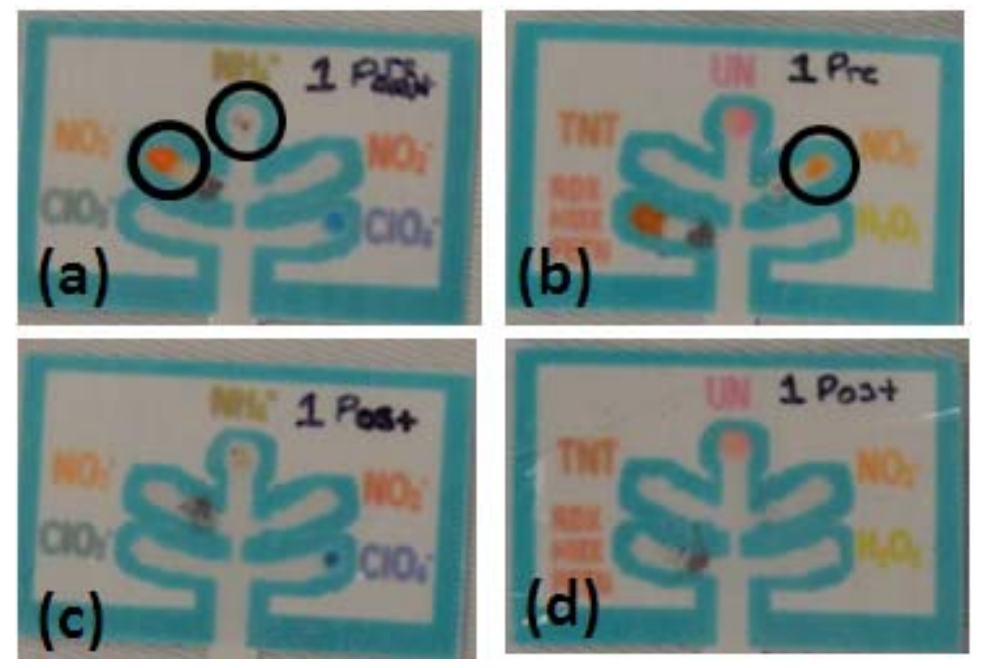

Figure 5.13. Pre- and post-blast results for $\mu$ PADs tested with ANAL. (a) Pre-blast inorganic $\mu$ PAD displays an orange color change for the presence of $\mathrm{NO}_{3}{ }^{-}$and a brown color change for the presence of $\mathrm{NH}_{4}{ }^{+}$. (b) Pre-blast high/organic $\mu \mathrm{PAD}$ displaying an orange color change for the presence of $\mathrm{NO}_{3}{ }^{-}$. The lane for $\mathrm{RDX}$ did produce a dark orange color change showing the presence of $\mathrm{NO}_{3}{ }^{-}$, not the presence of RDX/HMX/PETN. (c) Post-blast inorganic $\mu$ PAD displaying a brown color change for the present of $\mathrm{NH}_{4}{ }^{+}$. No color change was seen for the presence of $\mathrm{NO}_{3}{ }^{-}$ or $\mathrm{NO}_{2}^{-}$. (d) Post blast high/organic $\mu \mathrm{PAD}$ displaying no color change for $\mathrm{NO}_{3}{ }^{-}$. 
Urea nitrate was also successfully detected in both pre-blast and post-blast analyses (Figure 5.14).
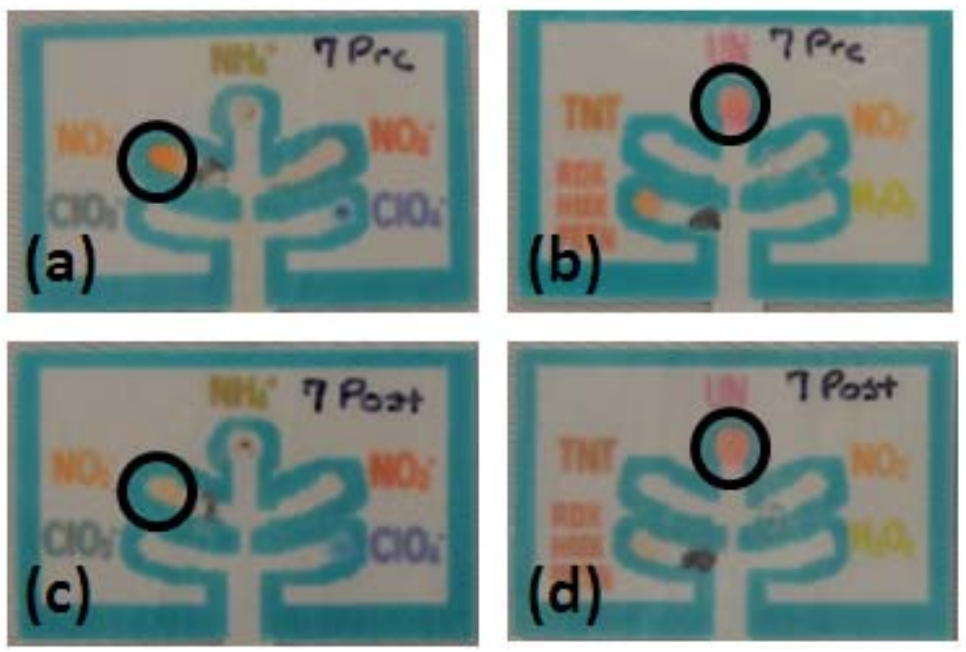

Figure 5.14. On-site analysis for urea nitrate. (a) Inorganic $\mu$ PAD for pre-blast testing displaying the presence of $\mathrm{NO}_{3}{ }^{-}$through an orange color change. (b) High/organic $\mu$ PAD for pre-blast testing showing a positive pink color change for UN. (c) Slight orange color change seen for $\mathrm{NO}_{3}{ }^{-}$for the post-blast analysis done with an inorganic $\mu P A D$. (d) Pink color change seen for UN on the high/organic $\mu P A D$ in post-blast analysis.

This was observed through the positive color changes displayed for the nitrate test and the urea nitrate test.

Nitrate $\left(\mathrm{NO}_{3}{ }^{-}\right)$was also successfully detected in the analysis completed for Helix (a mixture of nitromethane and aluminum), gel dynamite, and Composition-4 in pre-blast

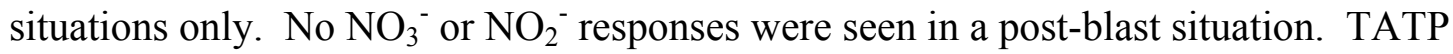
and $\mathrm{ClO}_{3}{ }^{-}$were not able to be detected on site. This could be due to the minute amount of TATP used for pre-blast testing and the sample age. TATP has a high vapor pressure allowing it to readily sublime at room temperature, so the presence of this material in the sample matrix may evaporate over time. Chlorate was not detected due to a solubility issue created by the Vaseline present in the mixture as a fuel source. In addition, no 
results were seen for Detasheet due to the insolubility of the rubberized backing. Future work will involve developing methods to deal with insoluble explosives formulations.

\section{Conclusions}

Two different five lane $\mu$ PADs were developed for the analysis of unknown, suspected explosive materials. The first device is able to identify multiple components of inorganic explosives, such as chlorate, perchlorate, nitrate, nitrite, and ammonium, using deionized water as the solvent. The second device is capable of identifying high/organic explosives, such as TNT, RDX, $\mathrm{H}_{2} \mathrm{O}_{2}$, and $\mathrm{UN}$ using $50 \%$ acetone $/ 50 \%$ water as the solvent. Limits of detection ranged from $0.4-20 \mu \mathrm{g}$ of explosive compound, making the devices well suited to characterize unknown powders recovered from improvised explosive manufacturing sites. Through the use of lamination, these devices can be stored for a period of three months before discoloration begins to occur. They are laminated to ensure that the powder pastes remain on the device, limit interferences and dehydration during analysis, and to reduce contact with the colorimetric reagents. The total analysis time including processing and interpretation of results is approximately 5 minutes.

The devices were also tested on-site in a pre- and post-blast scenario with the help of the Miami Police Department bomb squad. In a pre-blast scenario, multiple improvised explosive compounds were successfully detected on-site. These included ammonium nitrate contained in ANAL, nitrate in nitromethane for Helix, gel dynamite, Composition-4, and urea nitrate. These compounds were also successfully detected in a post-blast scenario. Potassium chlorate was not detected pre- or post-blast most likely 
due to the interference from Vaseline contained in the improvised explosive mixture. Detasheet also did not produce any pre-blast results due to solubility issues with the respective solvents for testing. Future work will involve developing methods to deal with insoluble explosives formulations.

These newly designed $\mu$ PADs are simpler, smaller, less expensive, and easily portable compared to current on-site colorimetric detection techniques for explosives. The devices facilitate the identification of combinations of explosive compounds by permitting simultaneous multiplex testing. Therefore, these $\mu \mathrm{PADs}$ will provide law enforcement and military personnel with inexpensive and portable chemical tests for rapid, on-site determination of suspected explosive samples.

\section{CHAPTER 6. CONFIRMATORY DETECTION UTILIZING INFUSION EC-ESI- TOF MS}

\section{A. Introduction}

A wide variety of materials can be utilized in explosive compositions. Military explosives typically consist of organic nitrates, while homemade or improvised explosive preparations may contain fertilizers and industrial chemicals containing oxidizers, such as chlorates, perchlorates, and nitrates, as well as other less stable compounds, such as peroxides. Due to the wide range of volatilities, polarities, and compositions encountered, multiple analyses must be run in a lab to identify the unknown explosive material present. GC-MS and LC-MS ${ }^{123}$ can be used to identify organic compounds while $\mathrm{IC}^{93}$ and $\mathrm{CE}^{26}$ can be used to identify inorganic ions. These devices are large, expensive pieces of instrumentation, and multiple tests must be run for identification. 
This process increases the amount of time before any analytical information on the identity of the explosive can be provided to personnel. An additional complication with the current analytical techniques is that improvised explosives, such as urea nitrate, can be difficult to discriminate from environmental matrices due to a metathetic exchange between ions, as well as decomposition of the uronium ion in water ${ }^{124,125}$.

The goal of this study was to develop one, single confirmatory method for the analysis of multiple improvised explosive compounds ranging from inorganic ions to organic molecules. This method utilizes infusion electrochemical detection electrospray ionization time-of-flight mass spectrometry (EC-ESI-TOF MS) to detect guest/host complexes generated through complexation of 18 -crown-6 ether with inorganic ions (ammonium nitrate, urea nitrate, potassium chlorate, and ammonium perchlorate). These inorganic salts can be successfully detected as ion pairs using electrospray ionization in positive ion mode while still permitting the analysis of other high explosives such as PETN, RDX, HMX, and $\mathrm{HMTD}^{1}$ using negative and positive electrospray ionization. An electrochemical detector placed before the mass spectrometer permits identification of hydrogen peroxide, an analyte normally difficult to detect through mass spectrometry due to its low mass (MW $=34 \mathrm{~g} / \mathrm{mol})$. Overall, this infusion EC-ESI-TOF MS technique allows for the detection of a wide range of components present in IEDs, including fertilizers, inorganic oxidizers, high explosives, and peroxides.

\section{B. Development of Method}

\section{Compounds of Interest}

Table 6.1 contains a list of compounds being detected and their expected $\mathrm{m} / \mathrm{z}$ ratio 
in the mass spectrometer. $\mathrm{H}_{2} \mathrm{O}_{2}$ is detected using an electrochemical detector, so it will

not have a peak in the mass spectrometer.

Table 6.1. Compounds of interest and their corresponding $\mathrm{m} / \mathrm{z}$ when complexes are formed. $\mathrm{H}_{2} \mathrm{O}_{2}$ is difficult to detect in a mass spectrometer due to its low molecular weight and does not complex with 18-crown-6 ether, therefore it is detected with an electrochemical detector. HMTD does not complex with 18-crown-6 ether and is detected as $[\mathrm{HMTD}+\mathrm{H}]^{+}$. 1:1 corresponds to 1 crown ethers for 1 ion pair while 1:2 corresponds to 2 crown ethers for 1 ion pair.

\begin{tabular}{|c|c|c|c|c|}
\hline $\begin{array}{l}\text { Chemical } \\
\text { Name }\end{array}$ & Formula & Structure & $\begin{array}{c}\text { MW } \\
(\mathrm{g} / \mathrm{mol} \\
\text { ) }\end{array}$ & $\begin{array}{c}\text { MS Peaks } \\
(\mathrm{m} / \mathrm{z})\end{array}$ \\
\hline $\begin{array}{c}\text { Hydrogen } \\
\text { Peroxide (30\% } \\
\text { solution) }\end{array}$ & $\mathrm{H}_{2} \mathrm{O}_{2}$ & & 34.01 & $\begin{array}{l}\text { Electrochemical } \\
\text { Detector }\end{array}$ \\
\hline $\begin{array}{c}\text { Hexamethylene } \\
\text { Triperoxide } \\
\text { Diamine } \\
\text { (HMTD) }\end{array}$ & $\mathrm{C}_{6} \mathrm{H}_{12} \mathrm{O}_{6} \mathrm{~N}_{2}$ & & 208.17 & $+\mathrm{H}-209.0683$ \\
\hline $\begin{array}{l}\text { Ammonium } \\
\text { Nitrate }\end{array}$ & $\mathrm{NH}_{4} \mathrm{NO}_{3}$ & & 80.04 & $1: 2-626.3661$ \\
\hline Urea Nitrate & $\left(\left(\mathrm{NH}_{2}\right)_{2} \mathrm{C}=\mathrm{OH}\right)^{+} \mathrm{NO}_{3}$ & & 123.07 & $\begin{array}{l}1: 1-325.1946 \\
1: 2-589.3505\end{array}$ \\
\hline $\begin{array}{l}\text { Ammonium } \\
\text { Perchlorate }\end{array}$ & $\mathrm{NH}_{4} \mathrm{ClO}_{4}$ & & 117.49 & $1: 2-689.1918$ \\
\hline $\begin{array}{l}\text { Potassium } \\
\text { Chlorate }\end{array}$ & $\mathrm{KClO}_{3}$ & & 122.55 & $1: 2-663.3287$ \\
\hline $\begin{array}{l}\text { 18-Crown-6 } \\
\text { Ether }\end{array}$ & $\mathrm{C}_{12} \mathrm{H}_{24} \mathrm{O}_{6}$ & & 264.32 & $\begin{array}{c}+\mathrm{H}-265.3278 \\
+\mathrm{NH}_{4}- \\
282.1965 \\
+\mathrm{Na}-287.1454 \\
+\mathrm{K}-303.1195\end{array}$ \\
\hline
\end{tabular}




\section{Theoretical Calculation of Complex Formation}

Due to high mass accuracy, the formation of the 18 -crown- 6 complexes could be determined. To determine the probable mechanism for formation of the complexes computer based calculations were performed using density functional theory with B3LYP and a basis set of $6-31 \mathrm{G}$.

The complex consisting of potassium chlorate with crown ether was determined to be a 1:2 complex, $\left[2(18 \mathrm{Cr} 6)+\mathrm{KClO}_{3}+\mathrm{K}\right]^{+}$. This complex is seen as a sandwich complex where the potassium ions are embedded in the macrorings of the 18-crown- 6 ethers, while the chlorate ion is sandwiched between them (Figure 6.1).

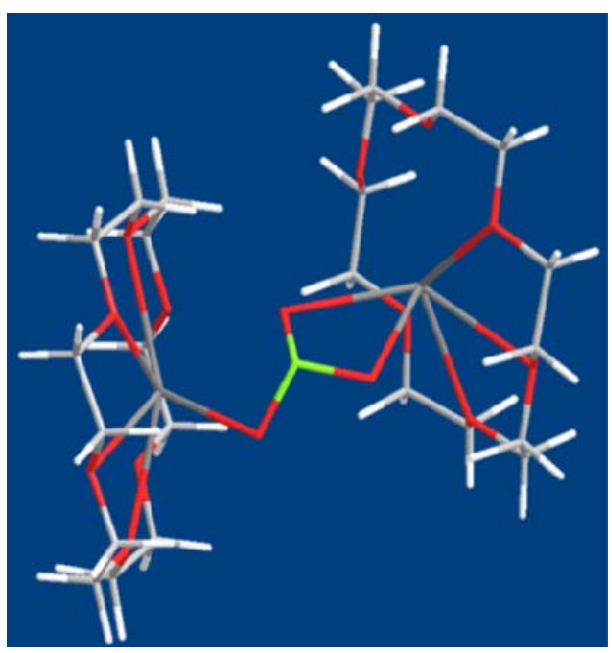

Figure 6.1. Most stable formation for the potassium chlorate complex with 18crown- 6 ether, $\left[2(18 \mathrm{Cr} 6)+\mathrm{KClO}_{3}+\mathrm{K}\right]^{+}$. The grey lines are not bonds; they are ionic interactions occurring between the positively charged potassiums and negatively charged chlorates. 
Potassium ions have the best selectivity for the 18 -crown- 6 ether ${ }^{126}$ since its ion radius of $1.33 \AA$ is the closest to the radius of the 18 -crown- 6 macroring $(1.45 \AA)^{127}$. The anion can also effect the selectivity, where nitrate $>$ thiocynate $>$ perchlorate, iodide $>$ bromide ${ }^{128,129}$. Therefore, potassium nitrate will complex better than potassium perchlorate.

Ammonium complexes, such as ammonium nitrate $\left(\left[2(18 \mathrm{Cr} 6)+\mathrm{NH}_{4} \mathrm{NO}_{3}+\mathrm{NH}_{4}\right]^{+}\right)$ and ammonium perchlorate $\left(\left[2(18 \mathrm{Cr} 6)+\mathrm{NH}_{4} \mathrm{ClO}_{4}+\mathrm{NH}_{4}\right]^{+}\right)$, form sandwich complexes through hydrogen bonding. Alternate oxygen atoms in the 18 -crown- 6 are positioned to form three $\mathrm{N}-\mathrm{H}---\mathrm{O}$ bonds with the ammonium ion ${ }^{105}$.
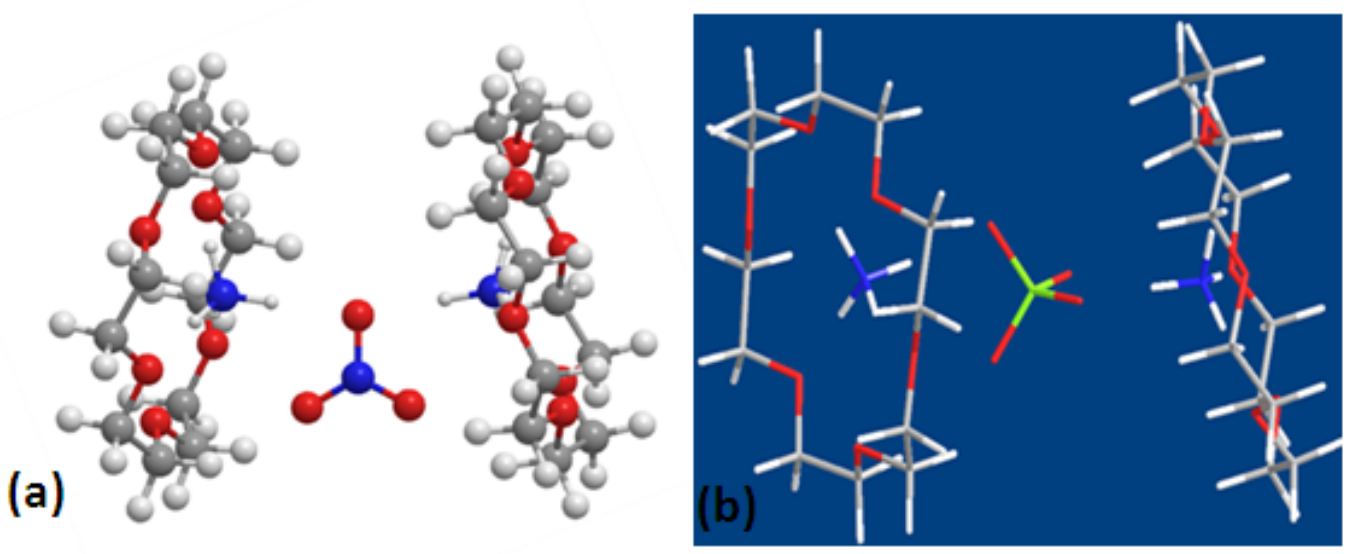

Figure 6.2. Most stable structure for (a) the ammonium nitrate complex with 18crown-6 ether $\left(\left[2(18 \mathrm{Cr} 6)+\mathrm{NH}_{4} \mathrm{NO}_{3}+\mathrm{NH}_{4}\right]^{+}\right)$and (b) the ammonium perchlorate complex with 18-crown-6 ether $\left(\left[2(18 \mathrm{Cr} 6)+\mathrm{NH}_{4} \mathrm{ClO}_{4}+\mathrm{NH}_{4}\right]^{+}\right)$.

Ammonium can also rotate rapidly in the cavity of the crown ether allowing for the energy to remain low and the complex to remain stable ${ }^{130}$. 
For urea nitrate, a complex with the uronium ion is formed, not urea nitrate as an ion pair. The 1:1 complex was determined to be $\left[18 \mathrm{Cr} 6+\left(\mathrm{NH}_{2}\right)_{2} \mathrm{COH}\right]^{+}$and the $1: 2$ complex was $\left[2(18 \mathrm{Cr} 6)+\left(\mathrm{NH}_{2}\right)_{2} \mathrm{COH}\right]^{+}$. Formations of the complexes in the most stable form are shown in Figure 6.3.
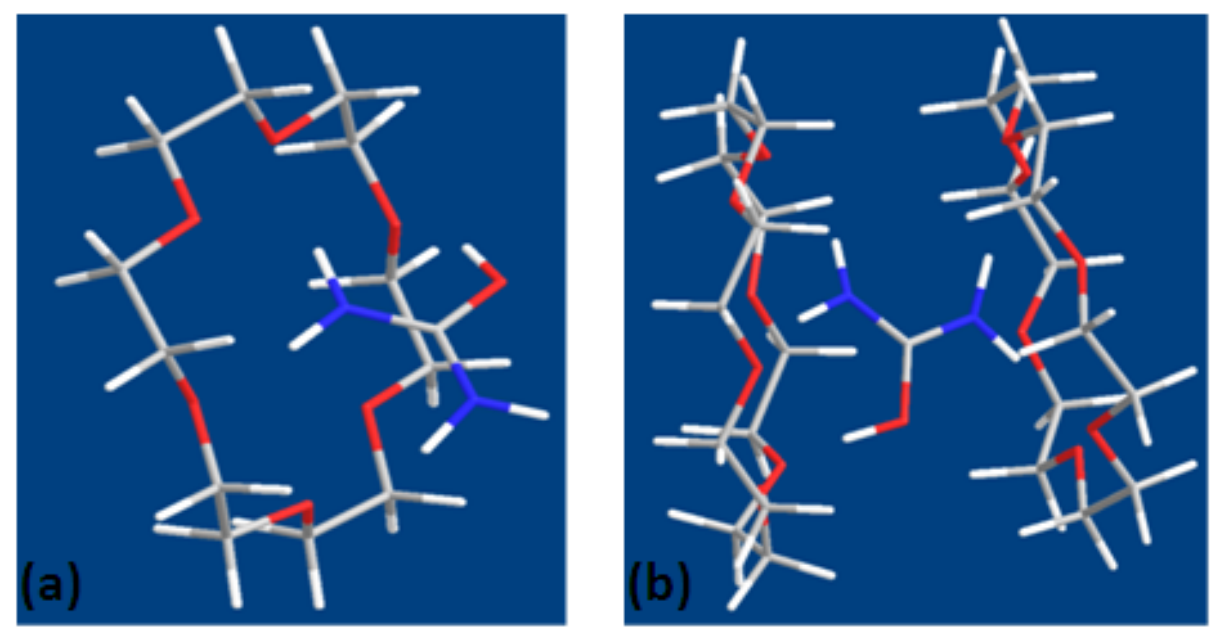

Figure 6.3. Most stable structure for (a) the 1:1 uronium complex with 18-crown-6 ether $\left(\left[18 \mathrm{Cr} 6+\left(\mathrm{NH}_{2}\right)_{2} \mathrm{COH}\right]^{+}\right)$and $(b)$ the 1:2 uronium complex with 18-crown-6 ether $\left(\left[2(18 \mathrm{Cr} 6)+\left(\mathrm{NH}_{2}\right)_{2} \mathrm{COH}\right]^{+}\right)$.

The hydrogens on the uronium, hydrogen bond with oxygens in the macroring contained in 18-crown-6 ether ${ }^{131}$, allowing for stable complex formation.

\section{Electrochemical Detection}

For the analysis of hydrogen peroxide in an acidic solution, the standard reduction potential for $\mathrm{H}_{2} \mathrm{O}_{2}$ is $\mathrm{E}_{0}=+1.80 \mathrm{~V}$, while the standard reduction potential for water is $\mathrm{E}_{0}=-$ $0.83 \mathrm{~V}$.

$$
\begin{array}{ll}
\mathrm{H}_{2} \mathrm{O}_{2}+2 \mathrm{H}^{+}+2 \mathrm{e}^{-} \rightarrow 2 \mathrm{H}_{2} \mathrm{O} & \mathrm{E}_{0}=+1.80 \mathrm{~V} \\
2 \mathrm{H}_{2} \mathrm{O}+2 \mathrm{e}^{-} \rightarrow \mathrm{H}_{2}(\mathrm{~g})+2 \mathrm{OH}^{-} & \mathrm{E}_{0}=-0.83 \mathrm{~V}
\end{array}
$$


When dissolved oxygen in the mobile phase is present at high working potentials, a problem occurs with the detection of hydrogen peroxide. Therefore, detection is better in the oxidative mode.

$$
\begin{array}{ll}
\mathrm{H}_{2} \mathrm{O}_{2} \rightarrow 2 \mathrm{H}^{+}+\mathrm{O}_{2}+2 \mathrm{e}^{-} & \mathrm{E}_{0}=-0.66 \mathrm{~V} \\
\mathrm{H}_{2} \mathrm{O}_{2}+\mathrm{OH}^{-} \rightarrow \mathrm{HOO}^{-}+\mathrm{H}_{2} \mathrm{O} & \\
\mathrm{OH}^{-}+\mathrm{OOH}^{-} \rightarrow \mathrm{O}_{2}+\mathrm{H}_{2} \mathrm{O}+2 \mathrm{e}^{-} & \mathrm{E}_{0}=+0.08 \mathrm{~V} \\
\mathrm{H}_{2} \mathrm{O}_{2}+2 \mathrm{OH}^{-} \rightarrow \mathrm{O}_{2}+2 \mathrm{H}_{2} \mathrm{O}+2 \mathrm{e}^{-} &
\end{array}
$$

When an acidic $\mathrm{pH}$ is used $(\mathrm{pH}=0)$, the oxidation of hydrogen peroxide occurs (3) at $\mathrm{E}_{0}=-0.66 \mathrm{~V}$. Since $\mathrm{H}_{2} \mathrm{O}_{2}$ is a weak acid with a pKa of 11.65 , in a strongly basic solution $(\mathrm{pH}=14)$ it will form the perhydroxyl ion $\left(\mathrm{HOO}^{-}, 4\right)$. In the presence of excess hydroxyl ions $\left(\mathrm{OH}^{-}\right)$an oxidation reaction occurs at $\mathrm{E}_{0}=+0.08 \mathrm{~V}(5)$. Therefore in the overall reaction $(\mathrm{pH}>7)$, hydrogen peroxide is oxidized to oxygen while the hydroxyl ions are reduced to water (6). This is the oxidizing reaction that occurs at the surface of the working electrode for the detection of hydrogen peroxide ${ }^{99}$.

\section{Solvent Composition}

Ammonium acetate was used to buffer the eluent, since it should contain a supporting electrolyte and weakly buffering the eluent will provide the necessary conductivity. Eluents containing salt concentrations of $10 \mathrm{mM}$ are suitable for use with electrochemical detection. The $\mathrm{pH}$ was adjusted to 8 with ammonium hydroxide to allow for the detection of hydrogen peroxide ${ }^{107}$. When the results with this solvent obtained with the electrochemical detector were compared to results obtained with methanol as the solvent, significant differences were not seen in the intensities (Figure 6.4). 


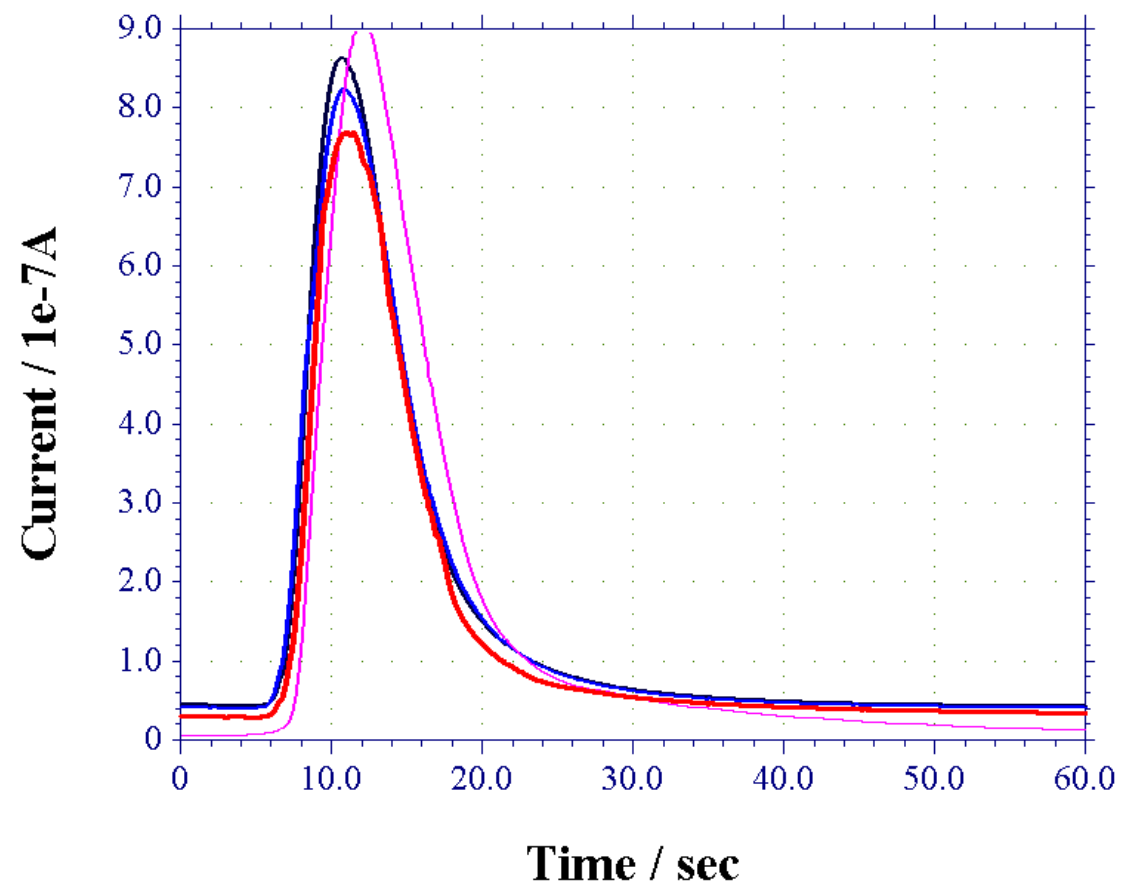

Figure 6.4. Comparison of response generated by the electrochemical detector with varying mobile phases such as methanol (red), $10 \mathrm{mM}$ sodium acetate in water (blue), $10 \mathrm{mM}$ ammonium acetate in water (black), and $10 \mathrm{mM}$ ammonium acetate pH adjusted with ammonium hydroxide (pink).

Therefore, to reduce the amount of extraneous salts present in the mobile phase capable of complexing with the 18-crown-6 ether, methanol was selected as the solvent of choice for analysis.

Infusion EC-ESI-TOF MS

Figure 6.5 presents the results for a $30 \mathrm{ppm}$ sample mixture of hydrogen peroxide, ammonium nitrate, potassium chlorate, ammonium perchlorate, urea nitrate, and HMTD in $1 \mathrm{mM} 18$-crown-6 ether in methanol. 


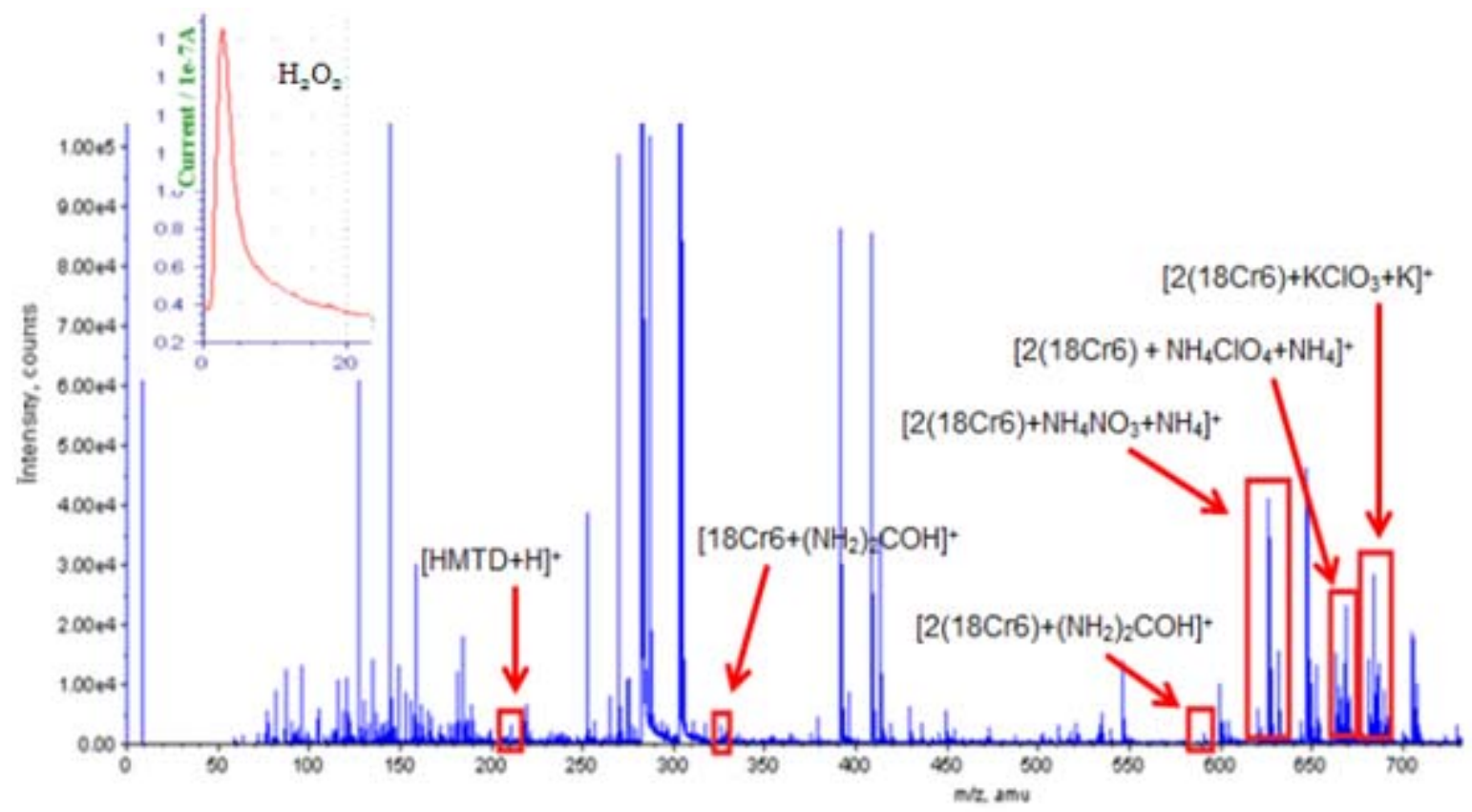

Figure 6.5. EC-ESI-TOF MS results for a $30 \mathrm{ppm}$ mixture of ammonium nitrate $\left(\left[2(18 \mathrm{Cr} 6)+\mathrm{NH}_{4} \mathrm{NO}_{3}+\mathrm{NH}_{4}\right]^{+}\right)$, urea nitrate $\left(\left[18 \mathrm{Cr} 6+\left(\mathrm{NH}_{2}\right)_{2} \mathrm{COH}\right]^{+}\right.$, $\left.\left[2(18 \mathrm{Cr6})+\left(\mathrm{NH}_{2}\right)_{2} \mathrm{COH}\right]^{+}\right)$, potassium chlorate $\left(\left[2(18 \mathrm{Cr} 6)+\mathrm{KClO}_{3}+\mathrm{K}^{+}\right)\right.$, ammonium perchlorate $\left(\left[2(18 \mathrm{Cr} 6)+\mathrm{NH}_{4} \mathrm{ClO}_{4}+\mathrm{NH}_{4}\right]^{+}\right), \mathrm{HMTD}\left([\mathrm{HMTD}+\mathrm{H}]^{+}\right)$and hydrogen peroxide $\left(\mathrm{H}_{2} \mathrm{O}_{2}\right)$ in $1 \mathrm{mM}$ 18-crown-6 ether in methanol.

The large excess peaks are generated from the presence of sodium $(\mathrm{m} / \mathrm{z} 287)$, potassium (m/z 303) and ammonium (m/z 282). The complexation peaks between uronium and 18-crown-6 ether are present as a lower intensity with respect to the other complexation peaks are a results of the selectivity difference of varying cations with 18crown- 6 ether. Eighteen-crown- 6 ether is more selective for potassium and ammonium than it is for uronium. 


\section{Table 6.2. Ion radii of cations determining selectivity of the 18-crown-6 ether.}

\begin{tabular}{|c|c|}
\hline Ion & Radius $(\AA)$ \\
\hline $\mathrm{Na}^{+}$ & 0.95 \\
\hline $\mathrm{K}^{+}$ & 1.33 \\
\hline $\mathrm{NH}_{4}^{+}$ & 1.48 \\
\hline
\end{tabular}

The closer the radius of the cation is to the macroring circle of the 18 -crown-6 (1.45 $\AA$ ), the more likely it is to bind. Based on the radius of ions available for complexation, 18crown-6 will be more selective for potassium than for uronium (Table 6.2).

In explosives detection, urea nitrate will be present in a higher concentration compared to other salts since it is a blasting agent. Therefore, this selectivity difference will not cause an issue. However the presence of additional ions in solution can cause an interference and careful attention should be made to the composition of the background matrix when running this method.

\section{Validation of Method}

Sensitivity

Calibration curves were generated for each compound across the range of 30-100 ppm increasing at increments of $10 \mathrm{ppm}$. The 18-crown- 6 ether concentration was held at $1 \mathrm{mM}$ for all samples including HMTD. For concentrations above $500 \mathrm{ppm}$, the calibration curve levels off due to a limited crown ether concentration. The limit of detection was calculated by determining the inorganic compound concentration equal to 
three times the standard deviation of eight replicates of the lowest detectable

concentration of the respective compound (Table 6.3).

Table 6.3. Figures of Merit for the explosive compounds detected using EC-ESITOF MS. Calibration curves were run for each individual compound from 30-100 ppm, increasing at increments of $10 \mathrm{ppm}$. LODs were calculated by determine the lowest detectable concentration of the respective compound, preforming 8 replicates, and determining the concentration equal to three times the standard deviation.

\begin{tabular}{|c|c|c|c|}
\hline Compound & $\mathbf{R}^{2}$ & $\begin{array}{c}\text { Slope } \\
\text { (Intensity/ppm) }\end{array}$ & LOD (ppm) \\
\hline Ammonium Nitrate & 0.9760 & 4719 & 1.1 \\
\hline Ammonium Perchlorate & 0.9696 & 1506.5 & 0.19 \\
\hline HMTD & 0.9877 & 630.43 & 2.0 \\
\hline Potassium Chlorate & 0.9904 & 3644.9 & 0.82 \\
\hline Urea Nitrate (325) & 0.8891 & 14151 & 0.076 \\
\hline Urea Nitrate (589) & 0.8810 & 9247.9 & 0.058 \\
\hline Hydrogen Peroxide & 0.9942 & $5.0 \mathrm{E}-9$ & 0.85 \\
\hline
\end{tabular}

In this method, the selectivity strength for crown ethers is ordered as follows: potassium complexes $>$ ammonium complexes $>$ uronium. Therefore care must be taken when analyzing unknown sample matrices. High concentrations of salts, particularly potassium ions can overwhelm the crown ether complexation. This problem is somewhat minimized through the use of organic solvent extracts, which limit the solubility of potassium salts. 
Since a time-of-flight mass analyzer was used, the identity of the compounds could be confirmed through analysis of the $\Delta \mathrm{ppm}$ value, which shows the measurement error for the anticipated compound using the following equation:

$$
\Delta \mathrm{ppm}=\frac{\text { Calculated } \mathrm{m} / \mathrm{z}-\text { Experimental } \mathrm{m} / \mathrm{z}}{\text { Calculated } \mathrm{m} / \mathrm{z}} * 1,000,000
$$

Table 6.4. Mass accuracies determined for the ions formed during analysis with the time-of-flight mass spectrometer.

\begin{tabular}{|c|c|c|c|c|}
\hline Compound & Calculated m/z & Experimental m/z & $\Delta \mathbf{m}$ & $\Delta$ ppm \\
\hline $\begin{array}{c}\text { Ammonium Nitrate } \\
{\left[2(18 \mathrm{Cr} 6)+\mathrm{NH}_{4} \mathrm{NO}_{3}+\mathrm{NH}_{4}\right]^{+}}\end{array}$ & 626.3711 & 626.3661 & $5.0 \mathrm{E}-3$ & 7.98 \\
\hline $\begin{array}{c}\text { Ammonium Perchlorate } \\
{\left[2(18 \mathrm{Cr} 6)+\mathrm{NH}_{4} \mathrm{ClO}_{4}+\mathrm{NH}_{4}\right]^{+}}\end{array}$ & 663.3318 & 663.3287 & $3.1 \mathrm{E}-3$ & 4.67 \\
\hline $\begin{array}{c}\mathrm{HMTD} \\
{[\mathrm{HMTD}+\mathrm{H}]^{+}}\end{array}$ & 209.0774 & 209.0785 & $1.1 \mathrm{E}-3$ & 5.26 \\
\hline $\begin{array}{c}\text { Potassium } \mathrm{Chlorate} \\
{[2(18 \mathrm{Cr} 6)+\mathrm{KClO}} \\
3\end{array}$ & 689.1960 & 689.1918 & $4.2 \mathrm{E}-3$ & 6.09 \\
\hline $\begin{array}{c}\text { Urea Nitrate }-325 \\
{\left[18 \mathrm{Cr} 6+(\mathrm{NH})_{2} \mathrm{COH}\right]^{+}}\end{array}$ & 325.1975 & 325.1946 & $1.1 \mathrm{E}-3$ & 3.38 \\
\hline $\begin{array}{c}\text { Urea Nitrate }-589 \\
{\left[2(18 \mathrm{Cr} 6)+(\mathrm{NH})_{2} \mathrm{COH}\right]^{+}}\end{array}$ & 589.3548 & 589.3505 & $4.3 \mathrm{E}-3$ & 7.30 \\
\hline
\end{tabular}

If this number is low (i.e. below 10) the mass accuracy is acceptable and the structure of the complex can be determined. 


\section{Stability}

Studies were conducted to determine the repeatability of results over time and how long samples could be stored in $1 \mathrm{mM}$ 18-crown-6 ether in methanol. All injections were performed in triplicate. After approximately five days, the complex samples started to deteriorate and could no longer be detected at concentrations below $100 \mathrm{ppm}$. Therefore, to ensure trace detection, samples were made fresh daily for the best results.

\section{Selectivity: Interference Testing}

Common drinks and products were chosen as intereferences based on substances that could be present on people's hands. These ranged from drinks such as Gatorade and coffee to bleach and Windex. Interferences were tested through a spiking process (see experimental procedures), where a small amount of interferent was added directly into the analyte liquid and then analyzed using the EC-ESI-TOF MS procedure described earlier (Figure 6.6). 


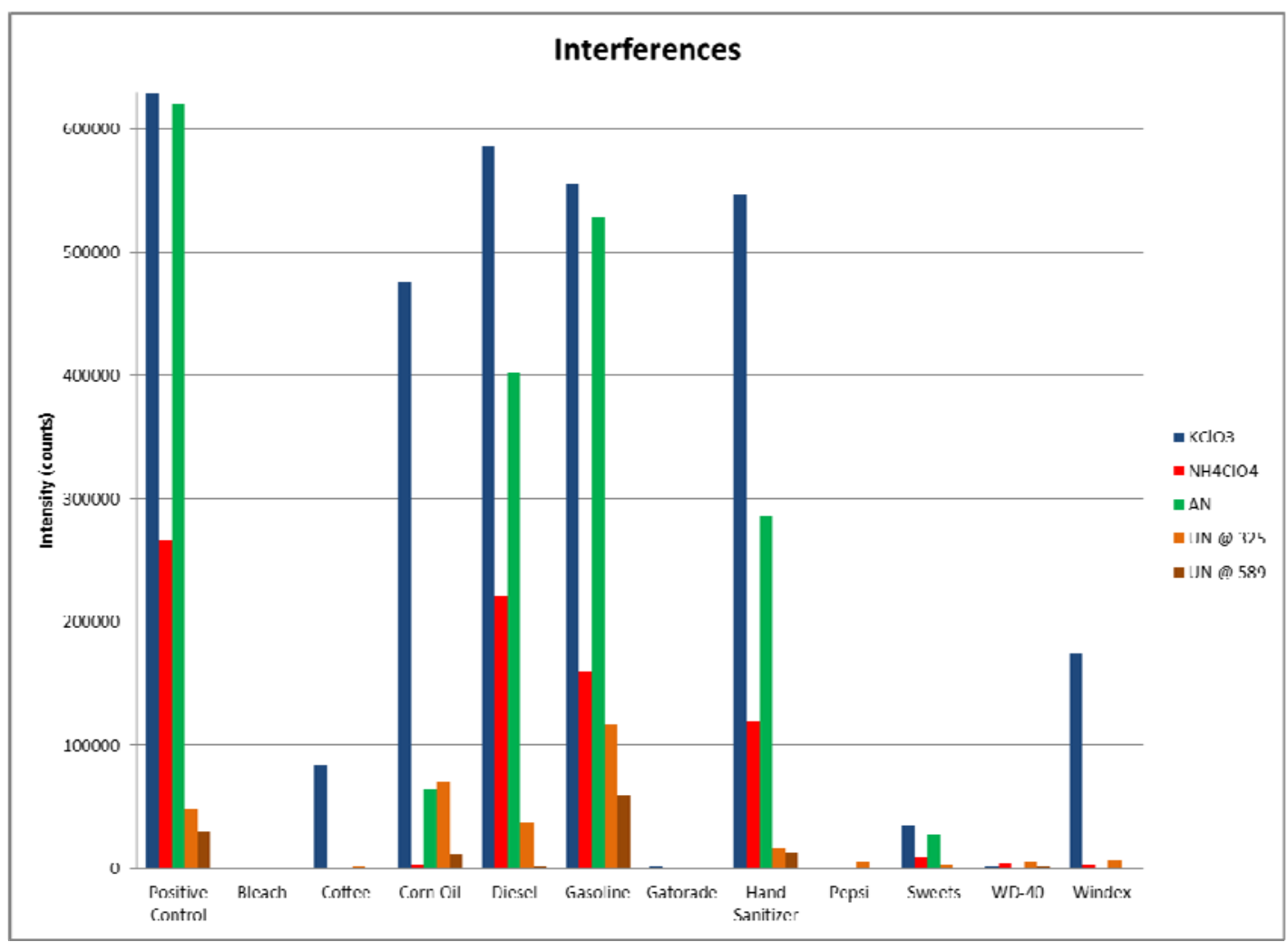

Figure 6.6. Common interference compounds that could be present on people's hands. The interference compounds were tested by adding $100 \mu \mathrm{L}$ of the interferent to $395 \mu \mathrm{Lof} 100 \mathrm{pm}$ of the analyte. Five microliters of $100 \mathrm{mM} 18 \mathrm{Cr} 6$ in methanol was added for a total of $500 \mu \mathrm{L}$. This sample was then analyzed using the infusion EC-ESI-TOF MS described previously.

Major interferences were seen for bleach, Gatorade, Pepsi, and WD-40 for all analytes being tested. This is due to the high concentration of salts present the interferent samples competing with the explosive analytes of interest for complexation with the 18crown-6 ethers. Since these salts complexed more readily with the ethers, the explosive analytes of interest were not able to be complexed and therefore were not readily detected. It should be noted that these materials were introduced directly as aqueous solutions, thus a higher level of ions was present in the mixture than would normally be seen with a methanol wetted swab where ion solubility is more limited. Thus, this type of interference testing is not fully representative of how interferences would affect the 
explosive analytes of interest. To obtain a more representative view of how this method would work for swabbing, hand swabbing should be completed to test for trace amounts of explosives present on people's hands when these interferences are also present. This will be the subject of future work.

Real Samples

Post-blast samples were collected for multiple shots sampled using sterile gauze wetted with methanol (see experimental section). These samples were analyzed utilizing the previously described EC-ESI-TOF MS method.

In positive ion mode, complexation ions were readily generated and detected for $\mathrm{AN}$ in $\mathrm{ANAL}$ and $\mathrm{KClO}_{3}$ in a mixture of Vaseline and $\mathrm{KClO}_{3}$ (Table 6.5). When switched to negative ion mode, RDX present in C4 was detected along with Sheet. TATP was not able to be determined through this analysis since the peak of interest could not be confirmed. This could be due to the fact that the post-blast residue of TATP does not stay in the environment for long periods of time ${ }^{28}$. Therefore, by the time the swab was analyzed, the post-blast residue for TATP was no longer present. This issue can be solve by immediately heat sealing remaining pieces in nylon bags and sampling in the lab immediately before analysis. 
Table 6.5. Mass error for the results obtained for post-blast analysis utilizing the infusion EC-ESI-TOF MS method.

\begin{tabular}{|c|c|c|c|c|}
\hline Compound & Calculated $\mathbf{m} / \mathbf{z}$ & Experimental $\mathbf{m} / \mathbf{z}$ & $\Delta \mathbf{m}$ & $\Delta \mathrm{ppm}$ \\
\hline $\begin{array}{c}\text { Ammonium Nitrate } \\
{\left[2(18 \mathrm{Cr} 6)+\mathrm{NH}_{4} \mathrm{NO}_{3}+\mathrm{NH}_{4}\right]^{+}}\end{array}$ & 626.3711 & 626.3634 & $7.7 \mathrm{E}-3$ & 12.3 \\
\hline $\begin{array}{c}\text { Potassium Chlorate } \\
{\left[2(18 \mathrm{Cr} 6)+\mathrm{KClO}_{3}+\mathrm{K}\right]^{+}}\end{array}$ & 689.1960 & 689.1956 & $4 \mathrm{E}-3$ & 0.58 \\
\hline $\begin{array}{c}\text { Urea Nitrate } \\
{\left[18 \mathrm{Cr} 6+\left(\mathrm{NH}_{2}\right)_{2} \mathrm{COH}\right]^{+}}\end{array}$ & 325.1975 & 325.1147 & $8.3 \mathrm{E}-2$ & 255 \\
\hline $\begin{array}{c}\text { Composition } \mathrm{C} 4-\mathrm{RDX} \\
{\left[\mathrm{M}+\mathrm{CH}_{2}(\mathrm{OH}) \mathrm{CO}_{2}\right]^{-}}\end{array}$ & 297.0431 & 297.0417 & $1.4 \mathrm{E}-3$ & 4.71 \\
\hline
\end{tabular}

A peak at $\mathrm{m} / \mathrm{z}$ of 325.1147 was present during the analysis of the post-blast

samples for urea nitrate. The $\Delta \mathrm{ppm}$ was calculated to be 255 , which is too high of a mass difference to confirm the presence of the uronium ion. Therefore, this analysis did not definitively detect the presence of uronium in a post-blast setting.

\section{Conclusions}

One, single analytical method utilizing infusion and electrochemical detection coupled with electrospray ionization time-of-flight mass spectrometry has been developed to detect multiple explosives in a run time of approximately two minutes. The electrochemical detector is utilized to detect the presence of $\mathrm{H}_{2} \mathrm{O}_{2}$, since it is difficult to detect with a mass spectrometer. Eighteen crown six ether is added to allow for complex formation between the 18-crown-6 ether and inorganic explosives such as ammonium nitrate, urea nitrate, potassium chlorate, and ammonium perchlorate. The crown ether does not interact with organic explosives such as HMTD, RDX, and HMTD. If the ionization mode is switched to negative mode, then military grade explosives such as TNT and RDX can also be detected. The development of this method creates one 
analytical method that is capable of detecting multiple explosives, such as the high/military grade explosives, along with inorganic explosives such as blasting agents and pyrotechnique mixtures.

This method has also been used for post-blast detection, where swabbing was done with a sterile guaze wetted with methanol and swiped over plastic pieces containing post-blast residue. Soil samples were also collected after each blast for analysis. Some of these samples resulted in successful detection of post-blast explosive residues ranging from improvised explosives, such as ANAL, to military explosives, such as RDX in C4.

Overall, this method has proven useful for the rapid, confirmatory detection of multiple types of explosive compounds with the use of one analytical method utilizing electrochemical detection and time of flight mass spectrometry.

\section{CHAPTER 7. CONCLUSIONS}

Two methods have been developed for on-site presumptive and laboratory based confirmatory detection of multiple explosive compounds. The presumptive method utilizes microfluidic paper-based analytical devices ( $\mu$ PADs) for the rapid, on-site analysis of suspected, unknown explosive materials. The first $\mu \mathrm{PAD}$ is able to identify multiple components of inorganic explosives, such as chlorate, perchlorate, nitrate, nitrite, and ammonium, using deionized water as the solvent. The second device is capable of identifying high/organic explosives such as TNT, RDX, hydrogen peroxide, and urea nitrate, using $50 \%$ acetone $/ 50 \%$ water as the solvent. Limits of detection ranged from 0.39-19.8 $\mu \mathrm{g}$ of explosive compound, making the devices well suited for identification of unknown powders recovered from explosive manufacturing sites. These 
devices can be stored for a period of three months before discoloration starts to occur. They are laminated to ensure that the powder pastes remain on the device, to increase storage time, to limit interferences and dehydration during analysis, to reduce the contact time with the colorimetric reagents, and to allow for the use of swabbing techniques for post-blast detection. Total analysis time is 5 minutes with very few steps needed to process the $\mu$ PADs.

These newly designed $\mu$ PADs are simpler, smaller, and easily portable compared to current on-site colorimetric detection techniques for explosives,. They facilitate the identification of combinations of explosive compounds by permitting simultaneous multiplex testing. Therefore, these $\mu$ PADs will provide law enforcement and military personnel with inexpensive and portable chemical tests for rapid, on-site determination of suspected explosive samples.

Future work for these devices will include extensive testing utilizing common improvised explosive mixtures such as ANFO and potassium chlorate mixtures with various fuel sources. This will help determine if these devices are applicable to on-site detection in theater. Testing will also be done to determine the cause of the false positives seen for urea nitrate during on-site and post-blast testing. Utilizing p-DMAC in its powder form as a paste will be explored to eliminate this false positive result.

A confirmatory technique was also developed consisting of one analytical method utilizing infusion and electrochemical detection coupled with electrospray ionization time-of-flight mass spectrometry to detect multiple explosives in a run time of approximately two minutes. The electrochemical detector is utilized to detect the presence of hydrogen peroxide since it is difficult to detect with a mass spectrometer. 
Eighteen crown six ether is added to allow for complex formation between the 18-crown6 ether and inorganic explosives, such as ammonium nitrate, urea nitrate, potassium chlorate, and ammonium perchlorate. These crown ethers do not interact with organic explosives, such as HMTD and TATP. If the ionization mode is switched to negative mode, then military grade explosives, such as TNT and RDX, can also be detected. The development of this method creates one analytical method that is capable of detecting multiple explosives such as the high/military grade explosives along with inorganic explosives such as blasting agents and pyrotechnique mixtures.

On-site pre- and post-blast detection was performed with improvised and military grade explosives with the assistance of the Miami Police Department bomb squad. The $\mu$ PADs were successfully able to detect multiple improvised explosive compounds, such as ammonium nitrate contained in ANAL, nitrate in nitromethane for Helix, gel dynamite, and $\mathrm{C} 4$, and urea nitrate. These compounds were also successfully detected in a post-blast scenario. Potassium chlorate was not detected due to the interference from Vaseline contained in the improvised explosive mixture. Sheet did not produce any preblast results due to solubility issues with the respective solvents for testing.

For the confirmatory method, swabbing was done with a sterile guaze wetted with methanol and swiped over plastic pieces containing post-blast residue. Soil samples were also collected after each blast for analysis. All of these samples resulted in successful detection of post-blast explosive residues ranging from improvised explosives such as ANAL and potassium chlorate and Vaseline. High/military grade explosives were also successfully detected, such as RDX in C4 and gel dynamite along with PETN contained in the detonator used for the blasts and Sheet. 
Future work will be done to improve post-blast analysis utilizing a mixture of $50 \%$ acetonitrile $/ 50 \%$ methanol as the extraction solvent to determine if that will aid in the detection of commercial/military explosives along with the inorganic explosives. Future work will also be done to add a separation method utilizing HPLC or CE, limiting the amount of water utilized in the mobile phase to keep the complexes together.

Overall, both of these methods have proven useful for the rapid detection of multiple explosive compounds. The presumptive method utilizing $\mu$ PADs allows for a rapid, inexpensive, and simplistic method for detection of multiple explosive compounds on-site. This will speed up the results obtained on-site and assist bomb squad and military personnel with a simpler detection technique. The confirmatory method utilizing infusion EC-ESI-TOF MS allows for a simple swabbing and extraction technique to be used along with one analytical method for the determination of multiple explosives. This minimizes the time needed to determine what explosive was present on-site in a pre- or post-blast scenario. 


\section{REFERENCES}

1. de Perre, C.; Prado, A.; McCord, B. R. Rapid and specific detection of urea nitrate and ammonium nitrate by electrospray ionization time-of-flight mass spectrometry using infusion with crown ethers. Rapid communications in mass spectrometry 2012, 26 (2), 154-162.

2. Yeager, K. Improvised Explosives Characteristics, Detection, and Analysis. In Forensic Investigation of Explosions, 2 ed.; Beveridge, A., Ed.; CRC Press: Florida, 2012; pp 494-534.

3. Davis, T. Chemistry of Powder and Explosives; Angriff Press: Hollywood, CA, 1943.

4. Akhavan, J. The Chemistry of Explosives; The Royal Society of Chemistry: Cambridge, UK, 1998.

5. Conkling, J. A. Chemistry of Pyrotechniques: Basic Principles and Theory; 2 ed.; CRC Press: Florida, 2011.

6. Robert B.Hopler The History, Development, and Characteristics of Exlplosives and Propellants. In Forensic Investigation of Explosives, A.Beveridge, Ed.; CRC Press: Florida, 2012; pp 1-17.

7. Thomas I.Perigrin Introductory Practical Pyrotechniques; Falcon Fireworks: Athens, OH, 1997.pp. 137-171.

8. NSW Government. Terrorist attacks using chemicals. 2011. 2014.

9. Esposito, R.; Williams, P.; Dedman, B. Boston Marathon bombs meant to act as 'homemade claymore,' sources say. 2013. 2014.

10. CNN Library . 1993 World Trade Center Bombing Fast Facts. 2014. 2014.

11. FBI . Terror Hits Home: The Oklahoma City Bombing. 2014. 2014.

12. Schulte-Ladbeck, R.; Kolla, P.; Karst, U. Trace analysis of peroxide-based explosives. Analytical chemistry 2003, 75 (4), 731-735.

13. Xu, X.; Van De Craats, A. M.; Kok, E. M.; De Bruyn, P. C. A. M. Trace analysis of peroxide explosives by high performance liquid chromatographyatmospheric pressure chemical ionization-tandem mass spectrometry (HPLC-APCI-MS/MS) for forensic applications. Journal of forensic sciences 2004, 49 (6), 1230-1236. 
14. CNN Library . July 72005 London Bombings Fast Facts. 11-6-2013. CNN. 617-2014.

15. Walter, M. A.; Pfeifer, D.; Kraus, W.; Emmerling, F.; Schneider, R. J.; Panne, U.; Weller, M. G. Triacetone triperoxide (TATP): Hapten design and development of antibodies. Langmuir 2010, 26 (19), 15418-15423.

16. Bellamy, A. Triacetone Triperoxide: Its Chemical Destruction. J Forensic Sci. 1999, 44, 603-608.

17. Yeager, K. Hidden Dangers of Organic Peroxides (Part 1-Acetone Peroxide); New Mexico Tech's Energetic Research and Testing Center: Socorro, NM, 2010.

18. Jiang, H.; Chu, G.; Gong, H.; Qiao, Q. Tin Chloride Catalysed Oxidation of Acetone with Hydrogen Peroxide to Tetrameric Acetone Peroxide. $J$. Chem. Research 1999, 288-289.

19. Zeman, S.; Bertei, C. Some properties of explosive mixtures containing peroxides Part II. Relationships between detonation parameters and thermal reactivity of the mixtures with triacetone triperoxide. Journal of Hazardous Materials 2008, 154, 199-203.

20. Zeman, S.; Trzcinski, W. A.; Matyas, R. Some properties of explosive mixtures containing peroxides Part I. Relative performance and detonation of mixtures with triacetone triperoxide. Journal of Hazardous Materials 2008, 154, 192-198.

21. Anthony H.Cordesman The Developing Iraqi Insurgency: Status at End-2004; Center for Strategic and International Studies: Washington, DC, 2004.pp. $1-21$.

22. Beveridge, A. Development in the Detection and Identification of Explosive Residues. Forensic Science Review 1992, 4 (1), 18-48.

23. McCord, B. R.; Hargadon, K. A.; Hall, K. E.; Burmeister, S. G. Forensic analysis of explosives using ion chromatographic methods. Analytica chimica acta 1994, 288 (1), 43-56.

24. Doyle, J. M.; Miller, M. L.; McCord, B. R.; McCollam, D. A.; Mushrush, G. W. A multicomponent mobile phase for ion chromatography applied to the separation of anions from the residue of low explosives. Analytical chemistry 2000, 72 (10), 2302-2307.

25. Pumera, M. Trends in analysis of explosives by microchip electrophoresis and conventional CE. Electrophoresis 2008, 29 (1), 269-273. 
26. Piccin, E.; Dossi, N.; Cagan, A.; Carrilho, E.; Wang, J. Rapid and sensitive measurements of nitrate ester explosives using microchip electrophoresis with electrochemical detection. Analyst 2009, 134 (3), 528-532.

27. Forensic Investigation of Explosions; Taylor \& Francis Ltd: London, 1998.

28. Yeager, K. Improvised Explosives as a Viable Terrorist Tool. Investigators Bulletin 97-3. 2014. Washington, DC, U.S. Government Printing Office.

29. Martinez, A.; Phillips, S.; Whitesides, G. Diagnostics for the Developing World: Microfluidic Paper-Based Analytical Devices. Anal. Chem. 2010, 82, 310.

30. National Terrorism Center . 2009 Report of Terrorism. 1-67. 2009.

31. Cagan, A.; Schmidt, H.; Rodriguez, J. E.; Eiceman, G. A. Fast gas chromatography-differential mobility spectrometry of explosives from TATP to Tetryl without gas atmosphere modifiers. International Journal for Ion Mobility Spectrometry 2010, 13 (3-4), 157-165.

32. Jiang, G. Simultaneous UHPLC/MS Analyses of Explosive Compounds. 1-8. Thermo Scientific.

33. Pumera, M. Analysis of explosives via microchip electrophoresis and conventional capillary electrophoresis: A review. Electrophoresis 2006, 27 (1), 244-256.

34. Berk, R. Automated SEM/EDS Analysis of Airbag Residue. J Forensic Sci. 2009, $54,60-68$.

35. Yang, G.; Nie, F.; Huang, H.; Zhao, L.; Pang, W. Preparation and Characterization of Nano-TATB Explosive. Propellants, Explsives, Pyrotechniques 2006, 31, 390-394.

36. Singh, S. Sensors - An effective approach for the detection of explosives. Journal of Hazardous Materials 2007, 144, 15-28.

37. Buttigieg, G. A.; Knight, A. K.; Denson, S.; Pommier, C.; Bonner Denton, M. Characterization of the explosive triacetone triperoxide and detection by ion mobility spectrometry. Forensic science international 2003, 135 (1), 53-59.

38. Moore, D. S. Instrumentation for trace detection of high explosives. Review of Scientific Instruments 2004, 75 (8), 2499-2512. 
39. A.Uzer; E.Ercag; R.Apak Spectrophotometric determination of cyclotrimethylenetrinitramine (RDX) in explosive mixtures and residues with the Berthelot reaction. Analytica chimica acta 2008, 612, 53-64.

40. Andrew, T. L.; Swager, T. M. Detection of Explosives via Photolytic Cleavage of Nitroesters and Nitramines. The Journal of organic chemistry 2011, 76 (9), 2976-2993.

41. Hill, H.; Simpson, G. Capabilities and Limitations of Ion Mobililty Spectrometry for Field Screening Applications. Field Analytical Chemistry and Technology 1997, 1 (3), 119-134.

42. Almog, J. Forensic Science Does Not Start in the Lab: The Concept of Diagnostic Field Tests. J Forensic Sci. 2006, 51 (6), 1228-1234.

43. Yinon, J. Field detection and monitoring of explosives. TrAC Trends in Analytical Chemistry 2002, 21 (4), 292-301.

44. Epicos. epicos.com. 2010.

45. Arrowhead Forensics . Arrowhead Forensics: Identa Alert Explosive Identifier. 2013.

46. Arrowhead Forensics . Arrowhead Forensics: DropEx Plus Explosives Detection \& ID Kit. 2013.

47. MEDIMPEX . EXPRAY Explosives Detection Identification Field Test Kit. 2014.

48. RedX Defense . RedX Defense SCAT. 2014.

49. Whitesides, G. M. The origins and the future of microfluidics. Nature 2006, 442 (7101), 368-373.

50. Osborn, J. L.; Lutz, B.; Fu, E.; Kauffman, P.; Stevens, D. Y.; Yager, P. Microfluidics without pumps: reinventing the T-sensor and $\mathrm{H}$-filter in paper networks. Lab on a Chip 2010, 10 (20), 2659-2665.

51. Yetisen, A.; Akram, M.; Lowe, C. Paper-based microfluidic point-of-care diagnostic devices. Lab Chip 2013, 13, 2210-2251. 
52. Ellerbee, A.; Phillips, S.; Siegel, A.; Mirica, K.; Martinez, A.; Striehl, P.; Jain, N.; Prentiss, M.; Whitesides, G. Quantifying Colorimetric Assays in PaperBased Microfluidic Devices by Measuring the Transmission of Light Through Paper. Anal. Chem. 2009, 81, 8447-8452.

53. Fenton, E.; Mascarenas, M.; Lopez, G.; Sibbett, S. Multiplex Lateral-Flow Test Strips Fabricated by Two-Dimensional Shaping. Applied Materials and Interfaces 2009, 1 (1), 124-129.

54. Nie, J.; Liang, Y.; Zhang, Y.; Le, S.; Li, D.; Zhang, S. One-step patterning of hollow microstructures in paper by laser cutting to create microfluidic analytical devices. Analyst 2013, 138, 671-676.

55. Weaver, A. A.; Reiser, H.; Barstis, T.; Benvenuti, M.; Ghosh, D.; Hunckler, M.; Joy, B.; Koenig, L.; Raddell, K.; Lieberman, M. Paper analytical devices for fast field screening of Beta lactam antibiotics and antituberculosis pharmaceuticals. Analytical chemistry 2013, 85 (13), 6453-6460.

56. Martinez, A.; Phillips, S.; Whitesides, G. Three-dimensional microfluidic devices fabricated in layered paper and tape. PNAS 2008, 105 (50), 19606-19611.

57. Nery, E.; Kubota, L. Sensing Approaches on paper-based devices: a review. Anal. Bioanal. Chem 2013, 405, 7573-7595.

58. Evan, E.; Gabriel, E.; Coltro, W.; Garcia, C. Rational selection of substrates to improve color intensity and uniformity on microfluidic paper-based analytical devices. Analyst 2014, 139, 2127-2132.

59. Liana, D.; Raguse, B.; Gooding, J.; Chow, E. Recent Advances in Paper-Based Sensors. Sensors 2012, 12, 11505-11526.

60. Li, X.; Ballerini, D.; Shen, W. A persepective on paper-based microfluidics: Current status and future trends. Biomicrofluidics 2012, 6, 011301-1011301-13.

61. Li, X.; Tian, J.; Nguyen, T.; Shen, W. Paper-Based Microfluidic Devices by Plasma Treatment. Anal. Chem. 2008, 80, 9131-9134.

62. Juuso Olkkonen; Kaisa Lehtinen; Tomi Erho. Flexographically Printed Fluidic Structures in Paper. Anal. Chem. 2010, 82, 10246-10250.

63. Carrilho, E.; Martinez, A.; Whitesides, G. Understanding Wax Printing: A Simple Micropatterning Process for Paper-Based Microfluidics. Anal. Chem. 2009, 81, 7091-7095. 
64. Dungchai, W.; Chailapakul, O.; Henry, C. A low-cost, simple, and rapid fabrication method for paper-based microfluidics using wax-screen printing. Analyst 2011, 136, 77-82.

65. Govindasamy, K.; Potgieter, S.; Land, K.; Muzenda, E. Fabrication of Paper Based Microfluidic Devices. Proceedings of the World Congress on Engineering 2012, 3, 1-6.

66. Bhakta, S.; Borba, R.; Taba, M.; Garcia, C.; Carrilho, E. Determination of nitrite in saliva using microfluidic paper-based analytical devices. Analytical Chimica Acta 2014, 809, 117-122.

67. Schilling, K.; Lepore, A.; Kurian, J.; Martinez, A. Fully Enclosed Microfluidic Paper-Based Analytical Devices. Anal. Chem. 2012, 84, 1579-1585.

68. Pesenti, A.; Taudte, R. V.; McCord, B. R.; Doble, P. A.; Roux, C.; Blanes, L. Coupling paper-based microfluidics and lab on a chip technologies for confirmatory analysis of trinitro aromatic explosives. Analytical chemistry 2014.

69. Dungchai, W.; Chailapakui, O.; Henry, C. Electrochemical Detection for PaperBased Microfluidics. Anal. Chem. 2009, 81 (14), 5821-5826.

70. Yu, J.; Ge, L.; Huang, J.; Wang, S.; Ge, S. Microfluidic paper-based chemiluminescence biosensor for simultaneous determination of glucose and uric acid. Lab on a Chip 2011, 11 (7), 1286-1291.

71. Taudte, R.; Beavis, A.; Wilson-Wilde, L.; Roux, C.; Doble, P.; Blanes, L. A portable explosive detector based on fluorescence quenching of pyrene deposited on coloured wax-printed uPADs. Lab Chip 2013.

72. Martinez, A.; Phillips, S.; Carrilho, E.; Thomas III, S.; Sindi, H.; Whitesides, G. Simple Telemedicine for Developing Regions: Camera Phones and PaperBased Microfluidic Devices for Real-Time, Off-Site Diagnosis. Anal. Chem. 2008, 80, 3699-3707.

73. Almog, J.; Klein, A.; Tamiri, T.; Shloosh, Y.; Abramovich-Bar, S. A field diagnostic test for the improvised explosive urea nitrate. J. Forensic Sci 2005, 50 (3), 582-586.

74. Mentele, M. M.; Cunningham, J.; Koehler, K.; Volckens, J.; Henry, C. S. Microfluidic paper-based analytical device for particulate metals. Analytical chemistry 2012, 84 (10), 4474-4480.

75. Zhao, W.; Ali, M. M.; Aguirre, S. D.; Brook, M. A.; Li, Y. Paper-based bioassays using gold nanoparticle colorimetric probes. Analytical chemistry 2008, 80 (22), 8431-8437. 
76. Feigl, F. Spot Tests: Iorganic and Organic Applications; Nordemann: New York, 1937.

77. Palazzo, G.; Facchini, L.; Mallardi, A. Colorimetric detection of sugars based on gold nanoparticle formation. Sensors and Actuators B: Chemical 2012, $161(1), 366-371$.

78. Al-Tamimi, M.; Shen, W.; Zeineddine, R.; Tran, H.; Garnier, G. Validation of paper-based assay for rapid blood typing. Analytical chemistry 2012, 84 (3), 1661-1668.

79. Erol Ercag; Aysem Uzer; Sule Eren; Sener Saglam; Hayati Filik; Resat Apak Rapid detection of nitroaromatic and nitramine explosives on chromatographic paper and their reflectometric sensing on PVC tablets. Talanta 2011, 85, 2226-2232.

80. Salles, M. O.; Meloni, G. N.; de Araujo, W. R.; Paixúo, T. R. L. C. Explosive colorimetric discrimination using a smartphone, paper device and chemometrical approach. Analytical Methods 2014, 6 (7), 2047-2052.

81. Wang, J. Electrochemical sensing of explosives. Electroanalysis 2007, 19 (4), 415-423.

82. Wang, J.; Escarpa, A.; Pumera, M.; Feldman, J. Capillary electrophoresiselectrochemistry microfluidic system for the determination of organic peroxides. Journal of Chromatography A 2002, 952 (1), 249-254.

83. Wang, J.; Chen, G.; Muck, A.; Collins, G. E. Electrophoretic microchip with dualopposite injection for simultaneous measurements of anions and cations. Electrophoresis 2003, 24 (21), 3728-3734.

84. Hutchinson, J. P.; Johns, C.; Breadmore, M. C.; Hilder, E. F.; Guijt, R. M.; Lennard, C.; Dicinoski, G.; Haddad, P. R. Identification of inorganic ions in post-blast explosive residues using portable CE instrumentation and capacitively coupled contactless conductivity detection. Electrophoresis 2008, 29 (22), 4593-4602.

85. Schulte-Ladbeck, R.; Edelmann, A.; Quintas, G.; Lendl, B.; Karst, U. Determination of peroxide-based explosives using liquid chromatography with on-line infrared detection. Analytical chemistry 2006, 78 (23), 81508155 .

86. Bender, E. Investigation of Pipe Bombs. In Forensic Investigation of Explosions, 2 ed.; CRC Press: Florida, 2012; pp 431-481.

87. Wu, Q.; Zhang, T.; Sun, H.; Kannan, K. Perchlorate in tap water, groundwater, surface waters, and bottled water from China and its association with other 
inorganic anions and with disinfection byproducts. Archives of environmental contamination and toxicology 2010, 58 (3), 543-550.

88. Wallenborg, S. R.; Bailey, C. G. Separation and detection of explosives on a microchip using micellar electrokinetic chromatography and indirect laserinduced fluorescence. Analytical chemistry 2000, 72 (8), 1872-1878.

89. Bottegal, M.; Lang, L.; Miller, M.; McCord, B. Analysis of ascorbic acid based black powder substitutes by high-performance liquid chromatography/electrospray ionization quadrupole time-of-flight mass spectrometry. Rapid communications in mass spectrometry 2010, 24 (9), 1377-1386.

90. Burks, R. M.; Hage, D. S. Current trends in the detection of peroxide-based explosives. Analytical and bioanalytical chemistry 2009, 395 (2), 301-313.

91. Schulte-Ladbeck, R.; Vogel, M.; Karst, U. Recent methods for the determination of peroxide-based explosives. Analytical and bioanalytical chemistry 2006, 386 (3), 559-565.

92. Parajuli, S.; Miao, W. Sensitive determination of hexamethylene triperoxide diamine explosives, using electrogenerated chemiluminescence enhanced by silver nitrate. Analytical chemistry 2009, 81 (13), 5267-5272.

93. Makinen, M.; Nousiainen, M.; Sillanpaa, M. Ion spectrometric detection technologies for ultra-traces of explosives: A review. Mass spectrometry reviews 2011, 30 (5), 940-973.

94. Sigman, M. E.; Clark, C. D.; Caiano, T.; Mullen, R. Analysis of triacetone triperoxide (TATP) and TATP synthetic intermediates by electrospray ionization mass spectrometry. Rapid communications in mass spectrometry 2008, 22 (2), 84-90.

95. Brady, J. J.; Judge, E. J.; Levis, R. J. Identification of explosives and explosive formulations using laser electrospray mass spectrometry. Rapid communications in mass spectrometry 2010, 24 (11), 1659-1664.

96. Crowson, A.; Beardah, M. S. Development of an LC/MS method for the trace analysis of hexamethylenetriperoxidediamine (HMTD). Analyst 2001, 126 (10), 1689-1693.

97. Widmer, L.; Watson, S.; Schlatter, K.; Crowson, A. Development of an LC/MS method for the trace analysis of triacetone triperoxide (TATP). Analyst 2002, 127 (12), 1627-1632. 
98. Laine, D. F.; Cheng, I. F. Electrochemical detection of the explosive, hexamethylene triperoxide diamine (HMTD). Microchemical Journal 2009, 91 (1), 125-128.

99. Tarvin, M.; McCord, B.; Mount, K.; Sherlach, K.; Miller, M. L. Optimization of two methods for the analysis of hydrogen peroxide: High performance liquid chromatography with fluorescence detection and high performance liquid chromatography with electrochemical detection in direct current mode. Journal of Chromatography A 2010, 1217 (48), 7564-7572.

100. Lu, D.; Cagan, A.; Munoz, R. A.; Tangkuaram, T.; Wang, J. Highly sensitive electrochemical detection of trace liquid peroxide explosives at a Prussianblue artificial-peroxidase modified electrode. Analyst 2006, 131 (12), 1279-1281.

101. Ko, H.; Chang, S.; Tsukruk, V. V. Porous substrates for label-free molecular level detection of nonresonant organic molecules. Acs Nano 2008, 3 (1), 181 188.

102. Banerjee, S.; Mohapatra, S. K.; Misra, M.; Mishra, I. B. The detection of improvised nonmilitary peroxide based explosives using a titania nanotube array sensor. Nanotechnology 2009, 20 (7), 075502.

103. TWGFEX Laboratory Explosion Group Standards \& Protocols Committee . Recommended Guidelines for Forensic Identification of Intact Explosives. TWGFEX , 1-4. 2014.

104. TWGFEX Laboratory Explosion Group Standards \& Protocols Committee . Recommended Guidelines for Forensic Identification of Post-Blast Explosive Residues. 1-9. 2007.

105. Gokel, G. W. Crown Ethers. In Encyclopedia of Supramolecular Chemistry, J.L.Atwood, J. W. S., Ed.; CRC Press: 2004; Vol. 1, pp 326-332.

106. D.E.Tallman; D.E.Weisshaar Carbon composite electrodes for liquidchromatography electrochemistry - Optimizing detector performance by tailoring the electrode composition. J. Liquid Chromatogr 1983, 6, 21572172 .

107. R.J.Flanagan; D.Perrett; R.Whelpton Electrochemical Detection in HPLC Analysis of Drugs and Poisons; The Royal Society of Chemistry: Cambridge, UK, 2005.

108. Edmond de Hoffman; Vincent Stroobant Mass Spectrometry: Principles and Applications; 3 ed.; John Wiley \& Sons, Ltd.: Chichester, West Sussex, England, 2007. 
109. de Hoffman, E.; Strrbant, V. Mass Spectrometry: Principles and Applications; 3 ed.; John Wiley \& Sons Ltd: Chichester, West Sussex, England, 2007.

110. Houghton, R. Field Confirmatoin Testing for Suspicious Substances; CRC Press: Boca Raton, FL, 2009.

111. Niki, K.; Kiso, Y.; Takeuchi, T.; Hori, T.; Oguchi, T.; Yamada, T.; Nagai, M. A spot test for nitrite and nitrate detection by color band length and number of colored zebra-bands formed in a mini-column. Analytical Methods 2010, 2 (6), 678-683.

112. Fu, E.; Ramsey, S. A.; Kauffman, P.; Lutz, B.; Yager, P. Transport in twodimensional paper networks. Microfluidics and nanofluidics 2011, 10 (1), 29-35.

113. Jungreis, E. Spot Test Analysis; John Wiley \& Sons, Inc.: 1985.

114. John H.Dillon Jr. Firearm Examiner Training. 2014.

115. Nitrogen, Ammonia For water, wastewater and seawater: Nessler Method and Salicylate Method. 2014.

116. Demutskaya, L. N.; Kalinichenko, I. E. Photometric determination of ammonium nitrogen with the Nessler reagent in drinking water after its chlorination. Journal of Water Chemistry and Technology 2010, 32 (2), 90-94.

117. ASM Microbe Library . Nitrate and Nitrite Reduction Test Protocols. 2014.

118. Chrostowski, J. E.; Thurman, W. O.; Jaworski, J. J. A Preliminary Test for the Detection of Perchlorate in Explosive Residue Analysis. Arson Analysis Newletter 1981, 5 (2), 14-19.

119. Jenkins, T. F.; Walsh, M. E. Development of field screening methods for TNT, 2, 4-DNT and RDX in soil. Talanta 1992, 39 (4), 419-428.

120. Xu, M.; Bunes, B. R.; Zang, L. Paper-based vapor detection of hydrogen peroxide: colorimetric sensing with tunable interface. ACS applied materials \& interfaces 2011, 3 (3), 642-647.

121. McRae, D.; Haywood, W.; Powell, J.; Harris, B. High explosive spot test analyses of samples from Operable Unit (OU) 1111; Los Alamos National Lab., NM (United States): 95.

122. Terrier, F. Rate and equilibrium studies in Jackson-Meisenheimer complexes. Chemical Reviews 1982, 82 (2), 77-152. 
123. Tamiri, T. Characterization of the improvised explosive urea nitrate using electrospray ionization and atmospheric pressure chemical ionization. Rapid communications in mass spectrometry 2005, 19 (14), 2094-2098.

124. Tamiri, T.; Rozin, R.; Lemberger, N.; Almog, J. Urea nitrate, an exceptionally easy-to-make improvised explosive: studies towards trace characterization. Analytical and bioanalytical chemistry 2009, 395 (2), 421-428.

125. Almog, J.; Burda, G.; Shloosh, Y.; Abramovich-Bar, S.; Wolf, E.; Tamiri, T. Recovery and Detection of Urea Nitrate in Traces*. Journal of forensic sciences 2007, 52 (6), 1284-1290.

126. Charles J.Pederson Cyclic Polyethers and Their Complexes with Metal Salts. Journal of the American Chemical Society 1967, 89 (10), 2495-2496.

127. Ray Colton; Shelly Mitchell; John C.Traeger Interactions of some crown ethers, cyclam and its tetrathia analouge with alkali, alkali earth and other metal ions: an electrospray mass spectrometric study. Inorganica Chimica Acta 1995, 231, 87-93.

128. Donnie J.Sam; Howard E.Simmons Crown Ether Chemistry. Substitution Reactions of Potassium Halide and Potassium Hydroxide Complexes of Dicyclohexyl-18-crown-6. Journal of the American Chemical Society 1974, 96, 2252-2253.

129. Matthew G.Hankins; Youn Doo Kim; Richard A.Bartsch Anion Effect on Selectivity in Crown Ether Extraction of Alkali Metal Cations. Journal of American Chemical Society 1993, 115, 3370-3371.

130. Hans-Jurgen Buschmann; Eckhard Schollmeyer The complexation of the ammonium ion by 18 -crown- 6 in different solvents and by noncyclic ligands, crown ethers and cryptands in methanol. Supramolecular Science 1998, 5, 139-142.

131. Jos W.H.M.Uiterwijk; Gerrit J.Van Hummel; Sybolt Harkema; Veronika M.L.J.Aarts; Kari Daasvatn; Jan Geevers; Herman J.Den Hertog Jr.; David N.Reinhoudt Preparation and X-Ray Structures of Complexes of 18Membered Crown Ethers with Polyfunctional Guests: Urea and (OAlkyliso) Uronium Salts. Journal of Inclusion Phenomena 1988, 6, 79100 . 
VITA

KELLEY L. PETERS

Born, Allentown, PA

2010

B.S., Chemistry, Bioscience Option

Magna cum Laude

University of Pittsburgh

Pittsburgh, PA

2014

Provost Award: Outstanding Graduate

Student Project

Florida International University

Miami, FL

2014

Scholarly Forum Winner

Oral Presentation

Florida International University

Miami, FL

2014

NIST/FLAS Stipend for Oral Presentation at 2014 IAI Annual

Education and Training Conference

Minneapolis, $\mathrm{MN}$

2014

$\mathrm{PhD}$, Chemistry with a Forensic Emphasis

Florida International University

Miami, FL

2014-Present

Scientist (ND-03)

US Navy

NSWC IHEODTECHDIV

Indian Head, MD 


\section{PUBLICATIONS AND PRESENATIONS}

Peters, K.; Corbin, I.; Kaufman, L.; Zreibe, K.; McCord, B. Simultaneous Colorimetric Detection of Improvised Explosive Compounds using Microfluidic Paper-Based

Analytical Devices ( $\mu$ PADs). Analytical Methods, 2014. DOI: 10.1039/C4AY01677G.

"Comprehensive Analysis of Multiple Improvised Explosives." International Forensic Research Institute Science Symposium; Miami, FL, USA, 2013.

"Comprehensive Analysis of Multiple Improvised Explosives" Pittcon 2013; Philadelphia, PA, USA, 2013.

"Comprehensive Analysis of Multiple Improvised Explosives." Florida International University Scholarly Forum; Miami, FL, 2013.

"Comprehensive detection of improvised explosives as ion pairs and single ions using non-aqueous electrospray mass spectrometry techniques." International Symposium for the Analysis and Detection of Explosives; The Hague, Netherlands, 2013.

“New Technology for Rapid Detection of Explosives.” TEDxFIU; Miami, FL, 2013.

"Presumptive and Confirmatory Detection of Multiple Explosive Compounds." IDGA $9^{\text {th }}$ Counter IED Summit; Washington, DC, 2014.

"Development of Paper Microfluidic Devices for the Rapid On-Site Detection of Explosives.” NIJ Grantees Meeting; Seattle, Washington, 2014.

"Development of Paper Microfluidic Devices for the Rapid On-Site Detection of Explosives." American Academy of Forensic Sciences 66th Annual Scientific Meeting; Seattle, Washington, 2014.

"Comprehensive Analysis for the Detection of Multiple Explosives." International Forensic Research Institute Science Symposium; Miami, FL, USA, 2014.

"Development of Paper Microfluidic Devices for the Rapid On-Site Detection of Explosives.” Florida International University Scholarly Forum; Miami, FL, 2014.

“On-Site Explosives Detection.” eMerge; Miami, FL, USA, 2014.

"Development of Paper Microfluidic Devices for the Rapid On-Site Detection of Explosives." 2014 International Association for Identification International Educational Conference; Minneapolis, MN, USA, 2014. 